\title{
Descriptions of five new species of the salamander genus Chiropterotriton (Caudata: Plethodontidae) from eastern Mexico and the status of three currently recognized taxa
}

\author{
Gabriela Parra Olea ${ }^{\text {Corresp., } 1}$, Mirna G. Garcia-Castillo ${ }^{1,2}$, Sean M. Rovito ${ }^{3}$, Jessica A. Maisano ${ }^{4}$, James Hanken ${ }^{5}$, \\ David B. Wake ${ }^{6}$ \\ ${ }^{1}$ Zoology, Instituto de Biología, Universidad Nacional Autonoma de México, Mexico city, México \\ 2 Posgrado en Ciencias Biológicas, Universidad Nacional Autónoma de México, Ciudad de México, México \\ 3 Unidad de Genómica Avanzada (Langebio), CINVESTAV, Irapuato, Guanajuato, México \\ 4 Jackson school of Geosciences, University of Texas at Austin, Austin, Texas, United States \\ 5 Department of Organismic and Evolutionary Biology and Museum of Comparative Zoology, Harvard University, Cambridge, Massachussetts, United \\ States \\ 6 Department of Integrative Biology and Museum of Vertebrate Zoology, University of California, Berkeley, California, United States \\ Corresponding Author: Gabriela Parra Olea \\ Email address: gparra@ib.unam.mx
}

The genus Chiropterotriton is endemic to Mexico with a geographical distribution along the Sierra Madre Oriental, the Trans Mexican Volcanic Belt and the Sierra de Juárez. The recent use of molecular tools has shown that Mexico's amphibian diversity is highly underestimated, including a large number of cryptic, unnamed species. Chiropterotriton has 18 described species including terrestrial, arboreal and cave dwelling species. In previous molecular studies, the presence of multiple undescribed species was evident. We present a phylogenetic hypothesis based on mitochondrial data, which includes all described species and six undescribed taxa. Based on the morphological analyses and, when available, combined with molecular data, we describe five new species of the genus; Chiropterotriton casasi sp. nov., C. ceronorum sp. nov., C. melipona sp. nov., C. perotensis sp. nov. and $C$. totonacus sp. nov. In addition, we redescribe two others: Chiropterotriton chiropterus and $C$. orculus, and provide a comparable account of one additional sympatric congener. This increases the number of species in the genus to 23 , which represent a considerable component of Mexican plethodontid richness. 
1

2

3

4

5

6

7

8

11

12

13

14

17

18

19

20

21

22

23
Descriptions of five new species of the salamander genus Chiropterotriton (Caudata:

Plethodontidae) from eastern Mexico and the status of three currently recognized taxa

G. Parra-Olea ${ }^{1 *}$, M. G. García-Castillo ${ }^{1,2}$, S. M. Rovito 3 , J. A. Maisano ${ }^{4}$, J. Hanken ${ }^{5}$, and D. B. Wake $^{6}$

${ }^{1}$ Instituto de Biología, Universidad Nacional Autónoma de México, Mexico City, Mexico

2 Posgrado en Ciencias Biológicas, Instituto de Biología, Universidad Nacional Autónoma de México, Ciudad de México, México

${ }^{3}$ Unidad de Genómica Avanzada (Langebio), CINVESTAV, Irapuato, Guanajuato, Mexico

${ }^{4}$ Jackson school of Geosciences, University of Texas at Austin, Texas, United States

${ }^{5}$ Department of Organismic and Evolutionary Biology and Museum of Comparative Zoology, Harvard University, Cambridge, Massachusetts, United States

${ }^{6}$ Department of Integrative Biology and Museum of Vertebrate Zoology, University of California, Berkeley, California, United States

Corresponding author:

Gabriela Parra-Olea

Email address: gparra@ib.unam.mx 


\begin{abstract}
The genus Chiropterotriton is endemic to Mexico with a geographical distribution along the Sierra Madre Oriental, the Trans Mexican Volcanic Belt and the Sierra de Juárez. The recent use of molecular tools has shown that Mexico's amphibian diversity is highly underestimated, including a large number of cryptic, unnamed species. Chiropterotriton has 18 described species including terrestrial, arboreal and cave dwelling species. In previous molecular studies, the presence of multiple undescribed species was evident. We present a phylogenetic hypothesis based on mitochondrial data, which includes all described species and six undescribed taxa. Based on the morphological analyses and, when available, combined with molecular data, we describe five new species of the genus, redescribe two others, and provide a comparable account of one additional sympatric congener. This increases the number of species in the genus to 23, which represent a considerable component of Mexican plethodontid richness.
\end{abstract}

Key words: plethodontids, phylogeny, taxonomy, Mexico, bolitoglossines

\title{
INTRODUCTION
}

The genus Chiropterotriton Taylor, 1944 has proven to be one of the taxonomically most difficult of all genera of neotropical salamanders. These salamanders vary widely in morphology and ecology from relatively large troglodytic forms to gracile arboreal species. Most species, however, are small to medium sized with a fairly generalized external morphology, representing minor variations on a conserved body plan (Darda and Wake, 2015). This external morphological similarity has complicated recognition of new species and the relationships between them, particularly based on morphological data alone.

When Taylor (1944) described the genus, he initially included a number of other Central American salamanders from Nuclear Central America and Costa Rica. These species, which are all relatively small and slender, were recognized as a distinct unit within the genus (Chiropterotriton Beta; Wake and Lynch, 1976) and eventually described as several distinct genera (Cryptotriton, Dendrotriton and Nototriton), leaving Chiropterotriton endemic to the highlands of Mexico and west of the Isthmus of Tehuantepec. Despite their external similarity, the divergence between each of these genera and Chiropterotriton spans the basal node in the Bolitoglossini clade (Rovito et al., 2015). Taxonomy of the Mexican Chiropterotriton was complicated not only by their small size and generalized morphology, but also by the fact that two of the earliest species descriptions for the group, C. chiropterus (Cope, 1863) and C. orculus (Cope, 1865) are very brief and provide imprecise localities, and because the holotype of each species has been lost.

Rabb (1958) made a major advance in our understanding of the taxonomy and morphology of the northern species in the group. By examining both topotypic specimens and material from additional localities, he showed that unappreciated diversity existed even within the subset of species from this region based on external morphology and tooth counts. Rabb's foundational morphological and taxonomic work on the genus was followed by a long period of taxonomic stasis. Following his discovery and description of Chiropterotriton magnipes (Rabb, 1965), the most morphological distinct species in the genus, no additional species were described for nearly fifty years. Despite the lapse in species descriptions, molecular data made it clear that much diversity lay hidden within already known populations. Darda (1994) derived an allozyme dataset that showed that many populations likely represented distinct species, and his results 
69

70

71

72

73

74

75

76

77

78

79

80

81

82

83

84

85

86

87

88

89

90

91

92

93

94

95

96

97

98

99

100

101

102

103

104

105

106

107

108

109

110

111

112

113

were largely corroborated by mtDNA sequence data (Parra-Olea, 2003) although there were some discrepancies between the results from the two data sets. Collection of new material from previously known populations for molecular analysis, as well as the discovery of new populations, led to the description of six new species since 2014 (Campbell et al., 2014; Rovito and Parra-Olea, 2015; García-Castillo et al., 2017; García-Castillo et al., 2018). Despite these recent descriptions, many populations from central Mexico have defied assignment to known species and are best recognized as distinct species.

The Chiropterotriton chiropterus complex has suffered from taxonomic rearrangements, mostly due to imprecise type localities and the lack of adequate samples from those localities. Based on external morphology, Wake and Lynch (1976) defined the chiropterus group to include C. chiropterus, $C$. chondrostega, $C$. dimidiatus and $C$. lavae. Later, on the basis of immunological data, Maxson and Wake (1981) redefined the chiropterus group to include only C. chiropterus and C. lavae. Based on allozyme data, Darda (1994) recognized a group of populations found along the Trans-Mexican Volcanic Belt, which he called the chiropterus complex. This group was formed by $C$. chiropterus from La Joya Veracruz, C. orculus from Zacualtipan, Hidalgo, and nine additional undescribed species. However, Parra-Olea (2003) concluded that $C$. chiropterus applies exclusively to the low-elevation populations located in or near the city of Huatusco, Veracruz.

The Chiropterotriton orculus complex is represented by a relatively widespread species of the genus. Based on morphological characters, Cope (1865) described C. orculus as Spelerpes orculus from Mexican Table Land, but four years later he placed this species in synonymy with C. chiropterus (Cope, 1869). Darda's (1994) allozyme data recognized C. orculus as a distinct species, restricting it to two populations. Parra-Olea (2003) added one more population to $C$. orculus and emphasized the differentiation level discordance between allozymes and mtDNA between some populations. Currently, C. orculus includes several morphologically uniform populations in the central Trans Mexican Volcanic Belt around Mexico City.

We focus on populations of Chiropterotriton from the eastern Trans Mexican Volcanic Belt and nearby regions of Veracruz and Puebla (Fig. 1). While some of these populations have already been included in allozyme and/or mtDNA analyses, data for others are presented here for the first time. Using a combination of linear morphological measurements, osteological data derived from micro-computed tomography $(\mu \mathrm{CT})$ scans, and previously published mtDNA and allozyme data we examine the taxonomic status of these populations. We present a phylogenetic hypothesis based on mtDNA which includes all 18 described species plus six undescribed taxa, including populations identified in previous studies as new species within complexes. Based on the molecular data and morphological analyses, we describe five new species. These increase the number of described species from 18 to 23 and still recognize one candidate species not yet described. We redescribe $C$. orculus and C. chiropterus, designating neotypes for each, in order to clarify the taxonomic status of nearby populations that resemble one or both of these species in external morphology. Finally, in order to make full comparisons with sympatric taxa for the newly described species, we provide a fuller description of $C$. lavae based on examination of the type series and additional specimens collected subsequently.

\section{Sampling}

\section{MATERIALS AND METHODS}

Animal use was approved by the University of California, Berkeley, IACUC protocol \#R0930205 to DBW. Collection permits were provided by the Secretaría del Medio Ambiente y 
114 Recursos Naturales (SEMARNAT): SGPA/DGVS/00947/16, SGPA/DGVS/03038/17 and

115 FAUT-0303, issued to Gabriela Parra-Olea.

116

117 Amplification and sequencing

118 Whole genomic DNA was extracted from liver, intestine or tail tissue using DNeasy tissue Kit

119 (Qiagen, Valencia, California, USA). Although a comprehensive molecular analysis of the genus

120 Chiropterotriton is beyond the scope of the present work, two mitochondrial fragments of each

121 new species (when available) were sequenced in order to allow comparisons to other members of

122 the genus (Table 1). PCR amplification was done using primers LX12SN1 and LX16S1R for

123 mitochondrial fragment L2; it includes partial sequences from the $12 \mathrm{~S}$ ribosomal subunit, the

124 tRNA and the large subunit 16S (Zhang et al., 2008). PCR conditions were as follow: 35 cycles

125 at $96^{\circ} \mathrm{C}(2 \mathrm{~min}), 55^{\circ} \mathrm{C}(1 \mathrm{~min})$ and $72^{\circ} \mathrm{C}(5 \mathrm{~min})$. We also amplified a fragment of the COI gene

126 using primers dgLCO and dgHCO (Meyer, 2003). PCR conditions were as follows: 35 cycles at

$12794^{\circ} \mathrm{C}(30 \mathrm{~s}), 50^{\circ} \mathrm{C}(30 \mathrm{~s})$ and $72^{\circ} \mathrm{C}(45 \mathrm{~s})$. We cleaned PCR products with ExoSap-IT (USB

128 Corporation, Cleveland, $\mathrm{OH})$ and sequencing reaction with BigDye Terminator v3.1 cycle kit

129 (Applied Biosystems, Foster City, CA). The products were purified using Sephadex G-50 (GE

130 Heathcare) and run on an ABI 3730 capillary sequencer at the Instituto de Biología, UNAM.

\section{Sequence alignment and phylogenetic analyses}

132 Editing and assembly of sequences were performed in Sequencher 5.0.1 (Gene Codes

133 Corporation). We used Muscle 3.8 (Edgar, 2004) to align L2 and COI sequences. The alignment

134 for the L2 fragment included 36 Chiropterotriton samples sequenced in this study, 35 sequences

135 available on GenBank from previous studies (Parra-Olea, 2003; Rovito et al., 2015; García-

136 Castillo et al., 2018) and two additional sequences from Aquiloeurycea cephalica and Thorius sp.

137 as outgroups. The alignment for $\mathrm{COI}$ included seven sequences from this study and 21 from

138 Genbank (García-Castillo et al., 2018). All sequence information is shown in Table 1. We used

139 Mesquite v3.40 (Maddison \& Maddison, 2018) to concatenate and review the data matrix. We

140 used PartitionFinder v1.0 (Lanfear et al., 2012) to select substitution model and a partitioning

141 scheme using the Bayesian Information Criterion (BIC). We ran Maximum Likelihood and

142 Bayesian inference through the CIPRES data portal (Miller et al., 2010) for phylogenetic

143 analyses; RAxML v8.2 (Stamatakis, 2014) to generate a Maximum Likelihood tree, with 1000

144 bootstrap replicates as nodal support; and MrBayes v3.2 (Huelsenbeck and Ronquist, 2001) for

145 Bayesian inference, with 20 million generations, sampling every 1000 generations, with four

146 chains to obtain a majority consensus tree. Finally, we used Tracer v.1.7 (Rambaut et al., 2018)

147 to review the convergence and stability of the chains.

\section{Morphological analyses and species descriptions}

149 Species descriptions largely follow the format used by Lynch \& Wake (1989) for species of

150 Neotropical plethodontids and include many of the same basic characters and measurements,

151 including coloration and external measurements. We used an electronic vernier calipers to

152 measure 11 characters: snout-vent length (SVL), tail length (TL), axilla-groin distance (AX),

153 forelimb length (FLL), hind limb length (HLL), snout-to-gular-fold distance (head length, HL),

154 head width at angle of jaw (HW), head depth (HD), shoulder width (SW), internarial distance

155 (IN) and right foot width (FW). In order to obtain an index for nostril shape, we used an ocular

156 micrometer to measure the longest and shortest nostril dimensions (nostril length, NL; nostril

157 width, NW) and we calculated a ratio of nostril dimensions (ND = NL/NW). We also counted

158 ankylosed premaxillary (PMT), maxillary (MT) and vomerine teeth (VT). We present counts for 
159 PMT and MT together because of the difficulty in distinguishing them in some specimens. We 160 also measured limb interval (LI) as the number of costal folds between adpressed limbs. Positive 161 values equal the number of folds visible between adpressed limbs that don't meet or overlap; negative values denote overlap between limbs. We treat males and females separately to evaluate the extent of sexual dimorphism (Table 2). Finally, 12 additional measurements were obtained for each holotype: anterior rim of orbit to snout, eyelid length, eyelid width, horizontal orbital diameter, interorbital distance, length of third (longest) toe, length of fifth toe, projection of snout beyond mandible, snout to anterior angle of vent, snout to forelimb, tail depth at base, and tail width at base.

In addition, $\mu \mathrm{CT}$ scans were used to prepare osteological accounts based primarily on the cranial characters and character states defined by Darda and Wake (2015; Table 3; Fig. 2). Scans made at the University of Texas High Resolution X-Ray CT facility are archived in a digital repository and may be viewed online via the Internet links provided below. The complete scans include the ossified forelimb skeleton as well as the bony skull, but only skulls are illustrated here.

We examined 123 individuals from the eight species of principal interest and used published data for comparisons to other species of Chiropterotriton. The latter species were chosen for comparison based on either geographic or phylogenetic closeness. All material, including holotypes or neotypes designated below, is deposited at the National Museum of Natural History, Smithsonian Institution, Washington, DC, USA (USNM) and the Museum of Vertebrate Zoology, University of California Berkeley, USA (MVZ) collections (Appendix I).

The electronic version of this article in Portable Document Format (PDF) will represent a published work according to the International Commission on Zoological Nomenclature (ICZN), and hence the new names contained in the electronic version are effectively published under that Code from the electronic edition alone. This published work and the nomenclatural acts it contains have been registered in ZooBank, the online registration system for the ICZN. The ZooBank LSIDs (Life Science Identifiers) can be resolved and the associated information viewed through any standard web browser by appending the LSID to the prefix http://zoobank.org/. The LSID for this publication is: [9B4B9DFF-E12B-430D-A541-BA0EBB9B90E6]. The online version of this work is archived and available from the following digital repositories: PeerJ, PubMed Central and CLOCKSS."

\section{RESULTS}

Our phylogenetic reconstruction was based on two mitochondrial fragments, with a final matrix of $2143 \mathrm{bp}$ (gaps included) from 75 individuals that includes all described species of Chiropterotriton. Both ML and Bayesian analysis show two main clades in the genus (Fig. 3). The first main clade, with rather low support ( $\mathrm{BS}=54$, not recovered in Bayesian tree), includes 12 species that correspond to the north-central distributions: $C$. cracens, $C$, cieloensis, $C$. arboreus, C. multidentatus, C. infernalis, C. mosaueri, C. chondrostega, C. magnipes, $C$. priscus, $C$. miquihuanus, $C$. terrestris and $C$. chico. The second main clade with strong support (Bootstrap, $\mathrm{BS}=100$ and Posterior Probability, $\mathrm{PP}=1.0$ ) also includes 12 species, but with central-southern distributions: $C$. dimidiatus, $C$. totonacus sp. nov., $C$. ceronorum sp. nov., $C$. lavae, $C$. perotensis sp. nov., C. sp. K, C. sp. G, C. orculus, C. melipona sp. nov., C. aureus, $C$. nubilus and C. chiropterus. The major clade is the main subject of the following species descriptions and includes four of the five new species that were initially proposed by Darda 
205 (1994) as Chiropterotriton sp. E, C. sp. F, C. sp. H and C. sp. I. This clade also contains the two

206

207

208

209

210

211

212

213

214

215

216

217

218

219

220

221

222

223

224

225

226

227

228

229

230

231

232

233

234

235

236

237

238

239

240

241

242

243

244

245

246 redescribed species, $C$. orculus and $C$. chiropterus, as well as $C$. lavae. One of the species we describe below, $C$. casasi sp. nov., has not been found since the collection of the type series in 1969 and no tissue has been available for molecular analyses. Each species is diagnosed by morphological characters through morphometric and osteological comparisons (Tables 2 and 3 ).

\section{Chiropterotriton ceronorum sp. nov.}

Ceron Family Salamander, Salamandra de los Cerón

Figures 4A, 5A, 6B, 7B, 8B.

Chresonymy

Chiropterotriton chiropterus (part)—Gadow, 1905.

Chiropterotriton sp. I.-Darda, 1994 (population 22); Parra-Olea, 2003; Rafaëlli, 2007; Rafaëlli, 2013; Rovito \& Parra-Olea, 2015; García-Castillo et al., 2017; García-Castillo et al., 2018.

Holotype: USNM 224212, an adult male from ca. $1 \mathrm{~km}$ NE Santa Cruz Texmalaquilla (4.7 mi by road NE of Atzitzintla), on south slope of Pico de Orizaba, Puebla, Mexico, 3110 masl, 18.9484 N, $97.2802^{\circ}$ W. Collected 3 September 1975 by R. W. McDiarmid.

Paratypes: Twenty specimens, all from Puebla, Mexico. Ten males: MVZ 201393, Santa Cruz Texmalaquilla, S side of Mt. Orizaba; USNM 224202, 224207-08, 224211, 224218-20, 224230 and 224236, same data as holotype. Ten females: USNM 224240-41, 224247, 224250, 224252$53,224257,224259$ and 224275-76, same data as holotype.

Referred specimens: Two hundred eighty-two specimens, all from Mexico. Santa Cruz Texmalaquilla, Puebla: MVZ 201387-92; USNM 224193-201, 224203-06, 224209-10, 224213-17, 224221-29, 224231-35, 224237-39, 224242-46, 224248-49, 224251, 224254-56, 224258 and 224260-74. Xometla, Veracruz: CAS 98934-36, 98939, 98953, 98957; KU 10664165; IBH 30987-88; LACM 117161-230; MVZ 114378-82, 138759, 138761-63, 143910-17, 163583-97, 163601-06, 163612, 184830, 195827-30, 198914-17, 198919, 198921, 231345-47, 233032-34; and USNM 492145-47.

Diagnosis: This medium-sized species of plethodontid salamander is phylogenetically close to Chiropterotriton perotensis, C. totonacus and C. lavae; mean SVL $33.9 \mathrm{~mm}$ in ten adult males (range 30.6-36.2) and $34.9 \mathrm{~mm}$ in ten adult females (range 33.3-38.4). The head is moderately wide; HW averages $15 \%$ of SVL in both males and females (range 14-16\%). In males, the snout is broad and truncated. Jaw muscles are pronounced and visible as a bulging mass immediately behind the eyes. Eyes are moderately protuberant and extend laterally beyond the jaw margin in ventral view. There are few maxillary teeth in males (mean MT 11.0, range 7-18) but they are more numerous in females (mean MT 47.7, range 36-56). There are few vomerine teeth in males (mean VT 13.0, range 11-17) and females (mean VT 15.9, range 13-22), and they arranged in a curved line that does not extend past the outer margin of the internal choanae. The tail is moderately long; mean TL equals 1.0 of SVL in males (range 0.89-1.12) and 0.97 of SVL in females (range 0.85-1.07). Limbs are moderately long; FLL+HLL averages 54\% of SVL in males (range 48-57\%) and 50\% in females (range 45-54\%). Adpressed limbs approach closely or overlap slightly in males (mean LI 0.0 , range $-0.5-1$ ) but they are separated by as many as two 
247 costal folds in females (mean LI 1.5, range 1-2). Digits are slender and expanded distally, with 248 distinct subterminal pads and moderate webbing at the base. All digits are discrete, including the

249

250

251

252

253

254

255

256

257

258

259

260

261

262

263

264

265

266

267

268

269

270

271

272

273

274

275

276

277

278

279

280

281

282

283

284

285

286

287

288

289

290

291

292 first, which extends beyond the margins of the webbing. The outermost toes are particularly well developed. The smallest male with a mental gland is $30.6 \mathrm{~mm} \mathrm{SVL}$. The mental gland is prominent and oval (nearly round) to round. Parotoid glands are not evident.

Comparisons: Chiropterotriton ceronorum differs from C. perotensis by its larger adult body size size (mean SVL $33.9 \mathrm{~mm}$ in male and $34.9 \mathrm{~mm}$ in female C. ceronorum vs. $29.7 \mathrm{~mm}$ in male and $31.7 \mathrm{~mm}$ in female C. perotensis), longer limbs (mean LI 0.0 in male and 1.5 in female $C$. ceronorum vs. 2.5 in male and 3.3 in female C. perotensis), longer head (mean HL $7.5 \mathrm{~mm}$ in male and $7.1 \mathrm{~mm}$ in female $C$. ceronorum vs. $6.6 \mathrm{~mm}$ in male and $6.7 \mathrm{~mm}$ in female $C$. perotensis), broader head (mean HW $5.1 \mathrm{~mm}$ in both male and female C. ceronorum vs. $4.2 \mathrm{~mm}$ in male and $4.4 \mathrm{~mm}$ in female $C$. perotensis), broader feet (mean FW $3.8 \mathrm{~mm}$ in male and 3.5 $\mathrm{mm}$ in female C. ceronorum vs. $2.6 \mathrm{~mm}$ in both male and female C. perotensis), more maxillary teeth (mean MT 11.0 in male and 47.7 in female C. ceronorum vs. 7.2 in male and 27.9 in female C. perotensis) and more vomerine teeth (mean VT 13.0 in male and 15.9 in female C. ceronorum vs. 9.0 in male and 11.1 in female C. perotensis).

Chiropterotriton ceronorum differs from C. totonacus in its slightly smaller adult body size (mean SVL $33.9 \mathrm{~mm}$ in male and $34.9 \mathrm{~mm}$ in female C. ceronorum vs. $35.7 \mathrm{~mm}$ in male and $35.5 \mathrm{~mm}$ in female C. totonacus), shorter tail (mean TL/SVL 1.0 in male and 0.97 in female $C$. ceronorum vs. 1.16 in male and 1.20 in female $C$. totonacus), shorter limbs (mean LI 0.0 in male and 1.5 in female C. ceronorum vs. -0.6 in male and 0.0 in female C. totonacus) and fewer maxillary teeth (mean MT 11.0 in male and 47.7 in female C. ceronorum vs. 32.9 in male and 52.6 in female C. totonacus).

Chiropterotriton ceronorum differs from C. melipona by its larger adult body size (mean SVL $33.9 \mathrm{~mm}$ in male and $34.9 \mathrm{~mm}$ in female C. ceronorum vs. $29.2 \mathrm{~mm}$ in male and $28.5 \mathrm{~mm}$ in female C. melipona), longer limbs in males (mean LI 0.0 in C. ceronorum vs. 2.3 in $C$. melipona), longer head (mean HL $7.5 \mathrm{~mm}$ in male and $7.1 \mathrm{~mm}$ in female C. ceronorum vs. 6.3 $\mathrm{mm}$ in male and $6.4 \mathrm{~mm}$ in female C. melipona), broader head (mean HW $5.1 \mathrm{~mm}$ in both male and female C. ceronorum vs. $4.3 \mathrm{~mm}$ in male and $4.2 \mathrm{~mm}$ in female C. melipona), broader feet (mean FW $3.8 \mathrm{~mm}$ in male and $3.5 \mathrm{~mm}$ in female C. ceronorum vs. $2.4 \mathrm{~mm}$ in male and $2.6 \mathrm{~mm}$ in female C. melipona), more maxillary teeth (mean MT 11.0 in male and 47.7 in female $C$. ceronorum vs. 9.5 in male and 31.0 in female C. melipona) and more vomerine teeth (mean VT 13.0 in male and 15.9 in female C. ceronorum vs. 11.0 in male and 13.0 in female C. melipona).

Chiropterotriton ceronorum differs from C. casasi in its smaller adult body size (mean SVL $33.9 \mathrm{~mm}$ in male and $34.9 \mathrm{~mm}$ in female C. ceronorum vs. $37.8 \mathrm{~mm}$ in male and $40.9 \mathrm{~mm}$ in one female C. casasi), shorter head (mean HL $7.5 \mathrm{~mm}$ in male and $7.1 \mathrm{~mm}$ in female $C$. ceronorum vs. $8.3 \mathrm{~mm}$ in male and $8.6 \mathrm{~mm}$ in one female $C$. casasi), narrower head (mean HW $5.1 \mathrm{~mm}$ in both male and female C. ceronorum vs. $5.8 \mathrm{~mm}$ in male and $5.9 \mathrm{~mm}$ in one female $C$. casasi), longer limbs in males (mean LI 0.0 in C. ceronorum vs. 0.8 in C. casasi), more maxillary teeth (mean MT 11.0 in male and 47.7 in female C. ceronorum vs. mean 9.0 in males and 30 in one female $C$. casasi) and more vomerine teeth (mean VT 13.0 in male and 15.9 in female C. ceronorum vs. mean 9.0 in males and 13 in one female C. casasi).

Chiropterotriton ceronorum differs from C. chiropterus in its smaller adult body size in males (mean SVL $33.9 \mathrm{~mm}$ in C. ceronorum vs. $37.5 \mathrm{~mm}$ in C. chiropterus), shorter tail (mean TL/SVL 1.0 in male and 0.97 in female $C$. ceronorum vs. 1.25 in male and 1.19 in female $C$. chiropterus), longer limbs (mean LI 0.0 in male and 1.5 in female C. ceronorum vs. 0.3 in male

Peer) reviewing PDF | (2019:11:43498:1:1:NEW 18 Feb 2020) 
293

294

295

296

297

298

299

300

301

302

303

304

305

306

307

308

309

310

311

312

313

314

315

316

317

318

319

320

321

322

323

324

325

326

327

328

329

330

331

332

333

334

335

336

337

and 2.0 in female $C$. chiropterus) and fewer maxillary teeth (mean MT 11.0 in male and 47.7 in female C. ceronorum vs. 12.6 in male and 48.0 in female C. chiropterus).

Chiropterotriton ceronorum differs from $C$. orculus in its smaller adult body size (mean SVL $33.9 \mathrm{~mm}$ in male and 34.9 in female C. ceronorum vs. $35.9 \mathrm{~mm}$ in male and 39.0 in female C. orculus), longer limbs (mean LI 0.0 in male and 1.5 in female C. ceronorum vs. 1.9 in male and 2.9 in female $C$. orculus), more maxillary teeth (mean MT 11.0 in male and 47.7 in female C. ceronorum vs. 8.2 in male and $28.8 \mathrm{~mm}$ in female $C$. orculus) and more vomerine teeth (mean VT 13.0 in male and 15.9 in female C. ceronorum vs. 8.6 in male and 12.0 in female C. orculus).

Chiropterotriton ceronorum differs from C. lavae in being slightly larger (mean SVL $33.9 \mathrm{~mm}$ in male and $34.9 \mathrm{~mm}$ in female C. ceronorum vs. $32.4 \mathrm{~mm}$ in male and $31.6 \mathrm{~mm}$ in female C. lavae), a shorter tail (mean TL/SVL 1.0 in male and 0.97 in female C. ceronorum vs. 1.19 in male and 1.02 in female C. lavae), shorter limbs (mean LI 0.0 in male and 1.5 in female C. ceronorum vs. -0.6 in male and 0.6 in female C. lavae), more maxillary teeth (mean MT 11.0 in male and 47.7 in female C. ceronorum vs. 7.0 in male and 20.8 in female C. lavae), and more vomerine teeth (mean VT 13.0 in male and 15.9 in female C. ceronorum vs. 8.9 in male and 11.4 in female C. lavae).

Chiropterotriton ceronorum differs from C. aureus by its larger adult body size size (mean SVL $33.9 \mathrm{~mm}$ in male and $34.9 \mathrm{~mm}$ in female C. ceronorum vs. $28.5 \mathrm{~mm}$ in one male and $26.8 \mathrm{~mm}$ in female $C$. aureus), a shorter tail (mean TL/SVL 1.0 in male and 0.97 in female $C$. ceronorum vs. 1.28 in one male and 1.16 in female C. aureus), longer limbs (mean LI 0.0 in male and 1.5 in female C. ceronorum vs. 2.0 in one male and 2.3 in female C. aureus), longer head (mean HL $7.5 \mathrm{~mm}$ in male and $7.1 \mathrm{~mm}$ in female C. ceronorum vs. $6.4 \mathrm{~mm}$ in one male and $6.0 \mathrm{~mm}$ in female $C$. aureus), broader head (mean HW $5.1 \mathrm{~mm}$ in both male and female $C$. ceronorum vs. $4.0 \mathrm{~mm}$ in one male and $3.6 \mathrm{~mm}$ in female $C$. aureus), broader feet (mean FW 3.8 $\mathrm{mm}$ in male and $3.5 \mathrm{~mm}$ in female C. ceronorum vs. $2.4 \mathrm{~mm}$ in one male and 1.8 in female $C$. aureus), and more maxillary teeth (mean MT 11.0 in male and 47.7 in female C. ceronorum vs. 10.0 in one male and 38.3 in female C. aureus).

Chiropterotriton ceronorum differs from C. nubilus by its larger adult body size size (mean SVL $33.9 \mathrm{~mm}$ in male and $34.9 \mathrm{~mm}$ in female C. ceronorum vs. $29.4 \mathrm{~mm}$ in one male and $30.5 \mathrm{~mm}$ in female C. nubilus), a shorter tail (mean TL/SVL 1.0 in male and 0.97 in female $C$. ceronorum vs. 1.37 in one male and 1.12 in female C. nubilus), longer limbs in males (mean LI 0.0 in male C. ceronorum vs. 2.0 in one male C. nubilus), longer head in males (mean HL 7.5 $\mathrm{mm}$ in male C. ceronorum vs. $6.6 \mathrm{~mm}$ in one male C. nubilus), broader head (mean HW $5.1 \mathrm{~mm}$ in both male and female $C$. ceronorum vs. $4.0 \mathrm{~mm}$ in one male and $4.4 \mathrm{~mm}$ in female $C$. nubilus), and broader feet (mean FW $3.8 \mathrm{~mm}$ in male and $3.5 \mathrm{~mm}$ in female C. ceronorum vs. 2.6 $\mathrm{mm}$ in male and 2.3 in female C. nubilus).

Description of holotype. SVL $36.2 \mathrm{~mm}$, TL $34.3 \mathrm{~mm}$, AX $17.9 \mathrm{~mm}$, SW $3.4 \mathrm{~mm}$, HL $8.1 \mathrm{~mm}$, HW $5.3 \mathrm{~mm}$, HD $2.6 \mathrm{~mm}$, projection of snout beyond mandible $0.8 \mathrm{~mm}$, distance from anterior rim of orbit to snout $2.0 \mathrm{~mm}$, interorbital distance $2.6 \mathrm{~mm}$, eyelid length $1.8 \mathrm{~mm}$, eyelid width $1.3 \mathrm{~mm}$, horizontal orbit diameter $1.6 \mathrm{~mm}$, nostril diameter $0.3 \mathrm{~mm}$, FLL $10.0 \mathrm{~mm}$, HLL 10.3 $\mathrm{mm}$, snout-to-forelimb length $11.5 \mathrm{~mm}$, snout to anterior angle of vent $35.2 \mathrm{~mm}$, tail width at base $2.4 \mathrm{~mm}$, tail depth at base $2.6 \mathrm{~mm}, \mathrm{FW} 4.6 \mathrm{~mm}$, length of fifth toe $0.7 \mathrm{~mm}$, length of third (longest) toe $1.3 \mathrm{~mm}$, mental gland length $2.0 \mathrm{~mm}$, mental gland width 1.7. Numbers of teeth: premaxillary 3, maxillary 5-4 (right-left) and vomerine 5-6 (right-left). Adpressed limbs are separated by two costal folds. 
338 Variation: Specimens of C. ceronorum from Xometla are smaller and have a longer tail than

339

340

341

342

343

344

345

346

347

348

349

350

351

352

353

354

355

356

357

358

359

360

361

362

363

364

365

366

367

368

369

370

371

372

373

374

375

376

377

378

379

380

381 those from the type locality: mean SVL $33.9 \mathrm{~mm}$ in males and $34.9 \mathrm{~mm}$ in females from Texmalaquilla vs. $31.0 \mathrm{~mm}$ in males and $32.0 \mathrm{~mm}$ in females from Xometla; and mean TL/SVL 1.0 in males and 0.97 in females from Texmalaquilla vs. 1.17 in males and 1.08 in females from Xometla.

Coloration in life: These notes are based on study of a series of diapositives taken by Gabriela Parra-Olea from near Xometla and by James Hanken and Roy W. McDiarmid from the vicinity of Santa Cruz Texmalaquilla. Colors are from Köhler (2012).

The single Xometla specimen is generally dark brown and lacks a dorsal stripe or band. Dorsal and lateral coloration reddish brown (Mahogany Red, 34) anteriorly becoming brown (Brussels Brown, 33) medially and posteriorly. Lateral and ventral surfaces grayish (Smoke Gray, 266). Face and cheeks as well as limbs bright gray-brown (Smoke Gray, 267, to Light Drab, 269). Snout Ground Cinnamon (270) to True Cinnamon (28) to Vinaceous (247) at its tip. Upper eyelid Cream Yellow (82) at rim. Iris Cream Yellow (82) to bright Trogon Yellow (81) dorsally but much darker and brownish ventrally. Manus and pes bright light gray (Pale Neutral Gray, 296) but essentially colorless at the digit tips, which are transparent and show underlying reddish blood vessels.

The Texmalaquilla specimens (nine) all have dark to very dark basic ground color dorsally and laterally (venter not visible). Usually a dorsal band or stripe is present that extends from the posterior surface of the head (over the anterior extension of the epaxial muscles) to the tail tip. The band is almost uninterrupted in some specimens but is discontinuous or contains numerous spots or flecks of darker color in others. The stripe can be very bright and can be rich reddish (Pratt's Rufous, 72), orange-brown (Flesh Ocher, 57, to Orange Rufous, 56) to Salmon Color (58) and Dark Salmon Color (59). In others it is Clay Color $(18,20)$.

Coloration in preservative: The holotype is a uniform dark tannish brown dorsally, becoming paler laterally and very pale cream color ventrally. The dark tannish brown extends to the tip of the tail. Limbs are yellowish. Mental gland is beige. Nine paratypes are uniform dorsally, ranging from golden tan to very dark grey; in some, the tail is slightly paler than the dorsum. These nine paratypes have lateral surfaces paler than dorsal, and ventral surfaces are much lighter than lateral surfaces. The remaining eleven paratypes have a stripe of some sort. The stripe is always paler than immediately adjacent lateral parts, but it can be very obscure and seen mainly in the tail or it can extend all the way from the nape to the tip of the tail. The stripe is bright yellow in some individuals but typically is darker; in some specimens there is a suffusion of black in the middle of the stripe. All individuals are paler ventrally, but in some very dark animals the venter is dark gray and only the gular area is pale. The mental gland is usually pale.

Osteology: This account is based on examination of a $\mu \mathrm{CT}$ scan of the anterior skeleton of USNM 224212, an adult male, $36.2 \mathrm{~mm}$ SVL (Figs. 6-7; Table 3). The skull is robust in its degree of ossification, although many roofing bones are extremely thin. Paired frontals and parietals are for the most part well-articulated with one another; there is only a narrow but elongate frontoparietal fontanelle, mostly along the midline. Anteriorly, the frontals articulate with the nasal and prefrontal bones, as well as with the ascending processes of the single premaxilla. The ascending processes never contact one another but gradually widen as they establish an articulation with the frontals, thereby enclosing the internasal fontanelle. The palatal shelf of the premaxilla is very narrow and barely evident. Paired septomaxillary bones are 
382 present but small. The nasal bone is triangular but very thin, and somewhat larger than the 383 prefrontal, which is more rectangular in shape. Both bones are overlapped by the facial process 384 of the maxilla, but where the three bones meet the foramen for the nasolacrimal duct has eroded the facial process and the prefrontal but not the adjacent nasal. The anterior, toothed portion of the maxilla comprises only around $40 \%$ of the length of the bone; the remaining $60 \%$ is edentulous and saber-shaped. In dorsal view, the posterior tip of each maxilla doesn't bow out laterally as they do in some congeners (e.g., C. orculus). There are five maxillary teeth on the right side and seven on the left. There is but a single, short premaxillary tooth. The orbitosphenoid, while relatively large, is only weakly articulated to the parasphenoid and frontal and mostly separated from the parietal.

The otic capsule bears a distinct crest that extends anteriorly from the midpoint of the lateral semicircular canal to about the anterior third of the anterior semicircular canal. A narrow, spine-like tab is reflected ventromedially from the posterolateral margin of the parietal, ending at about the middle of the vertical extent of the orbitosphenoid. The squamosal is robust and expanded anteroventrally. The quadrate is stout. A stubby, thick-based stylus is present on the operculum. Paired vomers are well developed but barely articulate at the midline posterior to the internasal fontanelle. The preorbital process of each vomer is elongate, twisted and somewhat expanded laterally. Each side bears six vomerine teeth, which are deployed medially and do not extend onto the preorbital process. The median parasphenoid bone is triangular, but its caudal end is slightly bowed posteriorly. Paired parasphenoid tooth patches are separate at the midline; each bears approximately 60 teeth. The mandible is relatively stout. The articular bone is well ossified. The prearticular bone is well developed and bluntly rounded anteriorly, with a high coronoid process. There are 15 or 16 teeth on each dentary bone.

Digital formulae are 1-2-3-2 on each side. The terminal phalanx is barely expanded on each finger. Mesopodial cartilages are not mineralized.

Distribution and ecology: Chiropterotriton ceronorum occurs on the southern slopes of Pico de Orizaba in the states of Puebla and Veracruz at elevations that range from 2600 to approximately 3100 masl. Specimens have been found in arboreal bromeliads as well as under terrestrial cover objects.

Remarks: Chiropterotriton ceronorum is found in sympatry with Pseudoeurycea gadovii, $P$. leprosa, Thorius spilogaster and T. lunaris. Much of the natural habitat has been destroyed in recent years, making the species difficult to find. This species occurs at higher elevations than the nearby (to the NE) Chiropterotriton chiropterus.

Conservation status: Chiropterotriton ceronorum was very common during the 1970s, but is now very difficult to find, probably because of extensive habitat modification. On two visits to the area in 2015, no individuals of this species were seen while all the species with which it is known to co-occur were found. The remaining forest in the area where it lives is severely fragmented with ongoing degradation. We recommend that it be designated as Critically Endangered (CR) based on criterion B1ab(iii) (extent of occurrence $<100 \mathrm{~km}^{2}$, severely fragmented range and continuing decline in area, extent, and quality of habitat).

Etymology: The species name honors the Ceron family of Cuautlalpan, Veracruz, who have assisted generations of herpetologists in collecting salamanders in the general region of Pico de Orizaba. 
426 Chiropterotriton perotensis, sp. nov.

427 Valle Alegre Salamander, Salamandra de Valle Alegre

428 Figures 4B, 5B, 6F, 7F, 8F.

429

430

Chresonymy

431 Chiropterotriton chiropterus (part).-Smith and Taylor, 1948; Wake et al., 1992.

432 Chiropterotriton sp. H.-Darda, 1994; Parra-Olea, 2003; Rafaëlli, 2007; Rafaëlli, 2013; Rovito

433

434

\& Parra-Olea, 2015; García-Castillo et al., 2017; García-Castillo et al., 2018.

435

436

Holotype: MVZ 200693, an adult female from $14.4 \mathrm{~km} \mathrm{~S}$ (by road surfaced with rocks) Las

437

438

Vigas de Ramírez at Microwave Station, Valle Alegre, Veracruz, Mexico, 3020 masl,

439 $19.56917^{\circ} \mathrm{N}, 97.09528^{\circ} \mathrm{W}(\mathrm{EPE}=$ max. error distance $1.142 \mathrm{~km})$. Collected 26 August 1982 by D. M. Darda and S. Sessions.

440 Paratypes: Nineteen specimens, all from Veracruz, Mexico. Twelve males: MVZ 114356 and

441

442

443

444

445

446

447

448

449

450

451

452

453

454

455

456

457

458

459

460

461

462

463

464

465

466 114359, road from Las Vigas de Ramírez to microwave station on N Flank Cofre de Perote, 11.6 km S (by road) Las Vigas; MVZ 173428-29, Las Vigas de Ramírez, microondas road; MVZ 178661 and 178663-65, 8-15.5 km S (via microondas road) Las Vigas de Ramírez; MVZ 200681-83 and 200698, 14.4 km S (by Rock Rd.) Las Vigas de Ramírez at microwave station. Seven females: MVZ 173438-39, Las Vigas de Ramírez, microondas road; MVZ 186711, road to microwave station, $15 \mathrm{~km} \mathrm{~S}$ (by road) Las Vigas de Ramírez; MVZ 200691, 200694-95 and 200702, 14.4 km S (by Rock Rd.) Las Vigas de Ramírez at microwave station.

Referred specimens: Seventy-one specimens, all from Veracruz, Mexico. IBH 16778-82, 22384, 22391, 22395, 23062, 23066, 23072, 29853, 29857, 29863-64, 29866, 29872, 30840-41, 30844, 30847, 31032-39 and 31055-62; KU 100747-54; MVZ 114351, 114355, 114357, 114358, 173440-41, 178659-60, 178662, 178666-68, 200684-86, 200688-90, 200692, 200695-97, 200699-701 and 200703.

Diagnosis: This is a small but stout species of plethodontid salamander that is phylogenetically related to Chiropterotriton lavae, C. ceronorum and C. totonacus; mean SVL $29.7 \mathrm{~mm}$ in 12 adult males (range 26.5-32.8) and $31.7 \mathrm{~mm}$ in eight adult females (range 27.4-34.3). The head is moderately wide; HW averages $14 \%$ of SVL in both males and females (range 13-15\%). The snout is short. Eyes are small and typically do not protrude laterally beyond the jaw margin in ventral view; they are less prominent than in most other species of Chiropterotriton. Jaw muscles caudal to the eyes are variably developed but generally pronounced. There are few maxillary teeth in males (mean MT 7.2, range 2-17) and moderate numbers in females (mean MT 27.9, range 19-36). There are few vomerine teeth in both males (mean VT 9.0, range 7-12) and females (mean MT 11.1, range 10-13), which are arranged in a curved line that does not extend lateral to the outer margin of the internal choana. The tail is moderately sized; mean TL equals 1.03 of SVL in males (range $0.92-1.16$ ) and 1.0 of SVL in females (range 0.79-1.11). Limbs are short; FLL +HLL averages $47 \%$ of SVL in males (range $44-50 \%$ ) and $43 \%$ of SVL in females (range 41-46\%). Adpressed limbs are widely separated - they never overlap —in both males 
467 (mean LI 2.5, range 1-3) and females (mean LI 3.3, range 2-4). Manus and pes are relatively 468 small for the genus. Digital webbing ranges from absent to slight; when present, it is limited to 469 the metatarsal region. The first digit is small and usually included within the webbing, although a

470

471

472

473

474

475

476

477

478

479

480

481

482

483

484

485

486

487

488

489

490

491

492

493

494

495

496

497

498

499

500

501

502

503

504

505

506

507

508

509

510

511

512 small portion of it may be free at the tip. The outermost digit is less prominent than in other species; digit 5 (pes) is distinctly shorter than digits 2-4. Subterminal pads are present but not prominent. An oval-shaped mental gland present in males but is not particularly prominent. The smallest male with a mental gland is $29.3 \mathrm{~mm}$ SVL. Paratoid glands are present in many individuals and prominent in some.

Comparisons: Chiropterotriton perotensis differs from C. ceronorum in its smaller adult body size (mean SVL $29.7 \mathrm{~mm}$ in male and $31.7 \mathrm{~mm}$ in female $C$. perotensis vs. $33.9 \mathrm{~mm}$ in male and $34.9 \mathrm{~mm}$ in female $C$. ceronorum), shorter limbs (mean LI 2.5 in male and 3.3 in female $C$. perotensis vs. 0.0 in male and 1.5 in female C. ceronorum), shorter head (mean HL $6.6 \mathrm{~mm}$ in male and $6.7 \mathrm{~mm}$ in female C. perotensis vs. $7.5 \mathrm{~mm}$ in male and $7.1 \mathrm{~mm}$ in female C. ceronorum), narrower head (mean HW $4.2 \mathrm{~mm}$ in male and $4.4 \mathrm{~mm}$ in female $C$. perotensis vs. $5.1 \mathrm{~mm}$ in both male and female $C$. ceronorum), narrower feet (mean FW $2.6 \mathrm{~mm}$ in both male and female $C$. perotensis vs. $3.8 \mathrm{~mm}$ in male and $3.5 \mathrm{~mm}$ in female $C$. ceronorum), fewer maxillary teeth (mean MT 7.2 in male and 27.8 in female $C$. perotensis vs. 11.0 in male and 47.7 in female $C$. ceronorum) and fewer vomerine teeth (VT 9.0 in male and 11.1 in female $C$. perotensis vs. 13.0 in male and 15.9 in female C. ceronorum).

Chiropterotriton perotensis differs from $C$. totonacus in its smaller adult body size (mean SVL $29.7 \mathrm{~mm}$ in male and $31.7 \mathrm{~mm}$ in female $C$. perotensis vs. $35.7 \mathrm{~mm}$ in male and $35.5 \mathrm{~mm}$ in female $C$. totonacus), shorter tail (mean TL/SVL 1.0 in both male and female $C$. perotensis vs. 1.16 in male and 1.20 in female C. totonacus), shorter limbs (mean LI 2.5 in male and 3.3 in female $C$. perotensis vs. -0.6 in male and 0.0 in female $C$. totonacus), shorter head (mean HL 6.6 $\mathrm{mm}$ in male and $6.7 \mathrm{~mm}$ in female $C$. perotensis vs. $8.5 \mathrm{~mm}$ in male and $7.6 \mathrm{~mm}$ in female $C$. totonacus), narrower head (mean HW $4.2 \mathrm{~mm}$ in male and $4.4 \mathrm{~mm}$ in female $C$. perotensis vs. $5.2 \mathrm{~mm}$ in both male and female $C$. totonacus), narrower feet (mean FW $2.6 \mathrm{~mm}$ in both male and female C. perotensis vs. $4.2 \mathrm{~mm}$ in male and $4.0 \mathrm{~mm}$ in female C. totonacus), fewer maxillary teeth (mean MT 7.2 in male and 27.9 in female C. perotensis vs. 32.9 in male and 52.6 in female $C$. totonacus) and fewer vomerine teeth (mean VT 9.0 in male and 11.1 in female $C$. perotensis vs. 11.6 in male and 13.7 in female C. totonacus).

Chiropterotriton perotensis, while very similar in morphological proportions to $C$. melipona, differs by its shorter limbs in females (mean LI 3.3 in C. perotensis vs. 1.8 in $C$. melipona), fewer maxillary teeth (mean MT 7.2 in male and 27.9 in female $C$. perotensis vs. 9.5 in male and 31.0 in female C. melipona) and fewer vomerine teeth (mean VT 9.0 in male and 11.1 in female $C$. perotensis vs. 11.0 in male and 13.0 in female $C$. melipona).

Chiropterotriton perotensis differs from $C$. casasi in its smaller adult body size (mean SVL $29.7 \mathrm{~mm}$ in male and $31.7 \mathrm{~mm}$ in female $C$. perotensis vs. $37.8 \mathrm{~mm}$ in male and $40.9 \mathrm{~mm}$ in one female C. casasi), shorter limbs (mean LI 2.5 in male and 3.3 in female C. perotensis vs. 0.80 in male and 1.0 in one female $C$. casasi), shorter head (mean HL $6.6 \mathrm{~mm}$ in male and 6.7 $\mathrm{mm}$ in female $C$. perotensis vs. $8.3 \mathrm{~mm}$ in male and $8.6 \mathrm{~mm}$ in one female $C$. casasi), narrower head (mean HW $4.2 \mathrm{~mm}$ in male and $4.4 \mathrm{~mm}$ in female $C$. perotensis vs. $5.8 \mathrm{~mm}$ in male and 5.9 $\mathrm{mm}$ in one female $C$. casasi), narrower feet (mean FW $2.6 \mathrm{~mm}$ in both male and female $C$. perotensis vs. $3.7 \mathrm{~mm}$ in both male and one female C. casasi), fewer maxillary teeth (mean MT 7.2 in male and 27.9 in female $C$. perotensis vs. 9.0 in male and 30.0 in one female C. casasi) and fewer vomerine teeth in females (11.1 in C. perotensis vs.13.0 in one C. casasi).

Peer) reviewing PDF | (2019:11:43498:1:1:NEW 18 Feb 2020) 
513

514

515

516

517

518

519

520

521

522

523

524

525

526

527

528

529

530

531

532

533

534

535

536

537

538

539

540

541

542

543

544

545

546

547

548

549

550

551

552

553

554

555

556

557

558

Chiropterotriton perotensis differs from $C$. chiropterus by its smaller adult body size (mean SVL $29.7 \mathrm{~mm}$ in male and $31.7 \mathrm{~mm}$ in female $C$. perotensis vs. $37.5 \mathrm{~mm}$ in male and 33.5 $\mathrm{mm}$ in female $C$. chiropterus), shorter tail (mean TL/SVL 1.0 in both male and female $C$. perotensis vs. 1.25 in male and 1.19 in female C. chiropterus), shorter limbs (mean LI 2.5 in male and 3.3 in female $C$. perotensis vs. 0.30 in male and 2.0 in female $C$. chiropterus), shorter head (mean HL $6.6 \mathrm{~mm}$ in male and $6.7 \mathrm{~mm}$ in female $C$. perotensis vs. $8.1 \mathrm{~mm}$ in male and 7.3 $\mathrm{mm}$ in female $C$. chiropterus), narrower head (mean HW $4.2 \mathrm{~mm}$ in male and $4.4 \mathrm{~mm}$ in female C. perotensis vs. $5.6 \mathrm{~mm}$ in male and $4.8 \mathrm{~mm}$ in female $C$. chiropterus), narrower feet (mean $\mathrm{FW}$ $2.6 \mathrm{~mm}$ in both male and female $C$. perotensis vs. $3.7 \mathrm{~mm}$ in male and $3.1 \mathrm{~mm}$ in female $C$. chiropterus), fewer maxillary teeth (mean MT 7.2 in male and 27.9 in female C. perotensis vs. 12.6 in male and 48.0 in female $C$. chiropterus) and fewer vomerine teeth (mean VT 9.0 in male and 11.1 in female C. perotensis vs. 10.6 in male and 12.5 in female C. chiropterus).

Chiropterotriton perotensis differs from $C$. orculus in its smaller adult body size (mean SVL $29.7 \mathrm{~mm}$ in male and $31.7 \mathrm{~mm}$ in female C. perotensis vs. $35.9 \mathrm{~mm}$ in male and $39.0 \mathrm{~mm}$ in female C. orculus), slightly shorter limbs (mean LI 2.5 in male and 3.3 in female C. perotensis vs. 1.9 in male and 2.9 in female $C$. orculus), shorter head (mean HL $6.6 \mathrm{~mm}$ in male and 6.7 $\mathrm{mm}$ in female $C$. perotensis vs. $7.4 \mathrm{~mm}$ in male and $8.0 \mathrm{~mm}$ in female $C$. orculus), narrower head (mean HW $4.2 \mathrm{~mm}$ in male and $4.4 \mathrm{~mm}$ in female $C$. perotensis vs. $5.0 \mathrm{~mm}$ in male and $5.2 \mathrm{~mm}$ in female $C$. orculus), narrower feet (mean FW $2.6 \mathrm{~mm}$ in both male and female $C$. perotensis vs. $3.2 \mathrm{~mm}$ in male and $3.4 \mathrm{~mm}$ in female $C$. orculus) and fewer maxillary teeth (mean MT 7.2 in male and 27.9 in female $C$. perotensis vs. 8.2 in male and 28.8 in female $C$. orculus).

Chiropterotriton perotensis differs from C. lavae in having a smaller adult body size in males (mean SVL $29.7 \mathrm{~mm}$ in C. perotensis vs. $32.4 \mathrm{~mm}$ in C. lavae), shorter limbs (mean LI 2.5 in male and 3.3 in female $C$. perotensis vs. -0.6 in male and 0.6 in female $C$. lavae), a slightly narrower head (mean HW 4.2 in male and 4.4 in female $C$. perotensis vs. 4.9 in male and 4.7 in female $C$. lavae), a shorter head (mean HL $6.6 \mathrm{~mm}$ in male and $6.7 \mathrm{~mm}$ in female $C$. perotensis vs. $7.5 \mathrm{~mm}$ in male and $7.0 \mathrm{~mm}$ in female $C$. lavae), narrower feet (FW $2.6 \mathrm{~mm}$ in both male and female $C$. perotensis vs. $3.7 \mathrm{~mm}$ in male and $3.3 \mathrm{~mm}$ in female C. lavae) and more maxillary teeth in females (mean MT 27.9 in C. perotensis vs. 20.8 in C. lavae).

Chiropterotriton perotensis differs from C. aureus in its smaller adult body size (mean SVL $29.7 \mathrm{~mm}$ in male and $31.7 \mathrm{~mm}$ in female C. perotensis vs. $28.5 \mathrm{~mm}$ in male and $26.8 \mathrm{~mm}$ in female $C$. aureus), shorter tail in males (mean TL/SVL 1.0 in both male and female $C$. perotensis vs. 1.28 in male and 1.16 in female $C$. aureus), broader head (mean HW $4.2 \mathrm{~mm}$ in male and 4.4 $\mathrm{mm}$ in female $C$. perotensis vs. $4.0 \mathrm{~mm}$ in male and $3.6 \mathrm{~mm}$ in female $C$. aureus), broader feet in females (mean FW $2.6 \mathrm{~mm}$ in female $C$. perotensis vs. $1.8 \mathrm{~mm}$ in female $C$. aureus), fewer maxillary teeth in females (mean MT 27.9 in female $C$. perotensis vs. 38.3 in female $C$. aureus) and fewer vomerine teeth in males (mean VT 9.0 in male $C$. perotensis vs. 15.0 in male $C$. aureus).

Chiropterotriton perotensis differs from C. nubilus in having a shorter tail (mean TL/SVL 1.0 in both male and female $C$. perotensis vs. 1.37 in male and 1.12 in female $C$. nubilus), shorter limbs (mean LI 2.5 in male and 3.3 in female $C$. perotensis vs. 2.0 in male and 1.5 in female $C$. nubilus), and fewer maxillary teeth (mean MT 7.2 in male and 27.9 in female $C$. perotensis vs. 13.0 in male and 41.5 in female C. nubilus)

Description of holotype: SVL $31.1 \mathrm{~mm}$, TL $30.7 \mathrm{~mm}$, AX $16.4 \mathrm{~mm}$, SW $3.1 \mathrm{~mm}$, HL $6.8 \mathrm{~mm}$, HW $4.2 \mathrm{~mm}$, HD $2.0 \mathrm{~mm}$, projection of snout beyond mandible $0.4 \mathrm{~mm}$, distance from anterior rim of orbit to snout $1.7 \mathrm{~mm}$, interorbital distance $1.8 \mathrm{~mm}$, eyelid length $2.2 \mathrm{~mm}$, eyelid width 
$5590.8 \mathrm{~mm}$, horizontal orbit diameter $1.4 \mathrm{~mm}$, FLL $6.5 \mathrm{~mm}$, HLL $6.7 \mathrm{~mm}$, snout-to-forelimb length $5608.8 \mathrm{~mm}$, snout to anterior angle of vent $29.5 \mathrm{~mm}$, tail width at base $2.1 \mathrm{~mm}$, tail depth at base 2.6 $561 \mathrm{~mm}$, FW $2.5 \mathrm{~mm}$, length of fifth toe $0.5 \mathrm{~mm}$, length of third (longest) toe $1.2 \mathrm{~mm}$. Numbers of

562 teeth: premaxillary 6, maxillary 15-16 (right-left) and vomerine 7-6 (right-left). Adpressed limbs

563 are separated by 4 costal folds.

564 Coloration in life: Color notes in life are not available for specimens in the type series, but notes were recorded for the following referred specimens. IBH 29853, 29857, 29863, 29864, 29866

566 and 29872, $15 \mathrm{~km} \mathrm{~S}$ of Las Vigas on road to Valle Alegre: General coloration dark with a dark reddish brown dorsal stripe in some and obscure brown to grayish brown stripe in others. The reddish stripe is brightest laterally with darker pigment medially. Small guanophores are abundantly distributed over the mainly very dark pigment dorsally. The iris is golden brown to dark brown. The venter is dark to very dark. In one adult there is a complete melanophore network; in another, dense punctuations. Some white guanophores are prominent in the darker individual. IBH 22384, 22395, 23062, 23066 and 23072, $15.9 \mathrm{~km}$ on microondas road, Las Vigas: Adults are very dark dorsally--almost black--with a fine speckling of obscure white overlying the ground color. Fine background mottling of dark brown on black. Limbs are black with some paler highlights medially, but become brown distally. The iris is dark brownish black. The venter is dark, dense mainly punctate melanophores, with a very fine superficial sprinkling of white ventrolaterally. The gular area is slightly paler. Juveniles have an indistinct brown stripe, which is less apparent in larger animals.

Coloration in preservative: The holotype is a uniform dark brown dorsally and laterally, becoming blackish brown on the tail. The venter is much paler than the dorsum, becoming dark brown under the tail. Limbs are dark brown. There is no other distinguishing color. Two of the paratypes have a hint of a dorsal stripe, which is slightly paler than surrounding areas. The manus and pes are paler, but in general are brown to blackish brown.

Osteology: This account is based on examination of a $\mu \mathrm{CT}$ scan of the anterior skeleton of MVZ 200693, an adult female, $31.1 \mathrm{~mm}$ SVL (Figs. 6-8; Table 3). The skull is compact. Individual cranial roofing bones are for the most part well developed, although there is a marked frontoparietal fontanelle that begins at the frontal-parietal border and extends posteriorly along the midline. The frontal is fairly robust. Anteriorly, it is solidly articulated with the ascending processes of the single premaxilla, which arise separately and remain distinct along their entire length. The processes expand laterally where they articulate with the frontal bones. The premaxilla lacks a palatal shelf and there are no septomaxillary bones. The nasal bone is triangular but very thin. It is considerably larger than the rectangular prefrontal, which is distinct but small. A foramen for the nasolacrimal duct has eroded the anteroventral margin of the prefrontal, the posteroventral margin of the nasal, and the dorsal edge of the facial process of the maxilla. The anterior, toothed portion of the maxilla comprises approximately $75-80 \%$ of the length of the bone; the remaining edentulous portion is thinner and cleaver-like. The facial process of the maxilla extends rostrally. There are 16 maxillary teeth on the left side and 17 on the right. There are seven premaxillary teeth. The orbitosphenoid is moderately well developed and relatively large, but it is only weakly articulated to the parasphenoid and frontal and separated from the parietal.

The otic capsule bears a modest dorsal crest above the anterior semicircular canal but there is no distinct otic process. A well-developed tab extends ventromedially from the 
603 posterolateral surface of the parietal. It is relatively long and spine-like and extends through 604 about two-thirds of the vertical extent of the orbitosphenoid. The squamosal bone is relatively 605 stout, roughly triangular, and abuts the otic capsule along a broad front that subtends the lateral 606 semicircular canal. The quadrate bone is relatively small and inconspicuous. The columella bears 607 a distinct stylus. Bodies of the vomer are well ossified but also well separated at the midline. 608 Each preorbital process is short, ending at the lateral edge of the internal naris. There are nine 609 vomerine teeth on the right side and six on the left; a few are deployed on the preorbital process. 610 The parasphenoid is fairly broad anteriorly; its posterior border is straighter (less rounded) than 611 in some other species. Paired parasphenoid tooth patches meet at the midline both anteriorly and posteriorly, but not in between. There are approximately 105 fully developed teeth on each side

613

614

615

616

617

618 and smaller, less-developed teeth along each lateral margin. The mandible is robust. The articular is only partly ossified. The prearticular is relatively small and has a low coronoid process. Teeth are small and very numerous on each dentary bone, but a reliable count cannot be made from the CT scan.

Digital formulae are 1-2-3-2 on each side. The distal tip of the terminal phalanx is slightly expanded on each finger. Mesopodial cartilages are not mineralized.

619 Distribution and ecology: Chiropterotriton perotensis is found in Cofre de Perote, Veracruz, Mexico, both in pine-and-fir forest and from the tree line to the summit. Elevations range from 2950 to $4015 \mathrm{~m}$. Specimens have been found under terrestrial objects and active on road banks and boulders at night. The species occurs in sympatry with Aquiloeurycea cephalica, Isthmura naucampatepetl, Pseudoeurycea leprosa and P. melanomolga.

Remarks: Allozymes of this species were studied by Darda (his unnamed species H) (1994),

625

626

627

628

629

630

631

632

633 who also reported a sympatric species (his species D). These two were separated by four fixed differences (out of 17 proteins studied). Parra-Olea (2003) was unable to obtain mtDNA sequence from his remaining (ground and degraded) tissue samples and did not find additional specimens. We consider the dissected carcasses to be inadequate for preparation of a formal description, but we note the presence of a likely additional species of Chiropterotriton at the Las Lajas locality. Like $C$ perotensis, this unnamed species is small, but apparently more slender and lighter in coloration. The two are not sister-taxa.

We think that the specimens reported as Chiropterotriton chiropterus from 11,000 feet on Cofre de Perote by Smith and Taylor (1948) belong to C. perotensis.

634 Conservation status: We recommend that the species be designated as Endangered based on criterion B1ab(iii) (extent of occurrence $<5000 \mathrm{~km}^{2}$, habitat severely fragmented with continuing decline in area, extent, and quality of habitat; IUCN, 2012).

Etymology: The species name is a noun in the genitive case. It refers to the Cofre de Perote volcano, where the species is found. 
645 Chresonymy

646 Chiropterotriton sp. E.-Darda, 1994.

647 Chiropterotriton chiropterus (part)._-Taylor and Smith, 1945; Smith and Taylor, 1948; Wake et

648 al., 1992.

649 Holotype: MVZ 163945, an adult female from $6 \mathrm{~km}$ W Las Vigas de Ramírez, Veracruz, 650 Mexico, 2420 masl, $19.635^{\circ} \mathrm{N}, 97.159166^{\circ} \mathrm{W}(\mathrm{EPE}=\max$. error distance $5.71 \mathrm{~km})$. Collected 65125 July 1979 by D. B. Wake.

652 Paratypes: Nineteen specimens, all from Veracruz, Mexico. Ten males: MVZ 163947-49, 653 163989-90, 163993, 171903, 171905, 171907 and 171909, 6 km W Las Vigas de Ramírez. Nine 654 females: MVZ 136981-82, 136986, pine forest along Mexican Hwy. 140, 4 km W Las Vigas de 655 Ramírez; MVZ 138703-04, 138716 and 138765, Mexican Hwy. 140, 4.5 km W (by road) Las 656 Vigas de Ramírez; MVZ 163943 and 171910, 6 km W Las Vigas de Ramírez.

657 Referred specimens: Fifty-two specimens, all from Veracruz, Mexico. IBH 00122 and 31030658 31031; MVZ 136983-85, 137029, 138702, 138705-15, 138717-19, 163942, 163944, 163946, 659 163991-92, 163994, 171904, 171906, 171908 and 171911-31.

660 Diagnosis: This medium-sized species of plethodontid salamander is phylogenetically close to 661 Chiropterotriton lavae, C. perotensis and C. ceronorum; mean SVL $35.7 \mathrm{~mm}$ in ten adult males 662 (range 32.0-38.6) and 35.5 $\mathrm{mm}$ in ten adult females (range 31.8-38.3). The head is moderately wide; HW averages $15 \%$ of SVL in both sexes (range 14-16). Jaw muscles are prominent in both sexes. Adult males have a broad, blunt snout with pronounced nasolabial protuberances that extend below the lip. Eyes are large and prominent and extend laterally beyond the jaw margin in ventral view. There are numerous maxillary teeth in males (mean MT 32.9, range 18-48) and even more teeth in females (mean MT 52.6, range 45-60). There are few vomerine teeth in both males (mean VT 11.6, range 10-15) and females (mean MT 13.7, range 9-17), which are arranged in a curved line that does not extend past the lateral margin of the internal choana. The tail is long and slender and typically exceeds SVL; mean TL equals 1.16 of SVL in males (range 0.92-1.24) and 1.20 in females (range 1.06-1.38). Limbs are moderately long; FLL+HLL averages $59 \%$ of SVL in males (range 55-64\%) and 57\% in females (range 53-62\%). Adpressed

673

674 limbs closely approach or overlap in males (mean LI -0.6, range -1-1) and females (mean LI 0.0, range $-1-1)$. The manus and pes are relatively wide; digital tips are somewhat expanded and there are distinct subterminal pads. Digital webbing extends to the base of the terminal phalanx. The first (innermost) digit, while distinct, is included in the web except at its tip. Mental glands are large, oval-shaped and relatively prominent in males. The smallest male with a mental gland is $32.0 \mathrm{~mm}$ SVL. Parotoid glands are well marked in some individuals but less evident in others.

Comparisons: Chiropterotriton totonacus differs from C. ceronorum in its larger adult body size (mean SVL $35.7 \mathrm{~mm}$ in male and $35.5 \mathrm{~mm}$ in female $C$. totonacus vs. $33.9 \mathrm{~mm}$ in male and 34.9 $\mathrm{mm}$ in female $C$. ceronorum), longer tail (mean TL/SVL 1.16 in male and 1.20 in female $C$.

683

684

685 totonacus vs. 1.0 in male and 0.97 in female $C$. ceronorum), longer limbs (mean LI -0.6 in male and 0.0 in female $C$. totonacus vs. 0.0 in male and 1.5 in female $C$. ceronorum), longer head (mean HL $8.5 \mathrm{~mm}$ in male and $7.6 \mathrm{~mm}$ in female C. totonacus vs. $7.5 \mathrm{~mm}$ in male and $7.1 \mathrm{~mm}$ in female $C$. ceronorum), slightly larger feet (mean FW $4.2 \mathrm{~mm}$ in male and $4.0 \mathrm{~mm}$ in female $C$.

686 totonacus vs. $3.8 \mathrm{~mm}$ in male and $3.5 \mathrm{~mm}$ in female $C$. ceronorum), more maxillary teeth (mean 
687 MT 32.9 in male and 52.6 in female $C$. totonacus vs. 11.0 in male and 47.7 in female $C$. 688 ceronorum) and fewer vomerine teeth (mean VT 11.6 in male and 13.7 in female C. totonacus vs. 13.0 in male and 15.9 in female $C$. ceronorum).

Chiropterotriton totonacus differs from C. perotensis in its larger adult body size (mean

691

692

693

694

695

696 SVL $35.7 \mathrm{~mm}$ in male and $35.5 \mathrm{~mm}$ in female $C$. totonacus vs. $29.7 \mathrm{~mm}$ in male and $31.7 \mathrm{~mm}$ in female $C$. perotensis), longer tail (mean TL/SVL 1.16 in male and 1.20 in female $C$. totonacus vs. 1.0 in both male and female $C$. perotensis), longer limbs (mean LI -0.60 in male and 0.0 in female $C$. totonacus vs. 2.5 in male and 3.3 in female $C$. perotensis), longer head (mean HL 8.5 $\mathrm{mm}$ in male and $7.6 \mathrm{~mm}$ in female C. totonacus vs. $6.6 \mathrm{~mm}$ in male and $6.7 \mathrm{~mm}$ in female $C$. perotensis), broader head (mean HW $5.2 \mathrm{~mm}$ in both male and female C. totonacus vs. $4.2 \mathrm{~mm}$ in male and $4.4 \mathrm{~mm}$ in female $C$. perotensis), larger feet (mean FW $4.2 \mathrm{~mm}$ in male and $4.0 \mathrm{~mm}$ in female $C$. totonacus vs. $2.6 \mathrm{~mm}$ in both male and female $C$. perotensis), more maxillary teeth (mean MT 32.9 in male and 52.6 in female $C$. totonacus vs. 7.2 in male and 27.9 in female $C$. perotensis) and more vomerine teeth (mean VT 11.6 in male and 13.7 in female $C$. totonacus vs. 9.0 in male and 11.1 in female $C$. perotensis).

Chiropterotriton totonacus differs from C. melipona in its larger adult body size (mean SVL $35.7 \mathrm{~mm}$ in male and $35.5 \mathrm{~mm}$ in female C. totonacus vs. $29.2 \mathrm{~mm}$ in male and $28.5 \mathrm{~mm}$ in female $C$. melipona), longer tail in females (mean TL/SVL 1.20 in C. totonacus vs. 1.11 in $C$. melipona), longer limbs (mean LI -0.60 in male and 0.0 in female C. totonacus vs. 2.3 in male and 1.8 in female C. melipona), longer head (mean HL $8.5 \mathrm{~mm}$ in male and $7.6 \mathrm{~mm}$ in female C. totonacus vs. $6.3 \mathrm{~mm}$ in male and $6.4 \mathrm{~mm}$ in female $C$. melipona), broader head (mean $\mathrm{HW} 5.2$ $\mathrm{mm}$ in both male and female $C$. totonacus vs. $4.3 \mathrm{~mm}$ in male and $4.2 \mathrm{~mm}$ in female $C$. melipona), larger feet (mean FW $4.2 \mathrm{~mm}$ in male and $4.0 \mathrm{~mm}$ in female C. totonacus vs. $2.4 \mathrm{~mm}$ in male and $2.6 \mathrm{~mm}$ in female C. melipona) and more maxillary teeth (mean MT 32.9 in male and 52.6 in female $C$. totonacus vs. 9.5 in male and 31.0 in female $C$. melipona).

Chiropterotriton totonacus differs from C. casasi in its smaller adult body size (mean SVL $35.7 \mathrm{~mm}$ in male and $35.5 \mathrm{~mm}$ in female $C$. totonacus vs. $37.8 \mathrm{~mm}$ in male and $40.9 \mathrm{~mm}$ in one female C. casasi), longer limbs (mean LI -0.6 in male and 0.0 in female C. totonacus vs. 0.80 in male and 1.0 in one female $C$. casasi), narrower head (mean HW 5.2 in both male and female $C$. totonacus vs. 5.8 in male and 5.9 in one female $C$. casasi), larger feet (mean FW 4.2 in male and 4.0 in female $C$. totonacus vs. 3.7 in both male and one female $C$. casasi) and fewer maxillary teeth (mean MT 32.9 in male and 52.6 in female C. totonacus vs. 9.0 in male and 30 in one female C. casasi).

Chiropterotriton totonacus differs from C. chiropterus in its smaller adult body size in males (mean SVL $35.7 \mathrm{~mm}$ in C. totonacus vs. $37.5 \mathrm{~mm}$ in C. chiropterus), shorter tail (mean TL/SVL 1.16 in male and 1.20 in female $C$. totonacus vs. 1.25 in male and 1.19 in female $C$. chiropterus), longer limbs (mean LI -0.60 in male and 0.0 in female C. totonacus vs. 0.3 in male and 2.0 in female $C$. chiropterus), longer head (mean HL $8.5 \mathrm{~mm}$ in male and $7.6 \mathrm{~mm}$ in female C. totonacus vs. $8.1 \mathrm{~mm}$ in male and $7.3 \mathrm{~mm}$ in female C. chiropterus), larger feet in males (mean FW $4.2 \mathrm{~mm}$ in C. totonacus vs. $3.7 \mathrm{~mm}$ in C. chiropterus), more maxillary teeth (mean MT 32.9 in male and 52.6 in female $C$. totonacus vs. 12.6 in male and 48.0 in female $C$. chiropterus) and more vomerine teeth (mean VT 11.6 in male and 13.7 in female C. totonacus vs. 10.6 in male and 12.5 in female $C$. chiropterus).

Chiropterotriton totonacus differs from $C$. orculus in its smaller adult body size in females (mean SVL $35.5 \mathrm{~mm}$ in C. totonacus vs. $39.0 \mathrm{~mm}$ in $C$. orculus), longer tail (mean TL/SVL 1.16 in male and 1.20 in female $C$. totonacus vs. 1.0 in both male and female $C$. 
733 orculus), longer limbs (mean LI -0.60 in male and 0.0 in female C. totonacus vs. 1.9 in male and 7342.9 in female C. orculus), longer head in males (mean HL $8.5 \mathrm{~mm}$ in C. totonacus vs. $7.4 \mathrm{~mm}$ in 735 C. orculus), larger feet (mean FW $4.2 \mathrm{~mm}$ in male and $4.0 \mathrm{~mm}$ in female C. totonacus vs. 3.2

$736 \mathrm{~mm}$ in male and $3.4 \mathrm{~mm}$ in female $C$. orculus), more maxillary teeth (mean MT 32.9 in male and 73752.6 in female $C$. totonacus vs. 8.2 in male and 28.8 in female $C$. orculus) and more vomerine 738 teeth (mean VT 11.6 in male and 13.7 in female C. totonacus vs. 8.6 in male and 12.0 in female 739 C. orculus).

$740 \quad$ Chiropterotriton totonacus differs from C. lavae in its larger adult body size (mean SVL

741

742

743

744

745

746

747

748

749

750

751

752

753

754

755

756

757

758

759

760

761

762

763

764

765 $35.7 \mathrm{~mm}$ in male and $35.5 \mathrm{~mm}$ in female C. totonacus vs. $32.4 \mathrm{~mm}$ in male and $31.6 \mathrm{~mm}$ in female C. lavae), longer tail in females (mean TL/SVL 1.20 in C. totonacus vs. 1.02 in C. lavae), longer limbs in females (mean LI 0.0 in C. totonacus vs. 0.6 in C. lavae), longer head (mean HL $8.5 \mathrm{~mm}$ in male and $7.6 \mathrm{~mm}$ in female C. totonacus vs. $7.5 \mathrm{~mm}$ in male and $7.0 \mathrm{~mm}$ in female $C$. lavae), slightly broader head (mean HW $5.2 \mathrm{~mm}$ in both male and female C. totonacus vs. 4.9 $\mathrm{mm}$ in male and $4.7 \mathrm{~mm}$ in female C. lavae), larger feet (mean FW $4.2 \mathrm{~mm}$ in male and $4.0 \mathrm{~mm}$ in female $C$. totonacus vs. $3.7 \mathrm{~mm}$ in male and $3.3 \mathrm{~mm}$ in female $C$. lavae), more maxillary teeth (mean MT 32.9 in male and 52.6 in female C. totonacus vs. 7.0 in male and 20.8 in female $C$. lavae) and more vomerine teeth (mean VT 11.6 in male and 13.7 in female C. totonacus vs. 8.9 in male and 11.4 in female C. lavae).

Chiropterotriton totonacus differs from C. aureus in its larger adult body size (mean SVL $35.7 \mathrm{~mm}$ in male and $35.5 \mathrm{~mm}$ in female C. totonacus vs. $28.5 \mathrm{~mm}$ in one male and $26.8 \mathrm{~mm}$ in female $C$. aureus), longer limbs (mean LI -0.6 in male and 0.0 in female C. totonacus vs. 2.0 in one male and 2.3 in female $C$. aureus), longer head (mean HL $8.5 \mathrm{~mm}$ in male and $7.6 \mathrm{~mm}$ in female $C$. totonacus vs. $6.4 \mathrm{~mm}$ in one male and $6.0 \mathrm{~mm}$ in female $C$. aureus), larger feet (mean FW $4.2 \mathrm{~mm}$ in male and $4.0 \mathrm{~mm}$ in female $C$. totonacus vs. $2.4 \mathrm{~mm}$ in one male and $1.8 \mathrm{~mm}$ in female $C$. aureus), more maxillary teeth (mean MT 32.9 in male and 52.6 in female $C$. totonacus vs. 10.0 in one male and 38.3 in female $C$. aureus) and fewer vomerine teeth (mean VT 11.6 in male and 13.7 in female $C$. totonacus vs. 15.0 in one male and 12.3 in female C. aureus).

Chiropterotriton totonacus differs from C. nubilus in its larger adult body size (mean SVL $35.7 \mathrm{~mm}$ in male and $35.5 \mathrm{~mm}$ in female C. totonacus vs. $29.4 \mathrm{~mm}$ in one male and 30.5 $\mathrm{mm}$ in female $C$. nubilus), longer limbs (mean LI -0.6 in male and 0.0 in female $C$. totonacus vs. 2.0 in one male and 1.5 in female $C$. nubilus), larger feet (mean FW $4.2 \mathrm{~mm}$ in male and $4.0 \mathrm{~mm}$ in female $C$. totonacus vs. $2.6 \mathrm{~mm}$ in one male and $2.3 \mathrm{~mm}$ in female $C$. nubilus), and more maxillary teeth (mean MT 32.9 in male and 52.6 in female C. totonacus vs. 13.0 in one male and 41.5 in female C. nubilus).

767 Description of holotype: SVL $35.8 \mathrm{~mm}$, TL $49.2 \mathrm{~mm}$, AX $18.3 \mathrm{~mm}$, SW $3.7 \mathrm{~mm}$, HL $7.7 \mathrm{~mm}$, 768 HW $5.3 \mathrm{~mm}$, HD $2.4 \mathrm{~mm}$, projection of snout beyond mandible $0.7 \mathrm{~mm}$, distance from anterior rim of orbit to snout $2.2 \mathrm{~mm}$, interorbital distance $2.0 \mathrm{~mm}$, eyelid length $2.2 \mathrm{~mm}$, eyelid width $1.2 \mathrm{~mm}$, nostril diameter $0.2 \mathrm{~mm}$, FLL $9.9 \mathrm{~mm}$, HLL $11.5 \mathrm{~mm}$, snout-to-forelimb length 12.4 $\mathrm{mm}$, snout to anterior angle of vent $33.5 \mathrm{~mm}$, tail width at base $3.0 \mathrm{~mm}$, tail depth at base 2.7 $\mathrm{mm}, \mathrm{FW} 4.6 \mathrm{~mm}$, length of fifth toe $0.8 \mathrm{~mm}$, length of third (longest) toe $1.8 \mathrm{~mm}$. Numbers of teeth: premaxillary 6, maxillary 27-23 (right-left) and vomerine 7-7 (right-left). Tips of adpressed limbs meet.

Coloration in life: No color information is available for the type series in life; description based on photos of three recently collected specimens (IBH 31030, 31031, IBH 30998). Dorsal background very dark brownish grey. Broad, reddish-brown dorsal band with background color 
778 showing only along midline (IBH 31030), broken and irregular (IBH 30998), or completely 779 absent (IBH 31031). Small, pale grey specks present in some specimens. Dorsal surface of tail 780 similar to dorsal coloration on body. IBH 30998 has two orangish-brown blotches at base of tail. 781 Head dark grey with brown blotches or grey specks, similar to dorsal coloration. Paratoid region 782 brownish in specimens with a regular or irregular dorsal band present, grey in IBH 31031 Flanks 783 and upper surface of limbs medium grey with small pale grey and brown flecks, numerous in some specimens while nearly absent in others; toe tips reddish. Gular region pale grey; ventral surface of body, tail, and limbs medium grey. Iris dark golden-brown.

Coloration in preservative: The holotype is medium brown with an obscure dorsal stripe, darker brown along the margin and more reddish brown on the stipe with a narrow darker median line. The head is medium brown with a light bar extending between the eyes and snout mottled with dark cream and brown. Limbs mottled with light brown upper limbs especially near the body, darker lower limbs with light tan digits. The venter is mainly pale with some mottled darker brown. The gular region is mottled with dark cream and brown. Undersides of the tail are paler than its lateral surfaces. One specimen (MVZ 193943) has a distinct yellowish stripe bordered laterally by a very dark band of pigment, with the stripe extending to the tip of the tail. Most others are uniformly pale brown to tan dorsally with some darker brown. One individual (MVZ 1639547) is generally paler gray brown.

Osteology: This account is based on examination of a $\mu \mathrm{CT}$ scan of the anterior skeleton of MVZ 163945, an adult female, $35.8 \mathrm{~mm}$ SVL (Figs. 6-8; Table 3). The skull is relatively broad and somewhat ovoid in dorsal and ventral views. Many of the dermal investing bones are thin and weakly ossified, especially anteriorly. Paired frontal bones extend anterolaterally, but they are largely eroded anteromedially except for a pair of anteriorly directed spikes along the midline (one per side). Each frontal has a posterolateral tab that overlaps the adjacent parietal, but otherwise these bones only weakly articulate with one another, leaving a moderately sized frontoparietal fontanelle. The single premaxilla is delicate and lacks a palatal shelf. Ascending processes initially approach one another but then diverge posterodorsally until they articulate with the weak anterior end of the frontal bone. They enclose a huge internasal fontanelle, but unlike in many congeners they are not expanded posteriorly. There are no septomaxillary bones. The nasal bone is triangular but irregular in outline. It barely articulates with the facial process of the maxilla and with the frontal but is separate from the prefrontal, which is relatively smallsmaller than the nasal. The foramen of the nasolacrimal duct has eroded the anteroventral margin of the prefrontal, the posterior margin of the nasal and the dorsal margin of the facial process of the maxilla. Teeth are deployed along nearly the entire length of the maxillary bone, leaving only a small edentulous portion at its posterior tip. There are 21 maxillary teeth on each side and six premaxillary teeth. The orbitosphenoid is shortened anteroposteriorly and rather thin. It is only weakly articulated to the parasphenoid and is mostly separated from both the frontal and the parietal.

Otic capsules lack crests except for a slight projection along the anterolateral margin of each lateral semicircular canal. However, the anteromedial edge of each capsule is overlapped by a bony shelf that extends from the posterolateral portion of the adjacent parietal bone. A relatively large, triangular tab descends from the posterolateral margin of the parietal. The tab is sharply reflected ventromedially and ends in a rounded point at about the midpoint of the vertical extent of the orbitosphenoid. The roughly triangular squamosal articulates with the otic capsule dorsally. The quadrate bone is relatively small and incompletely ossified. The columella bears a 
823 pronounced stylus. Paired vomers are relatively large, but the body of each bone is very weakly

824

825

826

827

828

829

830

831

832

833

834

835

836

837

838

839

840

841

842

843

844

845

846

847

848

849

850

851

852

853

854

855

856

857

858

859

860

861

862

863

864 Etymology: The specific epithet refers to the native Totonac culture of the central region of

865

ossified anteriorly. They do not articulate at the midline. Preorbital processes are very long.

There are six teeth on the left side and five on the right; one or two are deployed at the base of each preorbital process. The parasphenoid bone is triangular. Paired parasphenoid tooth patches progressively broaden posteriorly and then round off caudally. There are 80-85 teeth in each patch. The mandible is relatively weak. The articular bone is poorly ossified. The prearticular bone is small, with a relatively low coronoid process. Each dentary bone bears 24 teeth.

Digital formulae are 1-2-3-2 right and 1-2-2-2 left. The distal tip of the terminal phalanx is slightly expanded on each finger. Mesopodial cartilages are not mineralized.

Distribution and ecology: Chiropterotriton totonacus is known from Veracruz, Mexico, along the ridge between Cruz Blanca and Las Vigas at elevations between 2200 and 2450 masl, and from La Joya at 2000 masl. It occurs in mossy pine forest and is terrestrial. Recently collected specimens were found under logs in disturbed pine forest.

Remarks: This species occurs in sympatry at the upper end of its range above Las Vigas with $P$. leprosa and Thorius munificus, and at the lower end of its range near La Joya with

Chiropterotriton lavae, Pseudoeurycea lynchi, Thorius minydemas, and Isthmura gigantea, and throughout is range with Aquiloeurycea cephalica. We think this is Darda's (1994) species E (his population 7), which he assigned to C. chiropterus. It differs from C. lavae by two fixed allozymic differences and a Nei D value of 0.148 , but we have no samples of a second species (in addition to C. lavae) from La Joya so our assignment of Darda's material must be viewed as tentative. He had no specimens from the area west of Las Vigas or Cruz Blanca. If we assume that Darda's species E is assignable to C. totonacus, it is surprising that it is so distinct from $C$. perotensis (seven fixed differences, Nei $\mathrm{D}=0.725$ ). It is closer to Darda's species $\mathrm{C}$ from Puerto del Aire (3 fixed differences) and I from regions to the south of Pico de Orizaba (5 fixed differences), the latter here named C. ceronorum. We are not yet prepared to deal with species $\mathrm{C}$ at this time.

Chiropterotriton totonacus has long been known from the Las Vigas-Cruz Blanca area, and from Toxtlacoaya, above La Joya (Taylor and Smith, 1945; Smith and Taylor, 1948). The species was reported to occur under clumps of dead grass, under and in rotten logs, under loose bark, and in stump holes that had filled with pine needles and loose earth.

Conservation status: Most of the pine forest around Las Vigas de Ramírez has been cut down or fragmented into very small patches. Recently, we found three specimens (one in 2016 and two in 2017) in a secondary pine forest near the type locality at Cruz Blanca . This secondary forest, which is highly disturbed and has few logs or cover objects where salamanders could be found, is the only place where the species is currently known to occur given that nearly all forest from the type locality has been logged. The largest extent of remaining forest in the area is in the "Bosque Estatal San Juan del Monte", but C. totonacus has not been found there despite survey efforts. Based on its scarcity and very limited geographic range, we recommend that this species be designated as Critically Endangered under IUCN Red List criterion B1ab(iii) (extent of occurrence $<100 \mathrm{~km}^{2}$, distribution severely fragmented with continuing decline in area, extent, and quality of habitat; IUCN, 2012).

Etymology: The specific epithet refers to the native

Peer) reviewing PDF | (2019:11:43498:1:1:NEW 18 Feb 2020) 
866

867

868

869

870

871

872

873

874

875

876

877

878

879

880

881

882

883

884

885

886

887

888

889

890

891

892

893

894

895

896

897

898

899

900

901

902

903

904

905

906

907

\section{Chiropterotriton melipona, sp. nov.}

Xicotepec Salamander, Salamandra de Xicotepec

Figures 4D, 5D, 6D, 7D, 8D.

Chresonymy

Chiropterotriton sp. F.—Darda, 1994; Parra-Olea, 2003; Rafaëlli, 2007; Rafaëlli, 2013; Rovito \& Parra-Olea, 2015; García-Castillo et al., 2017; García-Castillo et al., 2018.

Holotype: MVZ 200726, an adult male from Xicotepec de Juárez, $3.3 \mathrm{~km} \mathrm{~S}$ of Hotel Mi Ranchito on Mexican Hwy. 130, $2.1 \mathrm{~km}$ E on road to La Unión, Puebla, México, 1080 masl, $20.227755^{\circ} \mathrm{N}, 97.953269^{\circ} \mathrm{W}(\mathrm{EPE}=\max$. error distance $1.0 \mathrm{~km})$. Collected 8 December 1983 by D. M. Darda and P. A. Garvey.

Paratypes: Seven specimens, all from Puebla, Mexico. Four males: MVZ 178706 and 178708, 3.9 km S of Xicotepec de Juárez on Mexican Hwy. 130; MVZ 200723-24, Xicotepec de Juárez, Mexican Hwy. 130, $21 \mathrm{~km}$ E on road to La Unión. Three females: MVZ 178707, $3.9 \mathrm{~km} \mathrm{~S}$ of Xicotepec de Juarez on Mexican Hwy. 130; MVZ 185972, $2.2 \mathrm{~km}$ on road to Patla from junction with Mexican Hwy. 130 SW out of Xicotepec de Juárez; MVZ 200725, Xicotepec de Juárez, Mexican Hwy. 130, $21 \mathrm{~km}$ E on road to La Unión.

Referred specimens: Two specimens: IBH 30112 and MVZ 133019, Cuetzalan, Puebla, Mexico.

Diagnosis: This is a small species of plethodontid salamander phylogenetically related to Chiropterotriton chiropterus; mean SVL $29.2 \mathrm{~mm}$ in four adult males (range 26.4-31.4) and $28.5 \mathrm{~mm}$ in three adult females (range 27.1-29.8). The head is moderately wide; HW averages $15 \%$ of SVL in both males and females (range 14-15\%). Adults have a broad, bluntly rounded snout and adult males have moderately developed nasolabial protuberances. Eyes are large and prominent and extend laterally beyond the jaw margin in ventral view. There are few maxillary teeth in males (mean MT 9.5, range 7-12) and moderate numbers of teeth in females (mean MT 31.0, range 25-34). There are few vomerine teeth in both males (mean VT 11.0, range 8-15) and females (mean VT 13.0, range 9-19), which are arranged in a row that does not extend lateral to the outer margin of the internal choana. The tail is long and slender and exceeds SVL in all adults with complete tails; mean TL/SVL 1.16 in males (range 1.10-1.22) and 1.11 in females (range 1.03-1.18). Limbs are short; FLL+HLL averages $46 \%$ of SVL in males (range 39-50) and $49 \%$ in females (range 46-52). Adpressed limbs are widely separated and never overlap in males (mean LI 2.3, range 2-2.5) and females (mean LI 1.8, range 1.0-2.5). Manus and pes are relatively small; digits are slender and their tips only slightly expanded. Digital webbing ranges from slight to absent and is limited to the metatarsal region. The first digit is distinct but largely included in the webbing. Subterminal pads are small but well developed. A relatively small, rounded to oval-shaped mental gland present in most adult males. The smallest adult male (pigmented testes) is $26.4 \mathrm{~mm} \mathrm{SVL}$; the smallest male with a mental gland is $28.5 \mathrm{~mm}$ SVL. Parotoid glands are not evident.

Comparisons: Chiropterotriton melipona differs from C. ceronorum in its smaller adult body size (mean SVL $29.2 \mathrm{~mm}$ in male and $28.5 \mathrm{~mm}$ in female $C$. melipona vs. $33.9 \mathrm{~mm}$ in male and

Peer) reviewing PDF | (2019:11:43498:1:1:NEW 18 Feb 2020) 
$90834.9 \mathrm{~mm}$ in female C. ceronorum), shorter tail (mean TL/SVL 1.16 in male and 1.11 in female $C$. 909 melipona vs. 1.0 in male and 0.97 in female $C$. ceronorum), shorter head (mean HL $6.3 \mathrm{~mm}$ in 910 male and $6.4 \mathrm{~mm}$ in female $C$. melipona vs. $7.5 \mathrm{~mm}$ in male and $7.1 \mathrm{~mm}$ in female $C$.

911 ceronorum), narrower head (mean HW $4.3 \mathrm{~mm}$ in male and $4.2 \mathrm{~mm}$ in female C. melipona vs.

$9125.1 \mathrm{~mm}$ in both male and female C. ceronorum), shorter limbs in males (mean LI 2.3 in $C$.

913 melipona vs. 0.0 in C. ceronorum), narrower feet (mean FW $2.4 \mathrm{~mm}$ in male and $2.6 \mathrm{~mm}$ in

914 female $C$. melipona vs. $3.8 \mathrm{~mm}$ in male and $3.5 \mathrm{~mm}$ in female $C$. ceronorum), fewer maxillary 915 teeth (mean MT 9.5 in male and 31.0 in female $C$. melipona vs. 11.0 in male and 47.7 in female

916 C. ceronorum) and fewer vomerine teeth (mean VT 11.0 in male and 13.0 in female C. melipona 917 vs. 13.0 in male and 15.9 in female C. ceronorum).

$918 \quad$ Chiropterotriton melipona differs from C. perotensis in its slightly smaller adult body 919 size (mean SVL $29.2 \mathrm{~mm}$ in male and $28.5 \mathrm{~mm}$ in female $C$. melipona vs. $29.7 \mathrm{~mm}$ in male and $92031.7 \mathrm{~mm}$ in female $C$. perotensis), shorter tail (mean TL/SVL 1.16 in male and 1.11 in female $C$. 921 melipona vs. 1.0 in both male and female $C$. perotensis), shorter head (mean HL $6.3 \mathrm{~mm}$ in male

922

923

924

925

926

927

928

929

930

931

932

933

934

935

936

937

938

939

940

941

942 and $6.4 \mathrm{~mm}$ in female $C$. melipona vs. $6.6 \mathrm{~mm}$ in male and $6.7 \mathrm{~mm}$ in female $C$. perotensis), more maxillary teeth (mean MT 9.5 in male and 31.0 in female $C$. melipona vs. 7.2 in male and 27.9 in female $C$. perotensis) and fewer vomerine teeth (mean VT 11.0 in male and 13.0 in female C. melipona vs. 9.0 in male and 11.1 in female C. perotensis).

Chiropterotriton melipona differs from C. totonacus in its smaller adult body size (mean SVL $29.2 \mathrm{~mm}$ in male and $28.5 \mathrm{~mm}$ in female $C$. melipona vs. $35.7 \mathrm{~mm}$ in male and $35.5 \mathrm{~mm}$ in female $C$. totonacus), shorter head (mean HL $6.3 \mathrm{~mm}$ in male and $6.4 \mathrm{~mm}$ in female $C$. melipona vs. $8.5 \mathrm{~mm}$ in male and $7.6 \mathrm{~mm}$ in female C. totonacus), narrower head (mean HW $4.3 \mathrm{~mm}$ in male and $4.2 \mathrm{~mm}$ in female C. melipona vs. $5.2 \mathrm{~mm}$ in both male and female C. totonacus), shorter limbs (mean LI 2.3 in male and 1.8 in female $C$. melipona vs. -0.6 in male and 0.0 in female $C$. totonacus), narrower feet (mean FW $2.4 \mathrm{~mm}$ in male and $2.6 \mathrm{~mm}$ in female $C$. melipona vs. $4.2 \mathrm{~mm}$ in male and $4.0 \mathrm{~mm}$ in female $C$. totonacus) and more maxillary teeth (mean MT 9.5 in male and 31.0 in female $C$. melipona vs. 32.9 in male and 52.6 in female $C$. totonacus).

Chiropterotriton melipona differs from C. casasi in its smaller adult body size (mean SVL $29.2 \mathrm{~mm}$ in male and $28.5 \mathrm{~mm}$ in female $C$. melipona vs. $37.8 \mathrm{~mm}$ in male and $40.9 \mathrm{~mm}$ in one female $C$. casasi), shorter tail in males (mean TL/SVL 1.16 in C. melipona vs. 1.0 in $C$. casasi), shorter head (mean HL $6.3 \mathrm{~mm}$ in male and $6.4 \mathrm{~mm}$ in female C. melipona vs. $8.3 \mathrm{~mm}$ in male and $8.6 \mathrm{~mm}$ in one female $C$. casasi), narrower head (mean HW $4.3 \mathrm{~mm}$ in male and 4.2 $\mathrm{mm}$ in female $C$. melipona vs. $5.8 \mathrm{~mm}$ in male and $5.9 \mathrm{~mm}$ in one female $C$. casasi), shorter limbs (mean LI 2.3 in male and 1.8 in female $C$. melipona vs. 0.8 in male and 1.0 in one female

943 C. casasi) and narrower feet (mean FW $2.4 \mathrm{~mm}$ in male and $2.6 \mathrm{~mm}$ in female C. melipona vs.

944

945

946

947 mean $3.7 \mathrm{~mm}$ in both male and one female C. casasi).

Chiropterotriton melipona differs from C. chiropterus in its smaller adult body size (mean SVL $29.2 \mathrm{~mm}$ in male and $28.5 \mathrm{~mm}$ in female $C$. melipona vs. $37.5 \mathrm{~mm}$ in male and 33.5 $\mathrm{mm}$ in female $C$. chiropterus), shorter tail in males (mean TL/SVL 1.16 in C. melipona vs. 1.25

948 in C. chiropterus), shorter head (mean HL $6.3 \mathrm{~mm}$ in male and $6.4 \mathrm{~mm}$ in female C. melipona vs.

949

950

951 $8.1 \mathrm{~mm}$ in male and $7.3 \mathrm{~mm}$ in female $C$. chiropterus), narrower head (mean HW $4.3 \mathrm{~mm}$ in male and $4.2 \mathrm{~mm}$ in female $C$. melipona vs. $5.6 \mathrm{~mm}$ in male and $4.8 \mathrm{~mm}$ in female $C$. chiropterus), shorter limbs in males (mean LI 2.3 in C. melipona vs. 0.3 in C. chiropterus),

952 narrower feet (mean FW $2.4 \mathrm{~mm}$ in male and $2.6 \mathrm{~mm}$ in female $C$. melipona vs. $3.7 \mathrm{~mm}$ in male 
953 and $3.1 \mathrm{~mm}$ in female $C$. chiropterus) and fewer maxillary teeth (mean MT 9.5 in male and 31.0

954

955

956

957

958

959

960

961

962

963

964

965

966

967

968

969

970

971

972

973

974

975

976

977

978

979

980

981

982

983

984

985

986

987

988

989

990

991

992

993

994

995

996

997

in female $C$. melipona vs. 12.6 in male and 48.0 in female $C$. chiropterus).

Chiropterotriton melipona differs from $C$. orculus in its smaller adult body size (mean SVL $29.2 \mathrm{~mm}$ in male and $28.5 \mathrm{~mm}$ in female C. melipona vs. $35.9 \mathrm{~mm}$ in male and $39.0 \mathrm{~mm}$ in female $C$. orculus), shorter tail (mean TL/SVL 1.16 in male and 1.11 in female $C$. melipona vs. 1.02 in both male and female $C$. orculus), shorter head (mean HL $6.3 \mathrm{~mm}$ in male and $6.4 \mathrm{~mm}$ in female $C$. melipona vs. $7.4 \mathrm{~mm}$ in male and $8.0 \mathrm{~mm}$ in female $C$. orculus), narrower head (mean HW $4.3 \mathrm{~mm}$ in male and $4.2 \mathrm{~mm}$ in female C. melipona vs. $5.0 \mathrm{~mm}$ in male and $5.2 \mathrm{~mm}$ in female $C$. orculus), shorter limbs in males (mean LI 2.3 in C. melipona vs. 1.9 in C. orculus), narrower feet (mean FW $2.4 \mathrm{~mm}$ in male and $2.6 \mathrm{~mm}$ in female $C$. melipona vs. $3.2 \mathrm{~mm}$ in male and $3.4 \mathrm{~mm}$ in female $C$. orculus), more maxillary teeth (mean MT 9.5 in male and $31.0 \mathrm{in}$ female $C$. melipona vs. 8.2 in male and 28.8 in female $C$. orculus) and more vomerine teeth (mean VT 11.0 in male and 13.0 in female $C$. melipona vs. 8.6 in male and 12.0 in female $C$. orculus).

Chiropterotriton melipona differs from C. lavae in its smaller adult body size (mean SVL $29.2 \mathrm{~mm}$ in male and $28.5 \mathrm{~mm}$ in female C. melipona vs. $32.4 \mathrm{~mm}$ in male and $31.6 \mathrm{~mm}$ in female C. lavae), shorter head (mean HL $6.3 \mathrm{~mm}$ in male and $6.4 \mathrm{~mm}$ in female C. melipona vs. $7.5 \mathrm{~mm}$ in male and $7.0 \mathrm{~mm}$ in female C. lavae), narrower head (mean HW $4.3 \mathrm{~mm}$ in male and $4.2 \mathrm{~mm}$ in female $C$. melipona vs. $4.9 \mathrm{~mm}$ in male and $4.7 \mathrm{~mm}$ in female $C$. lavae), shorter limbs (mean LI 2.3 in male and 1.8 in female $C$. melipona vs. -0.6 in male and 0.6 in female $C$. lavae), narrower feet (mean FW $2.4 \mathrm{~mm}$ in male and $2.6 \mathrm{~mm}$ in female $C$. melipona vs. $3.7 \mathrm{~mm}$ in male and $3.3 \mathrm{~mm}$ in female $C$. lavae), more maxillary teeth (mean MT 9.5 in male and 31.0 in female C. melipona vs. 7.0 in male and 20.8 in female $C$. lavae) and more vomerine teeth (mean VT 11.0 in male and 13.0 in female C. melipona vs. 8.9 in male and 11.4 in female C. lavae).

Chiropterotriton melipona differs from C. aureus in its larger adult body size (mean SVL $29.2 \mathrm{~mm}$ in male and $28.5 \mathrm{~mm}$ in female C. melipona vs. $28.5 \mathrm{~mm}$ in one male and $26.8 \mathrm{~mm}$ in female $C$. aureus), shorter tail in females(mean TL/SVL 1.11 in female C. melipona vs. 1.16 in female $C$. aureus), wider head (mean HW $4.3 \mathrm{~mm}$ in male and $4.2 \mathrm{~mm}$ in female $C$. melipona vs. $4.0 \mathrm{~mm}$ in one male and $3.6 \mathrm{~mm}$ in female C. aureus), longer limbs in females (mean LI $1.8 \mathrm{in}$ female C. melipona vs. 2.3 in female C. aureus), and wider feet in females (mean FW $2.6 \mathrm{~mm}$ in female C. melipona vs. $1.8 \mathrm{~mm}$ in female $C$. aureus).

Chiropterotriton melipona differs from C. nubilus in having a shorter head (mean HL 6.3 $\mathrm{mm}$ in male and $6.4 \mathrm{~mm}$ in female $C$. melipona vs. $6.6 \mathrm{~mm}$ in one male and $7.4 \mathrm{~mm}$ in female $C$. nubilus), and less maxillary teeth (mean MT 9.5 in male and 31.0 in female C. melipona vs. 13 in one male and 41.5 in female C. nubilus).

Description of holotype: SVL $28.5 \mathrm{~mm}$, TL $31.4 \mathrm{~mm}$, AX $15.5 \mathrm{~mm}$, SW $3.3 \mathrm{~mm}$, HL $6.3 \mathrm{~mm}$, HW $4.1 \mathrm{~mm}$, HD $2.1 \mathrm{~mm}$, projection of snout beyond mandible $0.7 \mathrm{~mm}$, distance from anterior rim of orbit to snout $1.5 \mathrm{~mm}$, interorbital distance $1.4 \mathrm{~mm}$, distance between corners of eyes 2.2 $\mathrm{mm}$, interorbital width $1.3 \mathrm{~mm}$, eyelid length $1.7 \mathrm{~mm}$, eyelid width $0.9 \mathrm{~mm}$, nostril diameter 0.2 $\mathrm{mm}$, FLL $5.1 \mathrm{~mm}$, HLL $6.1 \mathrm{~mm}$, snout-to-forelimb length $8.4 \mathrm{~mm}$, distance from snout to anterior angle of vent $24.4 \mathrm{~mm}$, snout to gular fold distance $6.3 \mathrm{~mm}$, tail depth at base $2.7 \mathrm{~mm}$ and FW $2.2 \mathrm{~mm}$. Numbers of teeth: premaxillary 3, maxillary 4-4 (right-left) and vomerine 7-8 (right-left). Adpressed limbs are separated by 2.5 costal folds.

Coloration in life: Color notes in life are not available for the type series of this species, thus we describe coloration from a photo of one of the referred specimens (IBH 30112). The head is dark

Peer) reviewing PDF | (2019:11:43498:1:1:NEW 18 Feb 2020) 
998 brown with numerous pale grey specks on the rostrum, sides of head, interocular region, and 999 eyelids. This brown coloration with grey specks extends from behind each eye in an inverted 1000 triangle to the nuchal region. Both sides of this triangle in parotoid region are orangish-brown. 1001 Orange-brown coloration extends in a band along dorsum and along the dorsal side of tail, where 1002 it is more yellowish along midline and orangish-brown along edges. Flanks are dark brown with 1003 numerous pale gray specks. Limbs Grey-brown with some pale yellow-brown specks; manus and 1004 pes greyish. Sides of tail dark brown. Iris coppery.

1005 Coloration in preservative: The holotype, while faded, is generally bright yellow to yellowish

1006

1007

1008

1009

1010

1011

1012

1013

1014

1015

1016

1017

1018

1019

1020

1021

1022

1023

1024

1025

1026

1027

1028

1029

1030

1031

1032

1033

1034

1035

1036

1037

1038

1039

1040

1041

1042 tan. The snout is pale yellow with scattered brown pigment. A broad, bright yellow dorsal stripe extends from the eyes to the tip of the tail. It is bordered by a dark stripe that arises at the eye and extends posteriorly onto the tail. This dark stripe, in turn, is bordered by a pale brown stripe that becomes paler ventrolaterally. The venter is very pale, almost pigmentless. The tail has some light brown pigment along its lateral margins. Paratypes all faded but yellowish tan with a pale yellowish tan dorsal stripe evident in all individuals to some degree.Dorsal stripe always bordered by a thin dorsal lateral light brown stripe. Venter very pale. Manus and pes are pale.

Osteology: This account is based on examination of a $\mu \mathrm{CT}$ scan of the anterior skeleton of MVZ 178706, an adult male, $28.5 \mathrm{~mm}$ SVL, which may be sexually immature and not representative of the adult condition (Figs. 6-8; Table 3). The skull is weakly developed and delicate, both in general and relative to other members of the genus such as C. chiropterus, and even C. casasi. Cranial roofing bones are very thin. Frontals are weakly articulated with each other and with the paired parietals, leaving a relatively large frontoparietal fontanelle that extends both anteroposteriorly (in the midline) and transversely (at the frontal-parietal interface). Paired ascending processes of the single premaxilla begin diverging immediately dorsal to the dental process. They continue to diverge posterolaterally and ultimately articulate in grooves on the anterior part of the paired frontals, enclosing a large internasal fontanelle. Unlike in many other congeners, they remain thin and are not expanded at their dorsal ends. A palatal shelf is barely evident on the premaxillary; it's virtually absent. Tiny paired septomaxillae lie approximately at the level of the articulation between premaxilla and maxilla. Nasal bones are expansive but otherwise weakly developed, with indistinct borders anteriorly and weak articulations with adjacent bones, including both the prefrontal and the maxilla. The prefrontal is well articulated with the facial process of the maxilla ventrally and overlaps the frontal dorsally. A foramen for the passage of the nasolacrimal duct is framed by the anterior margin of the prefrontal, the posterolateral margin of the nasal, and the dorsal midportion of the facial process of the maxilla. There are five large teeth on the anterior portion of each maxilla. The posterior half of the bone lacks teeth and resembles a shallow cleaver. There are three premaxillary teeth. The orbitosphenoid is fairly well developed, although not well articulated with the parietal. In general, the braincase is moderately well developed.

There is a nascent bony crest on the otic capsule above the anterior semicircular canal where it abuts a bony shelf that extends posterolaterally from the parietal. The parietal also bears a moderately developed, posterolateral tab that is sharply directed ventomedially. The tab is triangular and ends in a rounded point at a level about halfway through the vertical extent of the orbitosphenoid. The squamosal is a roughly triangular bone that articulates dorsally with the otic capsule opposite the lateral semicircular canal. In lateral view, its ventral portion appears to buttress the otic capsule ventral to the lateral semicircular canal, but when viewed from different angles these bones can be seen to be well separated. The quadrate bone is relatively small and

Peer) reviewing PDF | (2019:11:43498:1:1:NEW 18 Feb 2020) 
1043 inconspicuous. The columellar stylus is distinct, cylindrical and long. Paired vomers are 1044 relatively robust; they barely articulate in the midline posterior to the internasal fontanelle.

1045 Preorbital processes are very long. There are four-to-six vomerine teeth on each side; two or 1046 three of these are deployed at the base of each preorbital process. The parasphenoid bone is 1047 broadly triangular. Paired parasphenoid tooth patches are well separated from each other and 1048 from the vomerine teeth anteriorly. Each patch bears approximately 75 teeth. The mandible is 1049 unremarkable. The articular bone is poorly ossified. The prearticular bone has a coronoid process of moderate height. There are seven teeth on the right dentary bone and eight on the left.

Digital formula is $1-2-3-2$ on each side. There is a slightly expanded knob at the tip of the terminal phalanx on the two longest fingers of each hand (digits 3 and 4). Mesopodial cartilages are not mineralized.

1054 Distribution and ecology: Chiropterotriton melipona is known from the Sierra Norte in the northernmost part of Puebla near Cuetzalan, Xocoyolo and Xicotepec de Juarez at elevations between 690 and 1420 masl. It likely occurs between known localities near Cuetzalan and Xicotepec. This range includes the lowest elevational record of any known species of the genus. The species is arboreal and has been collected from banana plants and bromeliads and has been found in sympatry with Aquiloeurycea quetzalanensis.

1060 Remarks: This species was included in Darda's (1994) electrophoretic study as population 19, 1061 new species F. It was most similar to populations 12 (C. lavae; three fixed differences, Nei $\mathrm{D}=$ 10620.22 ) and 19 (new species F, sympatric with $C$. lavae; three fixed differences, Nei $\mathrm{D}=0.23$ ). The lowland population from near Cuetzalan is discussed and illustrated by Raffaëlli (2013). We think the specimens he describes are assignable to C. melipona. He reports them at 780 masl. In the outer leaves of bananas.

Conservation status: Most mature forest at known localities for this species has been cut down, and the species has recently been found in small patches of forest and secondary vegetation, as well as cafetales. Because of the highly fragmented nature and decreasing quality of forest habitat within its range, we recommend that the species be designated as Endangered based on IUCN criterion B1ab(iii) (extent of occurrence $<5000 \mathrm{~km}^{2}$, distribution severely fragmented continuing decline in extent, and quality of habitat; IUCN, 2012).

1072 Etymology. Xicotepec, the name of the type locality, comes from the Nahuatl language and means "place of the jicotes." Jicotes are stingless bees of the genus Melipona. The name used for this species is a noun in apposition referring to the genus Melipona.

1075

1076

1077

1078

1079

1080

1081

1082
Chiropterotriton casasi, sp. nov.

Tlapacoyan Salamander, Salamandra de Tlapacoyan

Figures 2, 4E, 5E, 6A, 7A, 8A.

Holotype: MVZ 92874, an adult male from $13 \mathrm{mi} \mathrm{SW}$ Tlapacoyan, Veracruz, Mexico, $19.868483^{\circ} \mathrm{N}, 97.301500^{\circ} \mathrm{W}(\mathrm{EPE}=$ max. error distance $2 \mathrm{~km})$. The elevation is between 1450 and 1550 masl. Collected 26 December 1969 by R. Altig. 
1083 Paratypes: Four males, MVZ 92875 and 92877-79, and one female, MVZ 92876, all from the 1084 type locality.

1085 Diagnosis: This is a relatively large species of Chiropterotriton that stands out from other 1086 species considered here in being relatively stout and long legged, and being morphologically 1087 distinct; mean SVL $37.8 \mathrm{~mm}$ in four adult males (range 34.5-42.0). Only one female has been 1088 collected, SVL $40.9 \mathrm{~mm}$. The head is moderately wide; HW averages $16 \%$ of SVL in males 1089 (range 13-17\%) and 14\% in the female. In males, the snout is broad and truncated. Jaw muscles 1090 are pronounced and visible as a bulging mass immediately caudal to the eyes. Eyes are 1091 moderately protuberant and extend laterally beyond the jaw margin in ventral view. There are 1092 few maxillary teeth in males (mean MT 9.0, range 6-13) but they are more numerous in the 1093 female (MT 30). There are few vomerine teeth in males (mean VT 9.0, range 8-11) and the 1094 female (VT 13), which are arranged in a row that extends to, or just lateral to, the inner margin of the internal choana. The tail is moderately long; mean TL equals 1.0 of SVL in males (range 0.90-1.15). Limbs are short and slender; FLL+HLL averages 57\% of SVL in males (range 5560 ) and 55\% in the female. Adpressed limbs approach closely in males (mean LI 0.8, range 0.01) and are separated by one costal fold in the female. Digits are long and slender with blunt tips, distinct subterminal pads, and moderate webbing that extends onto the penultimate phalanx of the third toe. Digits II-V are discrete, while digit I is very short and does not extend beyond the webbing. The outermost toes are particularly well developed. The mental gland is oval-shaped in adult males. The smallest male with a mental gland is $37.2 \mathrm{~mm} \mathrm{SVL}$. Parotoid glands are not evident.

1104 Comparisons: Chiropterotriton casasi differs from C. ceronorum in its larger adult body size (mean SVL $37.8 \mathrm{~mm}$ in male and $40.9 \mathrm{~mm}$ in one female $C$. casasi vs. $33.9 \mathrm{~mm}$ in male and 34.9 $\mathrm{mm}$ in female C. ceronorum), longer head (mean HL $8.3 \mathrm{~mm}$ in male and $8.6 \mathrm{~mm}$ in one female C. casasi vs. $7.5 \mathrm{~mm}$ in male and $7.1 \mathrm{~mm}$ in female $C$. ceronorum), broader head (mean $\mathrm{HW} 5.8$ $\mathrm{mm}$ in male and $5.9 \mathrm{~mm}$ in one female $C$. casasi vs. $5.1 \mathrm{~mm}$ in both male and female $C$. ceronorum) and shorter limbs in males (mean LI 0.8 in C. casasi vs. 0.0 in C. ceronorum).

Chiropterotriton casasi differs from $C$. perotensis in its larger adult body size (mean SVL $37.8 \mathrm{~mm}$ in male and $40.9 \mathrm{~mm}$ in one female $C$. casasi vs. $29.7 \mathrm{~mm}$ in male and $31.7 \mathrm{~mm}$ in female $C$. perotensis), longer head (mean HL $8.3 \mathrm{~mm}$ in male and $8.6 \mathrm{~mm}$ in one female $C$. casasi vs. $6.6 \mathrm{~mm}$ in male and $6.7 \mathrm{~mm}$ in female $C$. perotensis), broader head (mean $\mathrm{HW} 5.8 \mathrm{~mm}$ in male and $5.9 \mathrm{~mm}$ in one female $C$. casasi vs. $4.2 \mathrm{~mm}$ in male and $4.4 \mathrm{~mm}$ in female $C$. perotensis), longer limbs (mean LI 0.8 in male and 1.0 in one female C. casasi vs. 2.5 in male and 3.3 in female $C$. perotensis), larger feet (mean FW $3.7 \mathrm{~mm}$ in both male and one female $C$. casasi vs. $2.6 \mathrm{~mm}$ in both male and female $C$. perotensis).

Chiropterotriton casasi differs from $C$. totonacus in its larger adult body size (mean SVL $37.8 \mathrm{~mm}$ in male and $40.9 \mathrm{~mm}$ in one female $C$. casasi vs. $35.7 \mathrm{~mm}$ in male and $35.5 \mathrm{~mm}$ in female $C$. totonacus), shorter tail (mean TL/SVL 1.0 in male $C$. casasi vs. 1.16 in male $C$. totonacus; the only female specimen of $C$. casasi has a broken tail), longer head in females (mean HL $8.6 \mathrm{~mm}$ in one $C$. casasi vs. $7.6 \mathrm{~mm}$ in $C$. totonacus), broader head in females (mean HW $5.9 \mathrm{~mm}$ in one $C$. casasi vs. $5.2 \mathrm{~mm}$ in C. totonacus), shorter limbs (mean LI 0.8 in male and 1.0 in one female $C$. casasi vs. -0.6 in male and 0.0 in female $C$. totonacus), narrower feet (mean FW $3.7 \mathrm{~mm}$ in both male and one female $C$. casasi vs. $4.2 \mathrm{~mm}$ in male and $4.0 \mathrm{~mm}$ in female $C$. totonacus) and fewer maxillary teeth (mean MT 9.0 in male and 30 in one female $C$. casasi vs. 32.9 in male and 52.6 in female C. totonacus). 
1128

1129

1130

1131

1132

1133

1134

1135

1136

1137

1138

1139

1140

1141

1142

1143

1144

1145

1146

1147

1148

1149

1150

1151

1152

1153

1154

1155

1156

1157

1158

1159

1160

1161

1162

1163

1164

1165

1166

1167

1168

1169

1170

1171

1172

1173

Chiropterotriton casasi differs from C. melipona in its larger adult body size (mean SVL $37.8 \mathrm{~mm}$ in male and $40.9 \mathrm{~mm}$ in one female $C$. casasi vs. $29.2 \mathrm{~mm}$ in male and $28.5 \mathrm{~mm}$ in female C. melipona), shorter tail (mean TL/SVL 1.04 in male $C$. casasi vs. 1.16 in male $C$. melipona; the only female specimen of $C$. casasi has a broken tail), longer head (mean HL 8.3 $\mathrm{mm}$ in male and $8.6 \mathrm{~mm}$ in one female $C$. casasi vs. $6.3 \mathrm{~mm}$ in male and $6.4 \mathrm{~mm}$ in female $C$. melipona), broader head (mean HW $5.8 \mathrm{~mm}$ in male and $5.9 \mathrm{~mm}$ in one female C. casasi vs. 4.3 $\mathrm{mm}$ in male and $4.2 \mathrm{~mm}$ in female C. melipona), longer limbs (mean LI 0.8 in male and 1.0 in one female C. casasi vs. 2.3 in male and 1.8 in female C. melipona) and broader feet (mean FW $3.7 \mathrm{~mm}$ in both male and one female $C$. casasi vs. $2.4 \mathrm{~mm}$ in male and $2.6 \mathrm{~mm}$ in female $C$. melipona).

Chiropterotriton casasi differs from C. chiropterus in its larger adult body size in females (mean SVL $40.9 \mathrm{~mm}$ in one C. casasi vs. $33.5 \mathrm{~mm}$ in C. chiropterus), shorter tail (mean TL/SVL 1.04 in male $C$. casasi vs. 1.25 in male $C$. chiropterus; the only female specimen of $C$. casasi has a broken tail), longer head (mean HL $8.3 \mathrm{~mm}$ in male and $8.6 \mathrm{~mm}$ in one female C. casasi vs. 8.1 $\mathrm{mm}$ in male and $7.3 \mathrm{~mm}$ in female C. chiropterus), narrower head (mean HW $5.8 \mathrm{~mm}$ in male and $5.9 \mathrm{~mm}$ in one female $C$. casasi vs. $5.6 \mathrm{~mm}$ in male and $4.8 \mathrm{~mm}$ in female C. chiropterus), shorter limbs in males (mean LI 0.8 in C. casasi vs. 0.3 in C. chiropterus) and fewer maxillary teeth (mean MT 9.0 in male and 30 in one female C. casasi vs. 12.6 in male and 48.0 in female C. chiropterus).

Chiropterotriton casasi differs from C. orculus in its larger adult body size (mean SVL $37.8 \mathrm{~mm}$ in male and $40.9 \mathrm{~mm}$ in one female $C$. casasi vs. $35.9 \mathrm{~mm}$ in male and $39.0 \mathrm{~mm}$ in female $C$. orculus), longer head (mean HL $8.3 \mathrm{~mm}$ in male and $8.6 \mathrm{~mm}$ in one female $C$. casasi vs. $7.4 \mathrm{~mm}$ in male and $8.0 \mathrm{~mm}$ in female C. orculus), broader head (mean HW $5.8 \mathrm{~mm}$ in male and $5.9 \mathrm{~mm}$ in one female $C$. casasi vs. $5.0 \mathrm{~mm}$ in male and $5.2 \mathrm{~mm}$ in female $C$. orculus) and longer limbs (mean LI 0.8 in male and 1.0 in one female C. casasi vs. 1.9 in male and 2.9 in female C. orculus).

Chiropterotriton casasi differs from C. lavae in its larger adult body size (mean SVL $37.8 \mathrm{~mm}$ in male and $40.9 \mathrm{~mm}$ in one female $C$. casasi vs. 32.4 in male and 31.6 in female $C$. lavae), shorter tail in males (mean TL/SVL 1.04 in C. casasi vs. 1.19 in C. lavae), longer head (mean HL $8.3 \mathrm{~mm}$ in male and $8.6 \mathrm{~mm}$ in one female $C$. casasi vs. $7.5 \mathrm{~mm}$ in male and $7.0 \mathrm{~mm}$ in female C. lavae), broader head (mean HW $5.8 \mathrm{~mm}$ in male and $5.9 \mathrm{~mm}$ in one female $C$. casasi vs. $4.9 \mathrm{~mm}$ in male and $4.7 \mathrm{~mm}$ in female C. lavae), shorter limbs (mean LI 0.8 in male and 2.0 in one female $C$. casasi vs. -0.6 in male and 0.6 in female $C$. lavae) and more maxillary teeth in females (mean MT 30 in one C. casasi vs. 20.8 in C. lavae).

Chiropterotriton casasi differs from C. aureus in its larger adult body size (mean SVL $37.8 \mathrm{~mm}$ in male and $40.9 \mathrm{~mm}$ in one female C. casasi vs. $28.5 \mathrm{~mm}$ in one male and $26.8 \mathrm{~mm}$ in female $C$. aureus), shorter tail (mean TL/SVL 1.0 in male $C$. casasi vs. 1.28 in one male $C$. aureus; the only female specimen of $C$. casasi has a broken tail), longer head (mean HL $8.3 \mathrm{~mm}$ in male and 8.6 in one female $C$. casasi vs. $6.4 \mathrm{~mm}$ in one male and 6.0 in female C. aureus), broader head (mean HW $5.8 \mathrm{~mm}$ in male and 5.9 in one female C. casasi vs. $4.0 \mathrm{~mm}$ in one male and 3.6 in female $C$. aureus), longer limbs (mean LI 0.8 in male and 1.0 in one female $C$. casasi vs. 2.0 in one male and 2.3 in female $C$. aureus), and wider feet (mean FW $3.7 \mathrm{~mm}$ in both male and one female C. casasi vs. $2.4 \mathrm{~mm}$ in one male and $1.8 \mathrm{~mm}$ in female C. aureus).

Chiropterotriton casasi differs from C. nubilus in its larger adult body size (mean SVL $37.8 \mathrm{~mm}$ in male and $40.9 \mathrm{~mm}$ in one female C. casasi vs. $29.4 \mathrm{~mm}$ in one male and $30.5 \mathrm{~mm}$ in female $C$. nubilus), shorter tail (mean TL/SVL 1.0 in male $C$. casasi vs. 1.37 in one male $C$.

Peer) reviewing PDF | (2019:11:43498:1:1:NEW 18 Feb 2020) 
1174 nubilus; the only female specimen of C. casasi has a broken tail), longer head (mean HL $8.3 \mathrm{~mm}$

1175

1176

1177

1178

1179

1180

1181

1182

1183

1184

1185

1186

1187

1188

1189

1190

1191

1192

1193

1194

1195

1196

1197

1198

1199

1200

1201

1202

1203

1204

1205

1206

1207

1208

1209

1210

1211

1212

1213

1214

1215

1216

in male and 8.6 in one female $C$. casasi vs. $6.6 \mathrm{~mm}$ in one male and 7.4 in female C. nubilus), broader head (mean HW $5.8 \mathrm{~mm}$ in male and 5.9 in one female $C$. casasi vs. $4.0 \mathrm{~mm}$ in one male and 4.4 in female C. nubilus), longer limbs (mean LI 0.8 in male and 1.0 in one female C. casasi vs. 2.0 in one male and 1.5 in female C. nubilus), wider feet (mean FW $3.7 \mathrm{~mm}$ in both male and one female C. casasi vs. $2.6 \mathrm{~mm}$ in one male and $2.3 \mathrm{~mm}$ in female C. nubilus) and less maximally teeth in females (mean MT 30.0 in female $C$. casasi vs 41.5 in female $C$. nubilus).

Description of holotype: SVL $42.0 \mathrm{~mm}$, TL $37.6 \mathrm{~mm}$, AX $20.4 \mathrm{~mm}$, SW $3.8 \mathrm{~mm}$, HL $8.8 \mathrm{~mm}$, HW $5.6 \mathrm{~mm}$, HD $2.8 \mathrm{~mm}$, projection of snout beyond mandible $0.2 \mathrm{~mm}$, distance from anterior rim of orbit to snout $1.7 \mathrm{~mm}$, interorbital distance $2.4 \mathrm{~mm}$, eyelid length $2.1 \mathrm{~mm}$, eyelid width $1.1 \mathrm{~mm}$, horizontal orbit diameter $2.1 \mathrm{~mm}$, nostril diameter $0.4 \mathrm{~mm}$, FLL $10.7 \mathrm{~mm}$, HLL 12.6 $\mathrm{mm}$, snout-to-forelimb length $11.4 \mathrm{~mm}$, distance from snout to anterior angle of vent $36.6 \mathrm{~mm}$, tail width at base $3.3 \mathrm{~mm}$, tail depth at base $3.9 \mathrm{~mm}$, FW $4.0 \mathrm{~mm}$, length of fifth toe $0.8 \mathrm{~mm}$, length of longest (third) toe $1.2 \mathrm{~mm}$, mental gland length $1.3 \mathrm{~mm}$, mental gland width 1.3 . Numbers of teeth: premaxillary 4, maxillary 4-4 (right-left) and vomerine 4-4 (right-left). Adpressed limbs are separated by 0 costal folds.

\section{Coloration in life: No data.}

Coloration in preservative: Faded brown, dorsally and laterally. No sign of dorsal stripe. Limbs mottled. Head is uniform pale brown with some mottling on the snout. The paratypes present some variation. The entire body of MVZ 92876 is mottled with faded pale and dark brown. A pale band extends between the anterior part of the eyes; the snout is very mottled. Posteriorly, the body is strongly mottled; the anterior part of the tail has an irregularly bordered light dorsal stripe. MVZ 92875 is less boldly mottled but has some mottling. All of them have a paler venter than dorsum. MVZ 92877 also has a pale bar that extends between the eyes.

Osteology: This account is based on examination of a $\mu \mathrm{CT}$ scan of the anterior skeleton of MVZ 92874, an adult male, $42.0 \mathrm{~mm}$ SVL (Figs. 6-8; Table 3). The skull is robust and well developed. Notable features include the complete articulation of the paired frontals and parietals - there is no frontoparietal fontanelle — and a robust premaxillary bone with paired ascending processes that broaden laterally as each approaches a solid articulation with the frontal bone on the same side. A distinct, albeit narrow palatal shelf is present on the premaxilla, and the two ascending processes enclose a distinct fontanelle. Tiny paired septomaxillae bones are well separated from all other bones. The triangular nasal is weakly developed anteriorly, where the bone is very thin and has an irregular edge. It is partially overlapped laterally by the facial process of the maxilla. A large prefrontal articulates anteriorly with the nasal bone, its ventral portion is overlapped by the facial process of the maxilla, and it bears an ascending, pointed tab that overlaps the frontal extensively. The anteroventral margin of the prefrontal and the adjacent portion of the facial process of the maxilla are eroded by a foramen that allows passage of the nasolacrimal duct. Otherwise, the facial process of the maxillary bone is broad and robust and solidly articulated with adjacent bones. The maxillary bone resembles that in Aneides (Wake, 1963); the toothed portion is confined to the anterior $45-50 \%$ of the bone, whereas posteriorly the bone is cleavershaped with an extended posterior tip. There is a distinct, relatively broad palatal shelf on the lingual side. There are few maxillary teeth-five on each side-but they are large, sharp and recurved, with highly reduced anterior cusps. There are three premaxillary teeth. They appear

Peer) reviewing PDF | (2019:11:43498:1:1:NEW 18 Feb 2020) 
1217 unicuspid and sharp but are shorter than the maxillary teeth. The well-developed orbitosphenoid 1218 is solidly articulated with neighboring bones, forming a relatively stout braincase.

A prominent bony crest overlies the anterior semicircular canal dorsally. It is derived

1257 Etymology: The species name honors Gustavo Casas Andreu, a Mexican herpetologist who has from the posterolateral portion of the parietal and the anteromedial portion of the otic
An additional, crest-like spur emerges at right angles from this crest and is directed posterolaterally. A second, smaller crest similarly overlies the posterior semicircular canal. The parietal bears a very large and well-developed posterolateral tab that is sharply reflected ventromedially, extending nearly two-thirds down the vertical extent of the orbitosphenoid. The very robust squamosal articulates dorsally with the otic capsule opposite the lateral semicircular canal. As in other species, the shape of its curved anterior margin conforms closely with, but is nevertheless separate from, the lateral face of the otic capsule. The quadrate is small and inconspicuous, but appears to be well developed. There is a short, stout stylus on the columella, which otherwise is just a rounded ossicle. Bodies of the paired vomers articulate tightly at the midline posterior to the internasal fontanelle. Preorbital processes are long. There are four vomerine teeth on the right side and five on the left; one or two teeth are deployed at the base of each preorbital process. The unpaired parasphenoid bone is robust. It is narrow anteriorly but gradually widens posteriorly until very near the caudal end where it reaches its maximum width. Paired parasphenoid tooth patches are well separated from one another medially and from the vomerine teeth rostrally. There are approximately $95-100$ teeth in each patch. The mandible is robust. The articular is fully ossified and appears to be fused to the prearticular bone. The height of the large coronoid process on the prearticular exceeds that of the dentary bone ventral to it. There are six sharply recurved and somewhat enlarged teeth on each dentary bone.

Only the distal portion of each forelimb is visible in the CT scan. Digital formulae are 12-3-2 on each side. Mesopodial cartilages are not mineralized.

Distribution and ecology: Chiropterotriton casasi is known only from the type locality. Vegetation at this locality now consists of secondary forest and thicket, but was likely cloud forest in the past. The species could occur somewhat more widely, but little intact forest remains in the vicinity of the type locality.

Remarks: The phylogenetic position of Chiropterotriton casasi relative to congeners is unknown due to the lack of tissue samples for genetic analyses. Geographically associated species include C. chiropterus, C. melipona, C. perotensis, C. totonacus, C. ceronorum and C. lavae. We have searched repeatedly in the vicinity of the type locality and have found another, unnamed, species of Chiropterotriton, but not this species.

Conservation status: Chiropterotriton casasi has not been seen since the original collection in 1969 , and nearly all of the primary forest at the type locality has been cut down. Efforts to find this species at the type locality in recent years have not been successful. We recommend that it be designated as Critically Endangered based on criterion Blab(iii) (extent of occurrence $<100$ $\mathrm{km}^{2}$, distribution severely fragmented and known from only one locality, continuing decline in extent and quality of habitat; IUCN, 2012). Concerted efforts should be made to extant populations of this species in remaining habitat patches near the type locality.

dedicated his career to describe the biodiversity of Mexican amphibians and reptiles. 
1259 REDESCRIPTIONS

1260 Original descriptions of Chiropterotriton chiropterus (Cope, 1863) and C. orculus (Cope, 1865) 1261 were extremely brief and contained relatively little information about the species' morphology.

1262 We provide more detailed redescriptions of both of these species, including the designation of a

1263 neotype for each. Common names declared for these species are from Liner and Casas-Andreu

1264 (2008).

1265

1266 Chiropterotriton chiropterus Cope, 1863

1267 Common Flat-footed Salamander, Salamandra de Pie Plana Común

1268 Figures 4G, 5G, 6E, 7E, 8E.

1269

1270

1271

1272

Chresonymy

Chiropterotriton sp. J.-Darda, 1994 (population 23, 24)

1273

Chiropterotriton sp._Wake, 1987; Papenfuss and Wake, 1987; Lynch and Wake, 1989; Wake et al., 1992

1274

Neotype: MVZ 85590, an adult male from $1.4 \mathrm{mi}$ southwest by road southwest edge of Huatusco de Chicuellar, Veracruz, Mexico, $19.141388^{\circ} \mathrm{N}, 96.98083^{\circ} \mathrm{W}(\mathrm{EPE}=\max$. error distance 1.202

1276 mi). The estimated elevation is 1400 masl. Collected 16 January 1969 by R. W. McDiarmid and

1277 R. D. Worthington.

1278

1279

1280

1281

1282

1283

1284

1285

1286

1287

1288

1289

1290

1291

1292

1293

1294

1295

1296

1297

1298

1299

1300

1301

Additional specimens examined: Twelve specimens, all from $1.4 \mathrm{mi}$ southwest by road southwest edge of Huatusco de Chicuellar, Veracruz, Mexico. Eight males: MVZ 85588-89, 85591-92, 85594, 85599, 85613, and 85602; and four females: MVZ 85597-98, 85605 and 85632.

Diagnosis: This is a medium-sized species of plethodontid salamander phylogenetically related to C. melipona; mean SVL $37.5 \mathrm{~mm}$ in eight adult males (range 36.1-38.8) and $33.5 \mathrm{~mm}$ in four adult females (range 30.7-36.7). The head is of moderately wide; HW averages $15 \%$ of SVL in both males and females (range 14-16). The snout is broad and bluntly rounded in males. Jaw muscles are relatively pronounced. Eyes are moderately protuberant and extend laterally beyond the jaw margin in ventral view. There are few maxillary teeth in males (mean MT 12.6, range 917) but many in females (mean MT 48.0, range 42-57). There are few vomerine teeth in both males (mean VT 10.6, range 9-12) and females (mean VT 12.5, 10-15), which are arranged in a row that does not reach or barely reaches the inner margin of the internal choana. The tail is long and slender and exceeds SVL by a considerable amount in nearly all specimens; mean TL equals 1.25 of SVL in males (range 1.13-1.38) and 1.19 in females (1.01-1.26). Limbs are short to moderate length; FLL+HLL averages $52 \%$ of SVL in males (range $48-54 \%$ ) and $50 \%$ in females (range 47-53\%). Adpressed limbs closely approach or overlap slightly in males (mean LI 0.3, range -0.5-1) but are more widely separated in females (mean LI 2.0, range 1.5-2.5). Manus and pes are relatively small, digits are slender. Subterminal pads are small but well developed. Digital webbing ranges from slight to absent and is limited to the metatarsal region. The first digit is distinct but largely included in the webbing. Digital tips are only slightly expanded. The mental gland is oval-shaped and not especially prominent in males. The smallest mature male (pigmented testes) is $36.1 \mathrm{~mm} \mathrm{SVL}$; the smallest male with a mental gland is $33.3 \mathrm{~mm} \mathrm{SVL}$. Parotoid glands are not evident. 
1302 Comparisons: Chiropterotriton chiropterus differs from C. ceronorum in its larger adult body 1303 size in males (mean SVL $37.5 \mathrm{~mm}$ in C. chiropterus vs. $33.9 \mathrm{~mm}$ in C. ceronorum), longer tail 1304 (mean TL/SVL 1.25 in male and 1.19 in female C. chiropterus vs. 1.0 in male and 0.97 in female 1305 C. ceronorum), shorter limbs (mean LI 0.3 in male and 2.0 in female C. chiropterus vs. 0.0 in 1306 male and 1.5 in female C. ceronorum), longer head (mean HL $8.1 \mathrm{~mm}$ in male and $7.3 \mathrm{~mm}$ in female C. chiropterus vs. $7.5 \mathrm{~mm}$ in male and $7.1 \mathrm{~mm}$ in female C. ceronorum), broader head in males (mean HW $5.6 \mathrm{~mm}$ in C. chiropterus vs. $5.1 \mathrm{~mm}$ in C. ceronorum) and fewer vomerine teeth (mean VT 10.6 in male and 12.5 in female C. chiropterus vs. 13.0 in male and 15.9 in female C. ceronorum).

Chiropterotriton chiropterus differs from C. perotensis in its larger adult body size (mean SVL $37.5 \mathrm{~mm}$ in male and $33.5 \mathrm{~mm}$ in female C. chiropterus vs. $29.7 \mathrm{~mm}$ in male and $31.7 \mathrm{~mm}$ in female C. perotensis), longer tail (mean TL/SVL 1.25 in male and 1.19 in female $C$. chiropterus vs. 1.0 in both male and female C. perotensis), longer limbs (mean LI 0.3 in male and 2.0 in female $C$. chiropterus vs. 2.5 in male and 3.3 in female $C$. perotensis), longer head (mean HL $8.1 \mathrm{~mm}$ in male and $7.3 \mathrm{~mm}$ in female C. chiropterus vs. $6.6 \mathrm{~mm}$ in male and $6.7 \mathrm{~mm}$ in female C. perotensis), broader head (mean HW $5.6 \mathrm{~mm}$ in male and $4.8 \mathrm{~mm}$ in female $C$. chiropterus vs. $4.2 \mathrm{~mm}$ in male and $4.4 \mathrm{~mm}$ in female C. perotensis), broader feet (mean FW 3.7 $\mathrm{mm}$ in male and $3.1 \mathrm{~mm}$ in female $C$. chiropterus vs. $2.6 \mathrm{~mm}$ in both male and female $C$. perotensis), fewer maxillary teeth (mean MT 12.6 in male and 48.0 in female C. chiropterus vs. 7.2 in male and 27.9 in female $C$. perotensis) and more vomerine teeth (mean VT 10.6 in male and 12.5 in female C. chiropterus vs. 9.0 in male and 11.1 in female $C$. perotensis).

Chiropterotriton chiropterus differs from C. totonacus in its larger adult body size in males (mean SVL $37.5 \mathrm{~mm}$ in C. chiropterus vs. $35.7 \mathrm{~mm}$ in C. totonacus), longer tail (mean TL/SVL 1.25 in male and 1.19 in female C. chiropterus vs. 1.16 in male and 1.20 in female $C$. totonacus), shorter limbs (mean LI 0.3 in male and 2.0 in female C. chiropterus vs. -0.60 in male and 0.0 in female C. totonacus), shorter head (mean HL $8.1 \mathrm{~mm}$ in male and $7.3 \mathrm{~mm}$ in female C. chiropterus vs. $8.5 \mathrm{~mm}$ in male and $7.6 \mathrm{~mm}$ in female C. totonacus), narrower feet in males (mean FW $3.7 \mathrm{~mm}$ in C. chiropterus vs. $4.2 \mathrm{~mm}$ in C. totonacus), fewer maxillary teeth (mean MT 12.6 in male and 48.0 in female C. chiropterus vs. 32.9 in male and 52.6 in female $C$. totonacus ) and fewer vomerine teeth (mean VT 10.6 in male and 12.5 in female C. chiropterus vs. 11.6 in male and 13.7 in female C. totonacus).

Chiropterotriton chiropterus differs from C. melipona in its larger adult body size (mean SVL $37.5 \mathrm{~mm}$ in male and $33.5 \mathrm{~mm}$ in female C. chiropterus vs. $29.2 \mathrm{~mm}$ in male and $28.5 \mathrm{~mm}$ in female C. melipona), longer tail (mean TL/SVL 1.25 in male and 1.19 in female $C$. chiropterus vs. 1.16 in male and 1.11 in female C. melipona), longer head (mean HL $8.1 \mathrm{~mm}$ in male and $7.3 \mathrm{~mm}$ in female C. chiropterus vs. $6.3 \mathrm{~mm}$ in male and $6.4 \mathrm{~mm}$ in female $C$. melipona), wider head (mean HW $5.6 \mathrm{~mm}$ in male and $4.8 \mathrm{~mm}$ in female C. chiropterus vs. 4.3 $\mathrm{mm}$ in male and $4.2 \mathrm{~mm}$ in female C. melipona), longer limbs in males (mean LI 0.3 in C. chiropterus vs. 2.3 in C. melipona), wider feet (mean FW $3.7 \mathrm{~mm}$ in male and $3.1 \mathrm{~mm}$ in female C. chiropterus vs. $2.4 \mathrm{~mm}$ in male and $2.6 \mathrm{~mm}$ in female C. melipona) and more maxillary teeth (mean MT 12.6 in male and 48.0 in female $C$. chiropterus vs. 9.5 in male and 31.0 in female $C$. melipona).

Chiropterotriton chiropterus differs from C. casasi in its smaller adult body size in females (mean SVL $33.5 \mathrm{~mm}$ in C. chiropterus vs. $40.9 \mathrm{~mm}$ in one C. casasi), longer tail in males (mean TL/SVL 1.25 in C. chiropterus vs. 1.04 in C. casasi), shorter head (mean HL 8.1 $\mathrm{mm}$ in male and $7.3 \mathrm{~mm}$ in female C. chiropterus vs. $8.3 \mathrm{~mm}$ in male and $8.6 \mathrm{~mm}$ in one female 
1348 C. casasi), broader head (mean HW $5.6 \mathrm{~mm}$ in male and $4.8 \mathrm{~mm}$ in female C. chiropterus vs. 5.8

1349

1350

1351

1352

1353

1354

1355

1356

1357

1358

1359

1360

1361

1362

1363

1364

1365

1366

1367

1368

1369

1370

1371

1372

1373

1374

1375

1376

1377

1378

1379

1380

1381

1382

1383

1384

1385

1386

1387 Description of neotype: SVL $38.8 \mathrm{~mm}$, TL $46.0 \mathrm{~mm}$, AX $20.8 \mathrm{~mm}$, SW $4.1 \mathrm{~mm}$, HL $8.0 \mathrm{~mm}$, 1388 HW $5.4 \mathrm{~mm}$, HD $2.8 \mathrm{~mm}$, projection of snout beyond mandible $0.4 \mathrm{~mm}$, distance from anterior 1389

1390

1391

1392

1393

$\mathrm{mm}$ in male and $5.9 \mathrm{~mm}$ in one female C. casasi), longer limbs in males (mean LI 0.3 in $C$. chiropterus vs. 0.8 in C. casasi) and more maxillary teeth (mean MT 12.6 in male and 48.0 in female C. chiropterus vs. 9.0 in male and 30 in one female C. casasi).

Chiropterotriton chiropterus differs from C. orculus in its longer tail (mean TL/SVL 1.25 in male and 1.19 in female $C$. chiropterus vs. 1.02 in both male and female $C$. orculus), longer head in males (mean HL $8.1 \mathrm{~mm}$ in C. chiropterus vs. $7.4 \mathrm{~mm}$ in C. orculus), wider head in males (mean HW $5.6 \mathrm{~mm}$ in C. chiropterus vs. $5.0 \mathrm{~mm}$ in C. orculus), longer limbs (mean LI 0.3 in male and 2.0 in female $C$. chiropterus vs. 1.9 in male and 2.9 in female $C$. orculus), wider feet in males (mean FW $3.7 \mathrm{~mm}$ in C. chiropterus vs. $3.2 \mathrm{~mm}$ in C. orculus) and more maxillary teeth (mean MT 12.6 in male and 48.0 in female C. chiropterus vs. 8.2 in male and 28.8 in female $C$. orculus).

Chiropterotriton chiropterus differs from C. lavae in its larger adult body size (mean SVL $37.5 \mathrm{~mm}$ in male and $33.5 \mathrm{~mm}$ in female C. chiropterus vs. $32.4 \mathrm{~mm}$ in male and $31.6 \mathrm{~mm}$ in female C. lavae), longer tail (mean TL/SVL 1.25 in male and 1.19 in female C. chiropterus vs. 1.19 in male and 1.02 in female C. lavae), shorter limbs (mean LI 0.3 in male and 2.0 in female C. chiropterus vs. - 0.6 in male and 0.6 in female C. lavae), longer head (mean HL $8.1 \mathrm{~mm}$ in male and $7.3 \mathrm{~mm}$ in female C. chiropterus vs. $7.5 \mathrm{~mm}$ in male and $7.0 \mathrm{~mm}$ in female C. lavae), broader head (mean HW $5.6 \mathrm{~mm}$ in male and $4.8 \mathrm{~mm}$ in female C. chiropterus vs. $4.9 \mathrm{~mm}$ in male and $4.7 \mathrm{~mm}$ in female C. lavae), more maxillary teeth (mean MT 12.6 in male and 48.0 in female C. chiropterus vs. 7.0 in male and 20.8 in female C. lavae) and more vomerine teeth (mean VT 10.6 in male and 12.5 in female $C$. chiropterus vs. 8.9 in male and 11.4 in female $C$. lavae).

Chiropterotriton chiropterus differs from C. aureus in its larger adult body size (mean SVL $37.5 \mathrm{~mm}$ in male and $33.5 \mathrm{~mm}$ in female C. chiropterus vs. $28.5 \mathrm{~mm}$ in one male, mean $26.8 \mathrm{~mm}$ in females $C$. aureus), relatively longer limbs in males (mean LI 0.3 in male $C$. chiropterus vs. 2.0 in one male C. aureus), longer head (mean HL $8.1 \mathrm{~mm}$ in male and $7.3 \mathrm{~mm}$ in female C. chiropterus vs. $6.4 \mathrm{~mm}$ in one male, mean $6.0 \mathrm{~mm}$ in female $C$. aureus), broader head (mean HW $5.6 \mathrm{~mm}$ in male and $4.8 \mathrm{~mm}$ in female $C$. chiropterus vs. $4.0 \mathrm{~mm}$ in one male, 3.6 $\mathrm{mm}$ in female C. aureus), and larger feet (mean FW $3.7 \mathrm{~mm}$ in male and 3.1 in female $C$. chiropterus vs. $2.4 \mathrm{~mm}$ in one male, 1.8 in females of $C$. aureus).

Chiropterotriton chiropterus differs from C. nubilus in its larger adult body size (mean SVL $37.5 \mathrm{~mm}$ in male and $33.5 \mathrm{~mm}$ in female C. chiropterus vs. $29.4 \mathrm{~mm}$ in one male, mean $30.5 \mathrm{~mm}$ in females C. nubilus), relatively longer limbs in males (mean LI 0.3 in male $C$. chiropterus vs. 2.0 in one male C. nubilus), longer head in males (mean HL $8.1 \mathrm{~mm}$ in $C$. chiropterus vs. $6.6 \mathrm{~mm}$ in one male C. nubilus), broader head (mean HW $5.6 \mathrm{~mm}$ in male and 4.8 $\mathrm{mm}$ in female C. chiropterus vs. $4.0 \mathrm{~mm}$ in one male, $4.4 \mathrm{~mm}$ in female C. nubilus), and larger feet (mean FW $3.7 \mathrm{~mm}$ in male and 3.1 in female C. chiropterus vs. $2.6 \mathrm{~mm}$ in one male, 2.3 in females of C. nubilus). rim of orbit to snout $1.8 \mathrm{~mm}$, interorbital distance $2.4 \mathrm{~mm}$, eyelid length $2.7 \mathrm{~mm}$, eyelid width $1.2 \mathrm{~mm}$, horizontal orbit diameter $1.7 \mathrm{~mm}$, nostril diameter $0.4 \mathrm{~mm}$, FLL $9.5 \mathrm{~mm}$, HLL $10.8 \mathrm{~mm}$, snout-to-forelimb length $10.2 \mathrm{~mm}$, distance from snout to anterior angle of vent $36.7 \mathrm{~mm}$, tail width at base $2.8 \mathrm{~mm}$, tail depth at base $2.7 \mathrm{~mm}$, FW $3.6 \mathrm{~mm}$, length of fifth toe $0.9 \mathrm{~mm}$, length of longest (third) toe $1.5 \mathrm{~mm}$, mental gland length $1.3 \mathrm{~mm}$, mental gland width 1.3 . Numbers of

Peer) reviewing PDF | (2019:11:43498:1:1:NEW 18 Feb 2020) 
1394 teeth: premaxillary 5, maxillary 6-10 (right-left) and vomerine 5-5 (right-left). Adpressed limbs 1395 are separated by 0 costal folds.

1396 Coloration in life: Data have been derived from diapositives of seven specimens from Huatusco 1397 taken by Roy W. McDiarmid. This is a generally brightly colored species in which yellowish 1398 colors predominate. It is generally pale laterally and ventrally. A dorsal light band is generally present that extends onto the tail, sometimes to the tip, but there are some darker specimens that lack an obvious stripe. Coloration varies extensively from one specimen to the next with respect to the nature of the dorsal band and its coloration. In one large adult, the color is a relatively intense Orange Rufous (5) at the origin of the band, behind the eyes, but it becomes lighter and yellower posteriorly and on the sides of the head and neck, from Tawny Olive (17) to Pale Horn Color (11), then Yellow Ochre (14). Over the shoulder and more posteriorly, yellowish-to-cream spots (Light Buff, 2) form in a dorsolateral ragged line, with the dorsomedial stripe becoming Light Neutral Gray (297) grading into Pale Neutral Gray (296) and extending onto the tail as Pale Mauve (204) with speckles of Cinnamon Drab (50). The limbs are yellowish (Chamois, 84). The iris is dark ventrally but has a yellow-gold highlight. The dorsal eyelid is pale and colorless. A faint light cream bar extends between the eyes.

Another specimen is more colorful dorsally. The head is complexly colored with a bright snout (Salmon Color, 82) to the midpoint between the eyes. A dark bar extends between the eyes, beginning on the eyelid, and an inverted triangular dark area extends posteriorly to the anterior boundary of the epaxial muscles. The temporal region of the head back over the shoulders is light in coloration (Chamois, 84) and there is a lateral excursion of the color over the shoulder region. The base of the tail becomes brighter and rich reddish brown (Carmine, 64). The limbs are a bright mottling of gray and yellow (Cream Yellow, 82, to Chamois 84).

Some animals are darker than the above but most have a light, bright dorsal coloration in the tan-to-yellow range with some brighter orange on the snout. In some the dorsal coloration is pale to very pale. There is usually a bar between the eyes and a ventrolateral excursion of the dorsal band in front of and over the shoulders.

Coloration in preservative: The dorsum is a relatively pale brown, either uniform or with an indistinct, broad brown dorsal stripe bordered by thin, darker-brown dorsolateral lines that extend from the nape to the base of the tail. The dorsal surface of the tail is a relatively pale brown with some darker mottling; the head sometimes has a small amount of darker mottling. The venter and gular region are a uniform pale tan; the ventral side of the tail is a uniform, slightly darker brown.

1427 Osteology: This account is based primarily on examination of a $\mu \mathrm{CT}$ scan of the skull of MVZ 85602, an adult male, $38.9 \mathrm{~mm}$ SVL (Figs. 6-8; Table 3). In addition, four cleared-and-stained specimens were scored for osteological characters evaluated by Darda \& Wake (2015). The skull is well developed. The cranial roof is complete: paired frontals and parietals articulate across the midline - there is no frontoparietal fontanelle-although tabs that extend posteriorly from the frontals to overlap the parietals, which are present in some congeners, are absent. Rostral bones articulate firmly with one another, including many overlapping articulations, such as the prefrontal and nasal by the maxilla. Ascending processes of the single premaxilla are separate along their entire length and broaden laterally as they approach their articulation with the frontals. A very small septomaxilla is present on each side. The nasal is large, including an anteromedial protrusion that forms a medial wall to the external naris and nearly contacts the 
1438 premaxilla at its rostral articulation with the maxilla. The prefrontal is robust; dorsally, it 1439 overlaps the frontal bone whereas ventrally it is overlapped by the facial process of the maxilla. 1440 The foramen for the nasolacrimal duct has eroded abutting portions of the facial process of the maxilla, the nasal and the prefrontal. The five teeth on the left maxilla and six on the right are confined to the anterior $50 \%$ of each bone. The remaining (edentulous) portion of each maxilla is cleaver-like. There are four premaxillary teeth. The orbitosphenoid is fully articulated with the frontal and parietal dorsally and the parasphenoid ventrally, thus forming a solid braincase.

There are two large (elevated) crests on each otic capsule. One arises dorsal to the anterior semicircular canal. The other emerges at right angles from the midpoint of the first crest and extends posterolaterally towards the lateral semicircular canal. A moderately sized tab emerges from the posterolateral edge of the parietal and is sharply reflected ventromedially, extending at least halfway down the vertical extent of the orbitosphenoid. The squamosal, while typical for Chiropterotriton, bears a distinctive longitudinal ridge on its lateral face. The quadrate, while robust, is nevertheless small and inconspicuous. The columellar stylus is well developed for Chiropterotriton; it comprises a short but distinct rod that is directed towards but does not contact the squamosal. Paired vomers articulate medially both anteriorly and posteriorly, partially obliterating the internasal fontanelle in ventral view. Preorbital processes of the vomer are spine-like - elongate and pointed — and completely lack teeth. There are five vomerine teeth on the right side and six on the left. The parasphenoid bone is relatively narrow posteriorly. Paired parasphenoid tooth patches are separated across midline; each bears $45-50$ teeth. The mandible is robust. The articular bone is robust and solidly articulated with the prearticular and the dentary. The prearticular is well developed; the coronoid process is very high. There are 10 teeth on the right dentary bone and 11 on the left.

Digital formulae are 1-2-3-2 on each side. The distal tip of the terminal phalanx is greatly expanded on each finger except the first. Mesopodial cartilages are not mineralized.

Distribution and ecology: Chiropterotriton chiropterus is found from the vicinity of the type locality near Huatusco, Veracruz, south to the Sierra de Juárez, Oaxaca. Geographically associated species include $C$. orculus, $C$. perotensis, $C$. ceronorum and $C$. lavae. The species occurs at higher elevations in Oaxaca than in Veracruz and the overall elevational range is from 1400 to 2170 masl.

Remarks: Populations from the Sierra de Juárez, Oaxaca, were previously considered to represent an undescribed species (Chiropterotriton sp. J) based on allozyme data (Darda, 1994), but that study lacked specimens of topotypic $C$. chiropterus. Mitochondrial DNA sequenced data showed that Chiropterotriton sp. J is most closely related to C. chiropterus. Based on examination of a series of specimens from the north slope of Cerro Pelón, Oaxaca, we are unable to find any discrete morphological differences between these populations that would support the recognition of $C$. sp. J as a distinct species. We therefore assign populations from Oaxaca previously referred to Chiropterotriton sp. J to C. chiropterus. With the assignment of the Oaxacan populations to this species, it now has by far the widest geographic range of any species of the genus, approximately $200 \mathrm{~km}$ in direct linear distance.

most recent IUCN Red List of Threatened Species (Parra-Olea et al., 2008). 
1481 Chiropterotriton orculus Cope, 1865

1482 Cope's Flat-footed Salamander, Salamandra de Pie Plano de Cope

1483 Figures 4G, 5G, 6E, 7E, 8E.

1484

1485

1486

1487

1488

1489

1490

Chresonymy

Spelerpes orculus - Cope, 1865: 196. Syntypes: USNM or ANSP, not now present in either collection. Type locality: "Mexican Table Land" (Frost, 2019).

Spelerpes chiropterus (part)—Cope, 1869: 106; Taylor and Smith, 1945; Smith and Taylor, 1948.

Chiropterotriton orculus_Darda, 1994; Raffaëlli, 2007; Raffaëlli, 2013.

1491 Neotype: MVZ 138783, an adult male from the ridge between Popocatepetl and 1492 Iztaccihuatl, along Mexican Hwy. 196, $16.2 \mathrm{~km}$ by road east jct Mexican Hwy. 115, 1493 Mexico, Mexico, 3300 masl, 19.0973N, $98.6829^{\circ}$ W. Collected 26 July 1976 by J. F. 1494 Lynch, D. B. Wake and M. E. Feder.

1495 Additional specimens examined: Nineteen specimens, all from the ridge between 1496 Popocatepetl and Iztaccihuatl, México, Mexico. Nine males: MVZ 76161, 138694, 1497 138696-97, 138700, 138778, 138784, 138804 and 200630; and ten females: MVZ 138686, 1498 138688, 138776-77, 138779, 138781, 138793, 138796-97 and 200629.

Diagnosis: This is a medium-sized species of Chiropterotriton; mean SVL $35.9 \mathrm{~mm}$ in ten adult males (range 33.6-38.9) and $39.0 \mathrm{~mm}$ in ten adult females (range 34.9-43.0). The head is moderately wide; HW averages $14 \%$ of SVL in males (range $13-15$ ) and $13 \%$ in females (range 12-14). Jaw muscles are prominent in both males and females. Adult males have a broad, bluntly rounded snout with broad and moderately developed nasolabial protuberances. Eyes are large and relatively prominent and extend slightly beyond the jaw margin in ventral view. There are few maxillary teeth in males (mean MT 8.2, range 5-11) and moderate numbers in females (mean MT 28.8, range 23-35). There are few vomerine teeth in both males (mean VT 8.6, 5-11) and females (mean VT 12.0, range 9-15), which are arranged in a curved row that does not extend lateral to the outer margin of the internal choana. The tail is moderately long and slightly exceeds snout-vent length in most specimens; mean TL/SVL equals 1.02 in both males (range 0.86-1.15) and females (range 0.87-1.12). Limbs are short to moderately long in both females and males; FLL+HLL averages $51 \%$ of SVL in males (range $43-56$ ) and $47 \%$ in females (range 44-50).

1514 Adpressed limbs approach closely in males (mean LI 1.9, range 0.0-3.0) but are widely separated in females (mean LI 2.9, range 2.0-3.0). The manus and pes are relatively small, digits are broad. Subterminal pads are well developed. Digital webbing ranges from slight

1516 to moderate, extending to the base of the penultimate phalanx on the third toe. The first 1517 digit is distinct but barely emerges from the webbing. Digital tips are only slightly 1518 expanded. The mental gland is prominent, relatively large and oval (nearly round) in males. 1519 The smallest mature male is $33.6 \mathrm{~mm} \mathrm{SVL}$.

1520 Comparisons: Chiropterotriton orculus differs from C. ceronorum in its larger adult body size (mean SVL $35.9 \mathrm{~mm}$ in male and $39.0 \mathrm{~mm}$ in female $C$. orculus vs. $33.9 \mathrm{~mm}$ in male and $34.9 \mathrm{~mm}$ in female $C$. ceronorum), shorter limbs (mean LI 1.9 in male and 2.9 in

1523 female $C$. orculus vs. 0.0 in male and 1.5 in female $C$. ceronorum), fewer maxillary teeth 
1524 (mean MT 8.2 in male and 28.8 in female $C$. orculus vs. 11.0 in male and 47.7 in female $C$.

1525

1526

1527

1528

1529

1530

1531

1532

1533

1534

1535

1536

1537

1538

1539

1540

1541

1542

1543

1544

1545

1546

1547

1548

1549

1550

1551

1552

1553

1554

1555

1556

1557

1558

1559

1560

1561

1562

1563

1564

1565

1566

1567

1568

ceronorum) and fewer vomerine teeth (mean VT 8.6 in male and 12.0 in female $C$. orculus vs. 13.0 in male and 15.9 in female C. ceronorum).

Chiropterotriton orculus differs from C. perotensis in its larger adult body size (mean SVL $35.9 \mathrm{~mm}$ in male and $39.0 \mathrm{~mm}$ in female C. orculus vs. $29.7 \mathrm{~mm}$ in male and $31.7 \mathrm{~mm}$ in female C. perotensis), slightly longer limbs (mean LI 1.9 in male and 2.9 in female $C$. orculus vs. 2.5 in male and 3.3 in female C. perotensis), longer head (mean HL $7.4 \mathrm{~mm}$ in male and $8.0 \mathrm{~mm}$ in female C. orculus vs. $6.6 \mathrm{~mm}$ in male and $6.7 \mathrm{~mm}$ in female C. perotensis), broader head (mean HW $5.0 \mathrm{~mm}$ in male and $5.2 \mathrm{~mm}$ in female C. orculus vs. $4.2 \mathrm{~mm}$ in male and $4.4 \mathrm{~mm}$ in female C. perotensis), larger feet (mean FW $3.2 \mathrm{~mm}$ in male and $3.4 \mathrm{~mm}$ in female $C$. orculus vs. $2.6 \mathrm{~mm}$ in both male and female C. perotensis) and more maxillary teeth (mean MT 8.2 in male and 28.8 in female C. orculus vs. 7.2 in male and 27.9 in female $C$. perotensis).

Chiropterotriton orculus differs from C. totonacus in its larger adult body size in females (mean SVL $39.0 \mathrm{~mm}$ in C. orculus vs. $35.5 \mathrm{~mm}$ in C. totonacus), shorter tail (mean TL/SVL 1.02 in both male and female $C$. orculus vs. 1.16 in male and 1.20 in female $C$. totonacus), shorter limbs (mean LI 1.9 in male and 2.9 in female $C$. orculus vs. -0.60 in male and 0.0 in female $C$. totonacus), shorter head in males (mean HL $7.4 \mathrm{~mm}$ in $C$. orculus vs. $8.5 \mathrm{~mm}$ in C. totonacus), narrower feet (mean FW $3.2 \mathrm{~mm}$ in male and $3.4 \mathrm{~mm}$ in female C. orculus vs. $4.2 \mathrm{~mm}$ in male and $4.0 \mathrm{~mm}$ in female $C$. totonacus), fewer maxillary teeth (mean MT 8.2 in male and 28.8 in female C. orculus vs. 32.9 in male and 52.6 in female $C$. totonacus) and fewer vomerine teeth (mean VT 8.6 in male and 12.0 in female $C$. orculus vs. 11.6 in male and 13.7 in female $C$. totonacus).

Chiropterotriton orculus differs from C. melipona in its larger adult body size (mean SVL $35.9 \mathrm{~mm}$ in male and $39.0 \mathrm{~mm}$ in female C. orculus vs. $29.2 \mathrm{~mm}$ in male and $28.5 \mathrm{~mm}$ in female C. melipona), shorter tail (mean TL/SVL 1.02 in both male and female C. orculus vs. 1.16 in male and 1.11 in female C. melipona), longer head (mean HL $7.4 \mathrm{~mm}$ in male and $8.0 \mathrm{~mm}$ in female $C$. orculus vs. $6.3 \mathrm{~mm}$ in male and $6.4 \mathrm{~mm}$ in female $C$. melipona), broader head (mean HW $5.0 \mathrm{~mm}$ in male and $5.2 \mathrm{~mm}$ in female C. orculus vs. $4.3 \mathrm{~mm}$ in male and $4.2 \mathrm{~mm}$ in female C. melipona) and broader feet (mean FW $3.2 \mathrm{~mm}$ in male and $3.4 \mathrm{~mm}$ in female $C$. orculus vs. $2.4 \mathrm{~mm}$ in male and $2.6 \mathrm{~mm}$ in female $C$. melipona).

Chiropterotriton orculus differs from C. casasi in its smaller adult body size (mean SVL $35.9 \mathrm{~mm}$ in male and $39.0 \mathrm{~mm}$ in female C. orculus vs. $37.8 \mathrm{~mm}$ in male and $40.9 \mathrm{~mm}$ in one female $C$. casasi), shorter head (mean HL $7.4 \mathrm{~mm}$ in male and $8.0 \mathrm{~mm}$ in female $C$. orculus vs. $8.3 \mathrm{~mm}$ in male and $8.6 \mathrm{~mm}$ in one female C. casasi), narrower head (mean HW $5.0 \mathrm{~mm}$ in male and $5.2 \mathrm{~mm}$ in female C. orculus vs. $5.8 \mathrm{~mm}$ in male and $5.9 \mathrm{~mm}$ in one female $C$. casasi) and shorter limbs (mean LI 1.9 in male and 2.9 in female C. orculus vs. 0.8 in male and 1.0 in one female C. casasi).

Chiropterotriton orculus differs from C. chiropterus in its shorter tail (mean TL/SVL 1.02 in both male and female $C$. orculus vs. 1.25 in male and 1.19 in female $C$. chiropterus), shorter head in males (mean HL $7.4 \mathrm{~mm}$ in C. orculus vs. $8.1 \mathrm{~mm}$ in $C$. chiropterus), narrower head in males (mean HW $5.0 \mathrm{~mm}$ in $C$. orculus vs. $5.6 \mathrm{~mm}$ in $C$. chiropterus), shorter limbs (mean LI 1.9 in male and 2.9 in female C. orculus vs. 0.3 in male and 2.0 in female C. chiropterus), narrower feet in males (mean FW $3.2 \mathrm{~mm}$ in $C$.

Peer) reviewing PDF | (2019:11:43498:1:1:NEW 18 Feb 2020) 
1569 orculus vs. $3.7 \mathrm{~mm}$ in C. chiropterus) and fewer maxillary teeth (mean MT 8.2 in male and

1570

1571

1572

1573

1574

1575

1576

1577

1578

1579

1580

1581

1582

1583

1584

1585

1586

1587

1588

1589

1590

1591

1592

1593

1594

1595

1596

1597

1598

1599

1600

1601

1602

1603

1604

1605

1606

1607

1608

1609

1610

1611

1612

1613

1614

28.8 in female $C$. orculus vs. 12.6 in male and 48.0 in female $C$. chiropterus).

Chiropterotriton orculus differs from C. lavae in its larger adult body size (mean

SVL $35.9 \mathrm{~mm}$ in male and $39.0 \mathrm{~mm}$ in female $C$. orculus vs. $32.4 \mathrm{~mm}$ in male and $31.6 \mathrm{~mm}$ in female C. lavae), shorter tail in males (mean TL/SVL 1.02 in C. orculus vs. 1.19 in $C$. lavae), shorter limbs (mean LI 1.9 in male and 2.9 in female $C$. orculus vs. -0.60 in male and 0.6 in female C. lavae) and more maxillary teeth (mean MT 8.2 in male and 28.8 in female C. orculus vs. 7.0 in male and 20.8 in female C. lavae).

Chiropterotriton orculus differs from C. dimidiatus in its larger adult body size (mean SVL $35.9 \mathrm{~mm}$ in male and $39.0 \mathrm{~mm}$ in female C. orculus vs. $24.6 \mathrm{~mm}$ in male and $25.8 \mathrm{~mm}$ in female $C$. dimidiatus), longer tail (mean TL/SVL 1.02 in both male and female C. orculus vs. 0.89 in male and 0.87 in female C. dimidiatus), longer limbs (mean LI 1.90 in male and 2.90 in female $C$. orculus vs. 3.8 in male and 4.9 in female $C$. dimidiatus), longer head (mean HL $7.4 \mathrm{~mm}$ in male and $8.0 \mathrm{~mm}$ in female C. orculus vs. $5.2 \mathrm{~mm}$ in male and $5.0 \mathrm{~mm}$ in female $C$. dimidiatus), broader head (mean HW $5.0 \mathrm{~mm}$ in male and $5.2 \mathrm{~mm}$ in female $C$. orculus vs. $3.4 \mathrm{~mm}$ in male and $3.5 \mathrm{~mm}$ in female $C$. dimidiatus), broader feet (mean FW $3.2 \mathrm{~mm}$ in male and $3.4 \mathrm{~mm}$ in female $C$. orculus vs. $1.7 \mathrm{~mm}$ in both male and female $C$. dimidiatus), more maxillary teeth (mean MT 8.2 in male and 28.8 in female $C$. orculus vs. 3.8 in male and 17.0 in female $C$. dimidiatus) and more vomerine teeth (mean VT 8.6 in male and 12.0 in female C. orculus vs. 5.6 in male and 8.3 in female C. dimidiatus).

Chiropterotriton orculus differs from C. chico in its smaller adult body size in males (mean SVL $35.9 \mathrm{~mm}$ in C. orculus vs. $38.4 \mathrm{~mm}$ in C. chico), shorter tail (mean TL/SVL 1.02 in both male and female $C$. orculus vs. 1.18 in male and 1.12 in female $C$. chico), shorter limbs (mean LI 1.90 in male and 2.90 in female C. orculus vs. 0.6 in male and 2.1 in female C. chico), shorter head (mean HL $7.4 \mathrm{~mm}$ in male and $8.0 \mathrm{~mm}$ in female C. orculus vs. $8.8 \mathrm{~mm}$ in male and $8.7 \mathrm{~mm}$ in female C. chico), narrower head (mean HW $5.0 \mathrm{~mm}$ in male and $5.2 \mathrm{~mm}$ in female C. orculus vs. $5.6 \mathrm{~mm}$ in male and $5.7 \mathrm{~mm}$ in female C. chico), narrower feet (mean FW $3.2 \mathrm{~mm}$ in male and $3.4 \mathrm{~mm}$ in female $C$. orculus vs. $4.1 \mathrm{~mm}$ in male and $4.2 \mathrm{~mm}$ in female C. chico) and fewer vomerine teeth (mean VT 8.6 in male and 12.0 in female $C$. orculus vs. 13.6 in male and 15.6 in female $C$. chico).

Chiropterotriton orculus differs from C. arboreus in its larger adult body size (mean SVL $35.9 \mathrm{~mm}$ in male and $39.0 \mathrm{~mm}$ in female $C$. orculus vs. $33.4 \mathrm{~mm}$ in male and $32.2 \mathrm{~mm}$ in female $C$. arboreus), longer tail (mean TL/SVL 1.02 in both male and female C. orculus vs. 0.83 in male and 0.87 in female C. arboreus) and shorter limbs (mean LI 1.90 in male and 2.90 in female $C$. orculus vs. 0.20 in male and 1.0 in female C. arboreus). Chiropterotriton orculus differs from C. terrestris in its larger adult body size (mean SVL $35.9 \mathrm{~mm}$ in male and $39.0 \mathrm{~mm}$ in female C. orculus vs. $24.2 \mathrm{~mm}$ in male and $23.0 \mathrm{~mm}$ in female $C$. terrestris), longer head (mean HL $7.4 \mathrm{~mm}$ in male and $8.0 \mathrm{~mm}$ in female C. orculus vs. $5.7 \mathrm{~mm}$ in male and $5.2 \mathrm{~mm}$ in female $C$. terrestris), broader head (mean HW $5.0 \mathrm{~mm}$ in male and $5.2 \mathrm{~mm}$ in female $C$. orculus vs. $3.5 \mathrm{~mm}$ in male and 3.3 $\mathrm{mm}$ in female C. terrestris) and broader feet (mean FW $3.2 \mathrm{~mm}$ in male and $3.4 \mathrm{~mm}$ in female C. orculus vs. $1.9 \mathrm{~mm}$ in male and $1.7 \mathrm{~mm}$ in female C. terrestris).

Chiropterotriton orculus differs from C. aureus by being larger (mean SVL 35.9 $\mathrm{mm}$ in male and $39.0 \mathrm{~mm}$ in female C. orculus vs. $28.5 \mathrm{~mm}$ in one male, mean $26.8 \mathrm{~mm}$ in female $C$. aureus), shorter tail (mean TL/SVL 1.02 in both male and female C. orculus vs.

Peer) reviewing PDF | (2019:11:43498:1:1:NEW 18 Feb 2020) 
16151.28 in one male, mean 1.16 in female $C$. aureus), relatively shorter limbs in females (mean

1616 LI 2.9 in female $C$. orculus vs. 2.3 in female $C$. aureus), larger head (mean HL $7.4 \mathrm{~mm}$ in

1617 male and $8.0 \mathrm{~mm}$ in female $C$. orculus vs. $6.4 \mathrm{~mm}$ in one male, mean $6.0 \mathrm{~mm}$ in female $C$.

1618 aureus), broader head (mean HW $5.0 \mathrm{~mm}$ in male and $5.2 \mathrm{~mm}$ in female $C$. orculus vs. 4.0

$1619 \mathrm{~mm}$ in one male, $3.6 \mathrm{~mm}$ in female C. aureus), and broader feet (mean FW $3.2 \mathrm{~mm}$ in male

1620 and $3.4 \mathrm{~mm}$ in female $C$. orculus vs. $2.4 \mathrm{~mm}$ in one male, mean $1.8 \mathrm{~mm}$ in female $C$.

1621 aureus).

1622 Chiropterotriton orculus differs from C. nubilus in larger shorter (mean SVL $35.9 \mathrm{~mm}$ in

1623 male and $39.0 \mathrm{~mm}$ in female $C$. orculus vs. $29.4 \mathrm{~mm}$ in one male, mean $30.5 \mathrm{~mm}$ in female $C$.

1624 nubilus), shorter tail (mean TL/SVL 1.02 in both male and female $C$. orculus vs. 1.37 in one

1625 male, mean 1.12 in female $C$. nubilus), relatively shorter limbs in females (mean LI 2.9 in female

1626 C. orculus vs. 1.5 in female C. nubilus), longer head (mean HL $7.4 \mathrm{~mm}$ in male and $8.0 \mathrm{~mm}$ in

1627 female $C$. orculus vs. $6.6 \mathrm{~mm}$ in one male, mean $7.4 \mathrm{~mm}$ in female $C$. nubilus), broader head

1628 (mean HW $5.0 \mathrm{~mm}$ in male and $5.2 \mathrm{~mm}$ in female $C$. orculus vs. $4.0 \mathrm{~mm}$ in one male, mean 4.4

$1629 \mathrm{~mm}$ in female $C$. nubilus), and broader feet (mean FW $3.2 \mathrm{~mm}$ in male and $3.4 \mathrm{~mm}$ in female $C$.

1630 orculus vs. $2.6 \mathrm{~mm}$ in one male, mean $2.3 \mathrm{~mm}$ in female C. nubilus).

1631 Description of neotype: SVL $38.9 \mathrm{~mm}$, TL $33.6 \mathrm{~mm}$, AX $20.5 \mathrm{~mm}$, SW $4.0 \mathrm{~mm}$, HL 8.1

$1632 \mathrm{~mm}$, HW $5.5 \mathrm{~mm}$, HD $2.4 \mathrm{~mm}$, projection of snout beyond mandible $0.6 \mathrm{~mm}$, distance from

1633 anterior rim of orbit to snout $2.3 \mathrm{~mm}$, interorbital distance $2.3 \mathrm{~mm}$, eyelid length $3.5 \mathrm{~mm}$,

1634 eyelid width $1.6 \mathrm{~mm}$, horizontal orbit diameter $1.8 \mathrm{~mm}$, nostril diameter $0.3 \mathrm{~mm}$, FLL 9.3

$1635 \mathrm{~mm}$, HLL $9.6 \mathrm{~mm}$, snout-to-forelimb length $9.5 \mathrm{~mm}$, distance from snout to anterior angle

1636 of vent $33.8 \mathrm{~mm}$, tail width at base $3.1 \mathrm{~mm}$, tail depth at base $3.2 \mathrm{~mm}$, FW $3.5 \mathrm{~mm}$, length

1637 of fifth toe $0.5 \mathrm{~mm}$, length of longest (third) toe $1.2 \mathrm{~mm}$, mental gland length $1.3 \mathrm{~mm}$,

1638 mental gland width 1.3. Numbers of teeth: premaxillary 4, maxillary 4-5 (right-left) and

1639 vomerine 5-4 (right-left). Adpressed limbs are separated by 2 costal folds.

1640 Coloration in life: No information is available for the neotype or topotypic individuals; this

1641 description is based on photos of specimens from Lagunas de Zempoala. The background

1642 dorsal color is very dark grey. A broad dorsal band is typically present, varying in color

1643 from reddish brown to tan or nearly golden brown; the background color is visible only

1644 along midline. This coloration continues onto the tail, although the band is less regular and

1645 somewhat broken up in many individuals. The head is very dark brown, with splotches of

1646 brown similar in coloration to those on the dorsum. Small, pale-grey specks often present

1647 on both head and tail. The dorsal band is bordered by very dark grey. Some individuals lack

1648 a dorsal band and are very dark-brownish-grey dorsally with pale flecks throughout. Flanks

1649 are dark grey with pale grey specks, which are numerous on the body with some on the

1650 sides of the head and few to none on the sides of the tail. Upper side of limbs either similar

1651 in coloration to flanks or slightly paler. The iris is coppery.

1652 Coloration in preservative: The dorsum, head and tail are a uniform medium brown. The

1653 upper side of the limbs and feet are paler brown. The venter, gular region and underside of

1654 the forelimbs are tan to pale brown; the underside of the hind limbs and tail are slightly

1655 darker brown.

1656 Osteology: This account is based on examination of a $\mu \mathrm{CT}$ scan of the anterior skeleton of

1657 the neotype: MVZ 138783, an adult male, $38.9 \mathrm{~mm}$ SL (Figs. 6-8; Table 3). The skull is

Peer] reviewing PDF | (2019:11:43498:1:1:NEW 18 Feb 2020) 
1658 compact and robust, especially anteriorly. The snout is blunt in lateral view. Cranial roofing

1659 bones are moderately well ossified. Paired frontals articulate across the midline anteriorly

1660 for about two thirds of their length but then separate to participate in a relatively large

1661 frontoparietal fontanelle, which includes about three fourths of the length of the parietals.

1662 Posteriorly extending tabs of the frontals overlap the parietals anteriorly. Ascending

1663 processes of the single premaxilla approach one another medially but remain separate for

1664 their entire length. They twist and broaden greatly as they ascend before establishing a firm

1665 articulation with the frontal. The dental process of the premaxilla is deep (high) but no

1666 palatal shelf is evident. Septomaxillae are present on both sides; they are very small but

1667 nevertheless well developed for Chiropterotriton. The nasal bone is broadly triangular, but

1668 also thin and less well-developed anteromedially. It barely abuts the premaxilla medially

1669 and the maxilla laterally; is separated from the prefrontal posterolaterally; and slightly

1670 overlaps the frontal posteriorly. The prefrontal is broad, compact and almost quadrangular.

1671 The foramen for the nasolacrimal duct has eroded the ventral margin of the prefrontal and

1672 the dorsal margin of the facial process of the maxilla, but the nasal is not involved. The

1673 maxilla is edentulous posteriorly for about $55 \%$ of its length. Its posterior tips flare laterally

1674 beyond the margin of the lower jaw in dorsal view. There are five large maxillary teeth on

1675 each side and four premaxillary teeth. The orbitosphenoid, while moderately well-

1676 developed, is articulated solidly to the parasphenoid, weakly to the frontal, and not at all to

1677

1678

1679

1680

1681

1682

1683

1684

1685

1686

1687

1688

1689

1690

1691

1692

1693

1694

1695

1696

1697

1698 the parietal. The oculomotor foramen is absent on the right side.

There are no prominent crests on the dorsal surface of either otic capsule. The posterolateral tab of the parietal is well-developed but relatively short and triangular; it is reflected ventromedially and ends in a rounded point about halfway down the vertical extent of the orbitosphenoid. The squamosal bone is more elongate and less triangular than in other Chiropterotriton; its dorsal tip articulates with a small portion of the otic capsule opposite the lateral semicircular canal. The quadrate is small and inconspicuous. The stylus on the columella is short and stout. Paired bodies of the vomer are reasonably well developed but they barely articulate medially posterior to the internasal fontanelle. Postorbital processes of are long, thin and slightly curved. There are six vomerine teeth on the right side and six on the left; one or two teeth are deployed at the base of each preorbital process. The parasphenoid expands posteriorly but truncates abruptly at its caudal border. Each lateral edge is sculpted by a shallow notch opposite the jaw articulation, and by an erosion of bone (and teeth) opposite the ventromedially directed parietal tab. It has an unusual shape along the lateral margin. Paired parasphenoid tooth patches are separated across the midline; each bears 50-52 fully developed teeth, but there are many additional developing teeth along the lateral margin. The mandible is solid. The articular bone is well developed and may be at least partly fused to the pre articular on each side. The prearticular has a relatively high coronoid process. There are approximately 12 teeth on each dentary bone.

Digital formulae are 1-2-3-2 on each side. There is a tiny expanded knob at the tip of each terminal phalanx. Mesopodial cartilages are not mineralized.

1699

Distribution and ecology: Chiropterotriton orculus is restricted to the central and eastern portion of the Trans Mexican Volcanic Belt (La Marquesa, Desierto de los Leones, Ajusco, Lagunas de Zempoala, Iztaccihuatl, Popocatépetl, Rio Frio and La Malinche). It occurs in pine and fir forest and is terrestrial; it is typically found under the bark of logs or inside 1703 rotting logs. This widely distributed species ranges between 2500 and 3500 masl 
1704 Remarks: This species was raised from synonymy with C. chiropterus by Darda (his

1705

1706

1707

1708

1709

1710

1711

1712

1713

1714

1715

1716

1717

1718

1719

1720

1721

1722

1723

1724

1725

1726

1727

1728

1729

1730

1731

1732

1733

1734

1735

1736

1737

1738

1739

1740

1741

1742

1743

1744

1745

1746

species G, population 20). While it is relatively widespread, we are unsure of its northeastern limits. Population $\mathrm{G}$ is from near Chignahuapan, Puebla. We also include Darda's sp. A (Desierto de Los Leones, DF) and B (Rio Frio, Mexico) in our current understanding of this taxon.

Conservation status: Chiropterotriton orculus is designated as Vulnerable by the most recent IUCN Red List of Threatened Species (Parra-Olea \& Wake, 2008). The species remains relatively common near Lagunas de Zempoala.

\section{OTHER SPECIES OF CHIROPTEROTRITON FROM CENTRAL VERACRUZ}

In addition to the recently described $C$. aureus and $C$. nubilus, C. lavae also occurs in the mountains of central Veracruz. While Taylor's (1942) original description of this species was relatively thorough, we provide a brief overview of this species for comparative purposes using additional specimens collected since the type series. We also examined the holotype and several paratypes of this species to provide additional information not contained in Taylor's description.

\section{Chiropterotriton lavae (Taylor, 1942)}

Chresonymy

Bolitoglossa lavae-Taylor, 1942. Holotype: EHT-HMS 28937, now FMNH 100118. Type locality: "2 miles west of La Joya-Veracruz", Mexico.

Pigmy Flat-footed Salamander, Salamandra de pie plano pigmea

Figures $4 \mathrm{H}, 5 \mathrm{H}, 6 \mathrm{C}, 7 \mathrm{C}, 8 \mathrm{C}$.

Specimens examined: Nineteen specimens, all from La Joya, Veracruz, Mexico. Ten males: MVZ 163912-13, 163915, 171873-74, 173394-95, 173398, 178685 and 192789; and nine females: MVZ 106537, 106548, 171876, 171881, 171885, 171901, 192788, 197788 and 200638.

Diagnosis: This is a medium-sized species of plethodontid salamander phylogenetically related to Chiropterotriton totonacus, C. perotensis and C. ceronorum; mean SVL $32.4 \mathrm{~mm}$ in ten adult males (range 31.1-33.8) and $31.6 \mathrm{~mm}$ in nine adult females (range 27.9-34.9). The head is moderately wide; HW averages $15 \%$ of SVL in males (range 14-17) and 15\% in females (range 14-16). Jaw muscles are prominent in both males and females. Adult males and females have a bluntly rounded snout with moderately developed nasolabial protuberances. Eyes are large and prominent and extend laterally well beyond the jaw margin in ventral view. There are few maxillary teeth in males (mean MT 7.0, range 1-10) and moderate numbers in females (mean MT 20.8, range 13-36). There are few vomerine teeth in both males (mean VT 8.9, 7-10) and females (mean VT 11.4, range 8-15), which are arranged in a short row that does not reach or barely reaches the inner margin of the internal choana. The tail is moderately long and slightly exceeds SVL in most specimens; mean TL/SVL equals 1.19 in males (range 1.11-1.27) and 1.02 in females (range 0.851.15). Limbs are moderately to very long in both females and males; FLL+HLL averages $59 \%$ of SVL in males (range 53-65) and 54\% in females (range 50-59). Adpressed limbs closely approach or overlap in males (mean LI -0.60 , range -1.0-0.0) but are more separated in females (mean LI 0.6, range $0.0-2.0$ ). The manus and pes are moderate in size.

Peer) reviewing PDF | (2019:11:43498:1:1:NEW 18 Feb 2020) 
1747 Subterminal pads are well developed. Digital webbing is modest, reaching only to the base 1748 of the penultimate phalanx on the third toe. The first digit is included entirely in webbing. 1749 Digital tips are slightly expanded. The mental gland is oval (nearly round), somewhat 1750 prominent and moderately sized in males. The smallest male with a mental gland is 31.2 $1751 \mathrm{~mm}$ SVL.

1752 Comparisons: Chiropterotriton lavae differs from C. ceronorum in its slightly smaller adult

1753

1754

1755

1756

1757

1758

1759

1760

1761

1762

1763

1764

1765

1766

1767

1768

1769

1770

1771

1772

1773

1774

1775

1776

1777

1778

1779

1780

1781

1782

1783

1784

1785

1786

1787

1788

1789

1790

1791

1792 body size (mean SVL $32.4 \mathrm{~mm}$ in male and $31.6 \mathrm{~mm}$ in female C. lavae vs. $33.9 \mathrm{~mm}$ in male and $34.9 \mathrm{~mm}$ in female $C$. ceronorum), longer tail (mean TL/SVL 1.19 in male and 1.02 in female $C$. lavae vs. 1.0 in male and 0.97 in female C. ceronorum), longer limbs (mean LI - 0.6 in male and 0.6 in female $C$. lavae vs. 0.0 in male and 1.5 in female $C$. ceronorum), fewer maxillary teeth (mean MT 7.0 in male and 20.8 in female $C$. lavae vs. 11.0 in male and 47.7 in female $C$. ceronorum) and fewer vomerine teeth (mean VT 8.9 in male and 11.4 in female C. lavae vs. 13.0 in male and 15.9 in female C. ceronorum).

Chiropterotriton lavae differs from $C$. perotensis in its larger adult body size in males (mean SVL $32.4 \mathrm{~mm}$ in C. lavae vs. $29.7 \mathrm{~mm}$ in C. perotensis), longer limbs (mean LI -0.6 in male and 0.6 in female $C$. lavae vs. 2.5 in male and 3.3 in female $C$. perotensis), slightly wider head (mean HW 4.9 in male and 4.7 in female $C$. lavae vs. 4.2 in male and 4.4 in female $C$. perotensis), longer head (mean HL $7.5 \mathrm{~mm}$ in male and $7.0 \mathrm{~mm}$ in female C. lavae vs. $6.6 \mathrm{~mm}$ in male and $6.7 \mathrm{~mm}$ in female $C$. perotensis), wider feet (FW $3.7 \mathrm{~mm}$ in male and $3.3 \mathrm{~mm}$ in female C. lavae vs. $2.6 \mathrm{~mm}$ in both male and female C. perotensis) and slightly fewer maxillary teeth in females (mean MT 20.8 in C. lavae vs. 27.9 in C. perotensis).

Chiropterotriton lavae differs from $C$. totonacus in its smaller adult body size (mean SVL $32.4 \mathrm{~mm}$ in male and $31.6 \mathrm{~mm}$ in female C. lavae vs. $35.7 \mathrm{~mm}$ in male and $35.5 \mathrm{~mm}$ in female $C$. totonacus), shorter tail in females (mean TL/SVL 1.02 in C. lavae vs. 1.20 in $C$. totonacus), shorter limbs in females (mean LI 0.6 in C. lavae vs. 0.0 in C. totonacus), shorter head (mean HL $7.5 \mathrm{~mm}$ in male and $7.0 \mathrm{~mm}$ in female $C$. lavae vs. $8.5 \mathrm{~mm}$ in male and $7.6 \mathrm{~mm}$ in female C. totonacus), slightly narrower head (mean HW $4.9 \mathrm{~mm}$ in male and $4.7 \mathrm{~mm}$ in female $C$. lavae vs. $5.2 \mathrm{~mm}$ in both male and female $C$. totonacus), narrower feet (mean FW 3.7 $\mathrm{mm}$ in male and $3.3 \mathrm{~mm}$ in female $C$. lavae vs. $4.2 \mathrm{~mm}$ in male and $4.0 \mathrm{~mm}$ in female $C$. totonacus), fewer maxillary teeth (mean MT 7.0 in male and 20.8 in female C. lavae vs. 32.9 in male and 52.6 in female $C$. totonacus) and fewer vomerine teeth (mean VT 8.9 in male and 11.4 in female C. lavae vs. 11.6 in male and 13.7 in female $C$. totonacus).

Chiropterotriton lavae differs from $C$. melipona in its larger adult body size (mean SVL $32.4 \mathrm{~mm}$ in male and $31.6 \mathrm{~mm}$ in female $C$. lavae vs. $29.2 \mathrm{~mm}$ in male and $28.5 \mathrm{~mm}$ in female $C$. melipona), longer head (mean HL $7.5 \mathrm{~mm}$ in male and $7.0 \mathrm{~mm}$ in female C. lavae vs. $6.3 \mathrm{~mm}$ in male and $6.4 \mathrm{~mm}$ in female C. melipona), broader head (mean HW $4.9 \mathrm{~mm}$ in male and $4.7 \mathrm{~mm}$ in female C. lavae vs. $4.3 \mathrm{~mm}$ in male and $4.2 \mathrm{~mm}$ in female $C$. melipona), longer limbs (mean LI -0.6 in male and 0.6 in female $C$. lavae vs. 2.3 in male and 1.8 in female C. melipona), broader feet (mean FW $3.7 \mathrm{~mm}$ in male and $3.3 \mathrm{~mm}$ in female $C$. lavae vs. $2.4 \mathrm{~mm}$ in male and $2.6 \mathrm{~mm}$ in female C. melipona), fewer maxillary teeth (mean MT 7.0 in male and 20.8 in female C. lavae vs. 9.5 in male and 31.0 in female $C$. melipona) and fewer vomerine teeth (mean VT 8.9 in male and 11.4 in female C. lavae vs. 11.0 in male and 13.0 in female C. melipona).

Chiropterotriton lavae differs from C. casasi in its smaller adult body size (mean SVL $32.4 \mathrm{~mm}$ in male and $31.6 \mathrm{~mm}$ in female C. lavae vs. $37.8 \mathrm{~mm}$ in male and $40.9 \mathrm{~mm}$ in one female C. casasi), longer tail in males (mean TL/SVL 1.19 in C. lavae vs. 1.04 in C. casasi), shorter head (mean HL $7.5 \mathrm{~mm}$ in male and $7.0 \mathrm{~mm}$ in female C. lavae vs. $8.3 \mathrm{~mm}$ in male and 
$17938.6 \mathrm{~mm}$ in one female C. casasi), narrower head (mean HW $4.9 \mathrm{~mm}$ in male and $4.7 \mathrm{~mm}$ in

1794 female C. lavae vs. $5.8 \mathrm{~mm}$ in male and $5.9 \mathrm{~mm}$ in one female $C$. casasi), longer limbs (mean LI

$1795-0.6$ in male and 0.6 in female $C$. lavae vs. 0.8 in male and 1.0 in one female $C$. casasi) and

1796 fewer maxillary teeth in females (mean MT 20.8 in C. lavae vs. 30 in C. casasi).

1797

1798

Chiropterotriton lavae differs from C. chiropterus in its smaller adult body size (mean

1799 SVL $32.4 \mathrm{~mm}$ in male and $31.6 \mathrm{~mm}$ in female C. lavae vs. $37.5 \mathrm{~mm}$ in male and $33.5 \mathrm{~mm}$ in female $C$. chiropterus), shorter tail (mean TL/SVL 1.19 in male and 1.02 in female $C$. lavae vs.

1801

1802 1.25 in male and 1.19 in female $C$. chiropterus), longer limbs (mean LI -0.6 in male and 0.6 in female $C$. lavae vs. 0.3 in male and 2.0 in female $C$. chiropterus), shorter head (mean HL 7.5 $\mathrm{mm}$ in male and $7.0 \mathrm{~mm}$ in female $C$. lavae vs. $8.1 \mathrm{~mm}$ in male and $7.3 \mathrm{~mm}$ in female $C$.

1804

1805 chiropterus), narrower head (mean HW $4.9 \mathrm{~mm}$ in male and $4.7 \mathrm{~mm}$ in female C. lavae vs. 5.6 $\mathrm{mm}$ in male and $4.8 \mathrm{~mm}$ in female $C$. chiropterus), fewer maxillary teeth (mean MT 7.0 in male and 20.8 in female $C$. lavae vs. 12.6 in male and 48.0 in female C. chiropterus) and fewer vomerine teeth (mean VT 8.9 in male and 11.4 in female $C$. lavae vs. 10.6 in male and 12.5 in female C. chiropterus).

$1808 \quad$ Chiropterotriton lavae differs from $C$. orculus in its smaller adult body size (mean SVL $32.4 \mathrm{~mm}$ in male and $31.6 \mathrm{~mm}$ in female $C$. lavae vs. $35.9 \mathrm{~mm}$ in male and $39.0 \mathrm{~mm}$ in female $C$. orculus), longer tail in males (mean TL/SVL 1.19 in C. lavae vs. 1.02 in C. orculus) and longer 1812 orculus).

Chiropterotriton lavae differs from C. aureus in its larger adult body size (mean SVL $32.4 \mathrm{~mm}$ in male and $31.6 \mathrm{~mm}$ in female C. lavae vs. $28.5 \mathrm{~mm}$ in one male, mean $26.8 \mathrm{~mm}$ in female $C$. aureus), larger head (mean HL $7.5 \mathrm{~mm}$ in male and $7.0 \mathrm{~mm}$ in female C. lavae vs. 6.4 $\mathrm{mm}$ in one male, mean $6.0 \mathrm{~mm}$ in female $C$. aureus), broader head (mean HW $4.9 \mathrm{~mm}$ in male and $4.7 \mathrm{~mm}$ in female $C$. lavae vs $4.0 \mathrm{~mm}$ in one male, $3.6 \mathrm{~mm}$ in female $C$. aureus), longer limbs (mean LI -0.6 in male and 0.6 in female C. lavae vs. 2.0 in one male, mean 2.3 in female C. aureus), and broader feet (mean FW $3.7 \mathrm{~mm}$ in male and $3.3 \mathrm{~mm}$ in female C. lavae vs. 2.4 $\mathrm{mm}$ in one male, mean $1.8 \mathrm{~mm}$ in female C. aureus).

Chiropterotriton lavae differs from C. nubilus in its larger adult body size in males (mean SVL $32.4 \mathrm{~mm}$ in lavae vs. $29.4 \mathrm{~mm}$ in one male C. nubilus), shorter tail (mean TL/SVL 1.19 in male and 1.02 in female C. lavae vs. 1.37 in one male, mean 1.12 in female C. nubilus), broader head (mean HW $4.9 \mathrm{~mm}$ in male and $4.7 \mathrm{~mm}$ in female C. lavae vs. $4.0 \mathrm{~mm}$ in one male, mean $4.4 \mathrm{~mm}$ in female $C$. nubilus), relatively longer limbs (mean LI -0.6 in male and 0.6 in female C. lavae vs. 2.0 in one male, mean 1.5 in female $C$. nubilus), and broader feet (mean FW $3.7 \mathrm{~mm}$ in male and $3.3 \mathrm{~mm}$ in female $C$. lavae vs $2.6 \mathrm{~mm}$ in one male, mean $2.3 \mathrm{~mm}$ in female C. nubilus).

Measurements of holotype: Adult female, SVL $33.5 \mathrm{~mm}$, TL $40.7 \mathrm{~mm}$, AX $18.1 \mathrm{~mm}$, SW $4.8 \mathrm{~mm}$, HL $7.7 \mathrm{~mm}$, HW $5.6 \mathrm{~mm}$, HD $2.9 \mathrm{~mm}$, projection of snout beyond mandible, interorbital distance $2.1 \mathrm{~mm}$, eyelid length $1.3 \mathrm{~mm}$, FLL $9.2 \mathrm{~mm}$, HLL $9.7 \mathrm{~mm}$, snout-toforelimb length $10.2 \mathrm{~mm}$, snout to anterior angle of vent $33 \mathrm{~mm}$, length of fifth toe $0.9 \mathrm{~mm}$, distance from eye to nostril 1.2, internarial distance 2.0, FW 4.0, length of longest (third) toe $1.6 \mathrm{~mm}$. Numbers of teeth: premaxillary 6, maxillary 16-14 (right-left) and vomerine 66 (right-left). Taylor (1942) listed 28 maxillary and premaxillary teeth on each side but counted missing teeth, while we count only ankylosed teeth that are present. Adpressed limbs touch. 
1838 Coloration in life: Dorsal coloration highly variable. Background dorsal color dark brown; some 1839 individuals have a broad, continuous dorsal band of yellow, reddish-brown or orangish-brown to 1840 pale brown stretching from posterior portion of head to tip of tail, while in other individuals this 1841 dorsal band is either irregular, reduced to paler brown or golden-brown blotches or streaks, or 1842 absent. Head dark brown, often with golden-brown specks, especially between eyes and snout. 1843 Flanks, sides of tail, and dorsal side of limbs and feet dark brown, typically uniform along dorsal 1844 edge but often with paler brown or golden-brown flecks or tan streaks below; toe tips reddish. 1845 Venter dark grey to paler grey, with some white speckling in some individuals. Iris golden-

1846 brown.

1847 Coloration in preservative: The dorsum, tail and head are relatively pale to dark brown, often with a paler, broad dorsal band that is bordered by darker brown coloration. The paler background color is often faintly mottled with darker brown. The venter is a uniform tan to pale brown; the underside of the tail and limbs are a slightly darker brown. The gular region is tan to pale brown, sometimes with a small amount of mottling.

1852 Osteology: This account is based on examination of a $\mu \mathrm{CT}$ scan of the anterior skeleton of MVZ 163912, an adult male, $33.8 \mathrm{~mm}$ SVL (Figs. 6-8). The skull is well developed. The cranial roof is for the most part complete and solidly articulated. There is no frontoparietal fontanelle, although there are slight gaps medially between the paired frontals and paired parietals. Ascending processes of the single premaxillary bone remain separate along their entire length; each broadens laterally as it approaches its dorsal articulation with the adjacent frontal. A very narrow palatal shelf is present on each side of the premaxilla but absent medially. There are no septomaxillary bones. The nasal bone is large and triangular, but also very thin and poorly ossified. The prefrontal bone is rectangular and robust; its ventral portion is overlapped extensively by the facial process of the maxilla. The foramen of the nasolacrimal duct has eroded the prefrontal along its anteroventral margin and the dorsal margin of the facial process of the maxilla; the nasal abuts the foramen but is eroded minimally, if at all. The maxillary bone is saber-like in lateral view, not cleaver-like as in many other Chiropterotriton. Its posterior, edentulous portion comprises about $60 \%$ of the length of the bone. There are four maxillary teeth on each side and two premaxillary teeth. The teeth are thin and poorly developed. The orbitosphenoid is very thin and delicate. It is solidly articulated to the parasphenoid but weakly articulated to the frontal and parietal.

A prominent bony ridge overlies the anterior semicircular canal dorsally. It is derived from the posterolateral portion of the parietal bone and the anteromedial portion of the otic capsule. An additional, crest-like spur emerges at right angles from this crest and is directed posterolaterally. A second ridge similarly overlies the posterior semicircular canal. The squamosal bone is robust and roughly triangular. A well-developed, spine-like tab on the ventrolateral margin of each parietal is sharply reflected ventromedially and extends nearly the full vertical extent of the orbitosphenoid. The quadrate is small and inconspicuous and incompletely ossified. There is a stubby, stout stylus on the columella, with a limited free portion. Paired vomers are weakly ossified; they approach one another across the midline posterior to the internasal fontanelle but do not articulate. Preorbital processes are needle-likethin and elongate. There are four vomerine teeth on each side; one tooth is deployed at the base of the preorbital process, but only on the left side. The parasphenoid bone is relatively wide anteriorly. Each lateral edge is sculpted by a deep notch opposite the jaw articulation. Paired parasphenoid tooth patches are widely separated across the midline; each contains approximately 
188350 teeth. The mandible is stout. The articular is well ossified. The prearticular is very thin in its 1884 central portion but has a moderately high coronoid process. There are eight teeth on each dentary 1885 bone. The posterior teeth are sharply recurved and needle-like.

Digital formulae are 1-2-3-2 on each side. Phalanges appear to be slightly thinner than in other Chiropterotriton. There is a slightly expanded knob at the tip of each terminal phalanx of digits $2-4$. Mesopodial cartilages are not mineralized.

1889 Distribution and ecology: Chiropterotriton lavae is known only from forested areas between the towns of Toxtlacoaya and La Joya, along the road from Perote to Xalapa, Veracruz, Mexico. It occurs in bromeliads in the cloud forest and has been found in somewhat disturbed habitat in and around La Joya. This narrowly distributed species is known only between 2000 and 2200 masl.

Remarks: As part of the redescription of this species, we examined the holotype and part of the series of paratypes at the Field Museum of Natural History. The portion of the type series examined corresponds closely in morphology to the specimens that we examined.

There has long been a suspicion that two species of Chiropterotriton occur in the vicinity of La Joya. For example, Smith and Taylor (1948) report Chiropterotriton chiropterus (almost certainly not that species) from Toxtlacoaya, and they also report $C$. lavae from that site. This small village is at the western edge of La Joya. Darda (1994) also reports two species from La

1900 Joya, C. lavae and his new species $\mathrm{E}$ (which we tentatively assign to C. totonacus in this paper).

1901 We have only found one species in the La Joya region.

1902 Conservation Status: Chiropterotriton lavae is designated as Critically Endangered by the most recent IUCN Red List of Threatened Species (IUCN SSC Amphibian Specialist Group, 2016).

1904 Much of the habitat where it occurs is highly disturbed or has been converted to pasture, but this 1905 species remains relatively common even in disturbed forest where there are bromeliads.

\section{DISCUSSION}

Since its initial designation by Taylor (1944), Chiropterotriton has proven to be a problematic taxon. As originally conceived, the genus contained small montane species of tropical salamanders with broad hands and feet and the outermost digit relatively well developed. Species ranged from terrestrial to arboreal and occurred at relatively high elevations $(9,000$ to 11,000 feet, or roughly 2750 to $3350 \mathrm{~m}$ ). With a largely Mexican distribution, the initial ten species nevertheless extended geographically to Honduras. Later, species from as far south as Costa Rica were added to the genus. Today, the taxon is restricted to Mexico, north and west of the Isthmus of Tehuantepec but mainly in eastern Mexico (as far west as southeastern Coahuila, central San Luis Potosi and Queretaro, and western Distrito Federal and Morelos). The known elevational range is both lower (to about $690 \mathrm{~m}$ below Xicotepec de Juarez, Veracruz) and higher (to at least $4015 \mathrm{~m}$ on Cofre de Perote) than was known when Taylor worked. Species further to the south once considered congeneric are now assigned to the distantly related genera Cryptotriton, Dendrotriton and Nototriton. While most species are small, C. magnipes reaches about $60 \mathrm{~mm}$ SVL. Darda's (1994) southern group is the most taxonomically difficult group in the genus, and even after our description of four new members of it herein (C. casasi stands out as morphologically unique among the taxa named, and we can't determine at this time to which group it belongs) there is still taxonomic work remaining. Moreover, opportunities exist for additional research investigations, especially cytological. Chromosomal heteromorphism is reported for a few species of Chiropterotriton, including potential sex chromosomes and 
1926 supernumerary chromosomes (Sessions and Kezer 1991). Similarly, genome size has been

1927

1928

1929

1930

1931

1932

1933

1934

1935

1936

1937

1938

1939

1940

1941

1942

1943

1944

1945

1946

1947

1948

1949

1950

1951

1952

1953

1954

1955

1956

1957

1958

1959

1960

1961

1962

1963

1964

1965

1966

1967

1968

1969

1970

1971

studied in only four species. Known values are at the smaller end of the size range for the tropical salamander radiation; average C-value per species ranges from 24.7 to $28.5 \mathrm{pg}$ DNA (Sessions and Kezer 1991).

Despite the passage of nearly fifty years between the description of $C$. magnipes and $C$. miquihuanus, it has long been known based on both morphological and molecular evidence that a great deal of additional diversity exists within the genus (Rabb, 1958; Darda, 1994; Parra-Olea, 2003). The recent descriptions of three species identified as distinct in previous morphological or molecular analyses (C. chico, C. cieloensis and C. infernalis) went some way towards formalizing the known but undescribed diversity of Chiropterotriton, while the descriptions of three species more not included in previous analyses (C. aureus, C. miquihuanus, and C. nubilus) showed that there is still previously undocumented diversity left to discover. Of the five species we describe here, four were previously identified as distinct, while the fifth (C. casasi) has not been included in any previous analysis. These five species add to the already high diversity of the eastern portion of the Trans-Mexican Volcanic Belt (TMVB).

Using allozyme data, Darda (1994) provided the first in-depth taxonomic study of the genus Chiropterotriton that included molecular data. Darda's C. chiropterus complex (the southern clade) was formed by C. chiropterus (represented in his study by sp. E from La Joya, Veracruz) and C. orculus (represented by sp. G from Chignahuapan, Puebla), plus nine undescribed taxa: $C$. sp A, $C$. sp B, and $C$. sp F, from Puebla; $C$. sp C, $C$. sp D, $C$. sp H, and $C$. sp I from Veracruz; and $C$. sp. J and $C$. sp. K from Oaxaca. Once sequences of mitochondrial genes became available, Parra-Olea (2003) defined the type localities for C. chiropterus and $C$. orculus. Parra-Olea (2003) assigned the name C. chiropterus to populations from Huatusco, Veracruz leaving Darda's sp. E as an undescribed species. She also assigned the name $C$. orculus to populations from the central region of the Trans Mexican Volcanic belt including Darda's sp. A and sp. B, indicating that sp. $G$ from Chignahuapan might represent an undescribed taxon. No further taxonomic work was performed on this complex until now. Based on our analyses including molecular and morphological data, here, we describe four of these taxa: C. totonacus (sp. E from La Joya Veracruz), C. melipona (sp. F from Xicotepec, Veracruz), C. perotensis (sp. $\mathrm{H}$ and sp. D from Las Vigas, Veracruz) and C. ceronorum (sp. I from Santa Cruz Texmalaquilla, Puebla). We assign $C$. sp J from La Esperanza, Oaxaca as part of $C$. chiropterus.

Phylogenetic evidence, based first on allozyme data (Darda, 1994) and continuing with mtDNA data from the work of Parra-Olea (2003) to the present study has been indispensable to working out species limits within the genus. One of the most problematic taxonomic issues with the genus Chiroperotriton was the status of $C$. chiropterus. The fact that the original description contained little morphological information, combined with an imprecise type locality and lost holotype, made assignment of populations to this species difficult. At different times, this name has been applied to populations ranging from Tamaulipas south through San Luis Potosí, Querétaro, Hidalgo, and Veracruz. Furthermore, the species is relatively generalized in morphology, resembling a number of other small to medium-sized members of the genus. Our designation of a neotype formalized the assignment of the name $C$. chiropterus for populations from the region of Huatusco, Veracruz, following Parra-Olea (2003). Inclusion of samples from Huatusco in both phylogenetic and morphological analyses allowed us to distinguish several of the new species from the eastern edge of the TMVB. Furthermore, while Parra-Olea (2003) restricted C. chiropterus to the vicinity of Huatusco, we now understand that it ranges south to northern Oaxaca. Rather than being microendemic, it now has one of the largest ranges of any

Peer) reviewing PDF | (2019:11:43498:1:1:NEW 18 Feb 2020) 
1972 Chiropterotriton. Similarly, while Darda (1994) restricted C. orculus to a single population

1973 based on allozyme data, our results support the status of $C$. orculus as a more widely ranging

1974 species throughout the eastern TMVB.

1975 Of the species identified as undescribed in previous analyses (Darda, 1994; Parra-Olea,

1976 2003), only Chiropterotriton sp. C, sp. G, and sp. K have not been either described or assigned to

1977 an existing species. We believe that $C$. sp. C (from Puerto del Aire, Veracruz) likely represents a

1978 distinct species but currently lack sufficient material to describe it. Major declines in salamander

1979 abundance have occurred at this site (Rovito et al., 2009) and no Chiropterotriton have been

1980 found in recent years. Chiropterotriton sp. G is similar to C. orculus in external morphology and

1981 was assigned that species by Darda (1994), but Parra-Olea (2003) reversed this decision and

1982 applied the name C. orculus to populations around Mexico City. Additional morphological

1983 analyses are necessary to determine if $C$. sp. G represents a distinct species or can be assigned to

1984 the wider-ranging C. orculus. The case of C. sp. K, however, is more difficult. This species,

1985 collected only once in 1980, has not been seen over the course of many visits to Cerro San

1986 Felipe, Oaxaca. While it is possible that the locality is in error, many other species at this site

1987 have undergone catastrophic declines (Parra-Olea et al., 1999; Rovito et al., 2009).

1988 Chiropterotriton sp. K may be present on Cerro San Felipe at greatly diminished abundance, or it 1989 may simply exist on a part of the mountain that has not been checked on subsequent visits; the

1990 locality of the known specimens is not specific enough to determine exactly where they were

1991 collected. Concerted field efforts covering different parts of Cerro San Felipe are needed to

1992 confirm that $C$. sp. K does indeed exist at the locality. While the descriptions of $C$. perotensis

1993 (sp. D and sp. H), C. totonacus (sp. E), C. ceronorum (sp. I) and C. melipona (sp. F), together

1994 with the assignment of $C$. sp. J to $C$. chiropterus, nearly deal with all the identified but

1995 undescribed diversity within the genus, we continue to discover populations that likely represent

1996 additional, undescribed species of Chiropterotriton from eastern portions of the TMVB. A final

1997 issue is the status of a population from the Sierra Madre del Sur of Oaxaca, known from a single

1998

1999

2000

2001

2002

2003

2004

2005

2006

2007

2008

2009

2010

2011

2012

2013

2014

2015

2016

2017

long-preserved specimen in the American Museum of Natural History (Darda, 1994)

These five new species increase the content of Chiropterotriton from 18 to 23. This

represents a considerable increase to the somewhat slow but steady rise in species descriptions

trajectory that began in the 1980s when molecular data became readily available. With the use of protein electrophoresis data, 19 new species of salamanders were described from Mexico (Hanken and Wake, 1994, 1998, 2001; Hanken et al., 1999) and with the use of mitochondrial markers 31 new species have been described from Mexico since 2001 (Parra-Olea et al., 2001, 2002, 2004, 2004b, 2005, 2005b, 2010, 2016; Brodie et al., 2002; Canseco-Márquez \& ParraOlea, 2003; Canseco-Márquez \& Gutiérrez-Mayen, 2005; Rovito et al., 2012, 2015b; Rovito \& Parra-Olea, 2015; García-Castillo et al., 2017, 2018; Sandoval-Comte et al., 2017). Thus, almost $40 \%$ of Mexican bolitoglossines have been described using molecular characters in combination with morphological and ecological traits. The number of described species in Chiropterotriton alone has nearly doubled over the course of five years, and we expect that additional fieldwork in the TMVB and Sierra Madre Oriental will reveal additional species.

\section{CONCLUSSIONS}

The genus Chiropterotriton, an endemic group of Mexican salamanders has been a taxonomic challenge to researchers for many years. Previously published molecular data indicated that a number of undescribed species were present, but lack of a thorough morphological analysis had stalled the advances in the description of the diversity of this group. This paper is a big step 
2018 towards this goal. Herein we describe 5 new species of Chiropterotriton and re described two 2019 more, based on molecular and morphological data, increasing considerably the known diversity 2020 of the genus. However, more work is still needed for the description of several more taxa when 2021 additional data is available.

2022

2023

\section{REFERENCES}

2025

2026

2027

2028

2029

2030

2031

2032

2033

2034

2035

2036

2037

2038

2039

2040

2041

2042

2043

2044

2045

2046

2047

2048

2049

2050

2051

2052

2053

2054

2055

2056

Brodie Jr ED, Mendelson III JR, Campbell JA. 2002. Taxonomic revision of the Mexican plethodontid salamanders of the genus Lineatriton, with the description of two new species. Herpetologica, 58: 194-204.

Canseco-Marquez L, Parra-Olea G. 2003. A new species of Pseudoeurycea (Caudata: Plethodontidae) from northern Oaxaca, Mexico. Herpetological Journal, 13: 21-26.

Canseco-Márquez L, Gutiérrez-Mayén G. 2005. New species of Pseudoeurycea (Caudata: Plethodontidae) from the mountains of the Mixteca region of Oaxaca, Mexico. Journal of Herpetology, 39: 181-186.

Campbell JA, Streicher JW, Cox CL, Brodie ED. 2014. A new salamander of the genus Chiropterotriton (Caudata: Plethodontidae) from the Sierra Madre Oriental of Tamaulipas, Mexico. South American Journal of Herpetology, 9: 228-235.

Cope ED. 1863. On Trachycephalus, Scaphiopus and other Batrachia. Proceedings of the Academy of Natural Sciences of Philadelphia, 15: 43-54.

Cope ED. 1865. Third contribution to the herpetology of tropical America. Proceedings of the Academy of Natural Sciences of Philadelphia, 17: 185-198.

Cope ED. 1869. A review of the species of Plethodontidae and Desmognathidae. Proceedings of the Academy of Natural Sciences of Philadelphia, 21: 93-118.

Darda D. 1994. Allozyme variation and morphological evolution among Mexican salamanders of the genus Chiropterotriton (Caudata: Plethodontidae). Herpetologica, 50: 164-187.

Darda D, Wake DB. 2015. Osteological variation among extreme morphological forms in the Mexican salamander genus Chiropterotriton (Amphibia: Plethodontidae): morphological evolution and homoplasy. PLOS ONE, 10: e0127248.

Edgar RC. 2004. MUSCLE: A multiple sequence alignment method with reduced time and space complexity. BMC Bioinformatics, 5: 1-19.

Frost D. 2019. Amphibian Species of the world: An Online Reference. Version 6.0

(October 7th, 2019) electronic data base accessible at http://research.amnh.org/vz/herpetology/amphibia/index.php. American Museum of Natural History, NY, USA.

Gadow H. 1905. The distribution of Mexican amphibians and reptiles. In Proceedings of the Zoological Society of London, 1905: 191-244. 
2057

2058

2059

2060

2061

2062

2063

2064

2065

2066

2067

2068

2069

2070

2071

2072

2073

2074

2075

2076

2077

2078

2079

2080

2081

2082

2083

2084

2085

2086

2087

2088

2089

2090

2091

2092

2093

2094

2095

2096

2097

García-Castillo MG, Rovito SM, Wake DB, Parra-Olea G. 2017. A new terrestrial species of Chiropterotriton (Caudata: Plethodontidae) from central Mexico. Zootaxa, 4363: 489-505.

García-Castillo MG, Soto-Pozos ÁF, Aguilar-López JL, Pineda, E, Parra-Olea G. 2018. Two new species of Chiropterotriton (Caudata: Plethodontidae) from central Veracruz, Mexico. Amphibian \& Reptile Conservation, 12(2): 37-54.

Hanken J, Wake DB. 1994. Five new species of minute salamanders, genus Thorius (Caudata: Plethodontidae), from northern Oaxaca, Mexico. Copeia, 1994: 573-590.

Hanken J, Wake DB. 1998. Biology of tiny animals: systematics of the minute salamanders (Thorius: Plethodontidae) from Veracruz and Puebla, Mexico, with descriptions of five new species. Copeia, 1998: 312-345.

Hanken J, Wake DB. 2001. A seventh species of minute salamander (Thorius: Plethodontidae) from the Sierra de Juárez, Oaxaca, México. Herpetologica, 57: 515-523.

Hanken J, Wake DB, Freeman HL. 1999. Three new species of minute salamanders (Thorius: Plethodontidae) from Guerrero, Mexico, including the report of a novel dental polymorphism in urodeles. Copeia, 1999: 917-931.

Huelsenbeck JP, Ronquist F. 2001. MrBayes: Bayesian inference of phylogenetic trees. Bioinformatics, 17: 754- 755.

IUCN. 2012. IUCN Red List Categories and Criteria: Version 3.1. Second edition. Gland, Switzerland and Cambridge, UK: IUCN. iv, 32pp.

IUCN SSC Amphibian Specialist Group. 2016. Chiropterotriton lavae. The IUCN Red List of Threatened Species 2016: e.T59226A53978402. DOI 10.2305/IUCN.UK.20161.RLTS.T59226A53978402.en.

Köhler G. 2012. Color Catalogue for Field Biologists. Herpeton, Offenbach, Germany, $49 \mathrm{pp}$.

Lanfear R, Calcott B, Ho SYW, Guindon S. 2012. PartitionFinder: Combined selection of partitioning schemes and substitution models for phylogenetic analyses. Molecular Biology and Evolution, 29: 1695-1701.

Liner EA, Casas-Andreu G. 2008. Standard Spanish, English and scientific names of the amphibians and reptiles of Mexico. Herpetological Circular, 38: 1-162.

Lynch JF, Wake DB. 1989. Two new species of Pseudoeurycea (Amphibia: Caudata) from Oaxaca, Mexico. Contributions in Science, Natural History Museum of Los Angeles County, 411: 11-22.

Maddison WP, Maddison DR. 2018. Mesquite: a modular system for evolutionary analysis. Version $3.40 \mathrm{http}: / /$ mesquiteproject.org.

Maxson LR, Wake DB. 1981. Albumin evolution and its phylogenetic implications in the plethodontid salamander genera Pseudoeurycea and Chiropterotriton. Herpetologica, 37: 109-117.

Meyer CP. 2003. Molecular systematics of cowries (Gastropoda: Cypraeidae) and diversification patterns in the tropics. Biological Journal of the Linnean Society, 79: 401459

Peer) reviewing PDF | (2019:11:43498:1:1:NEW 18 Feb 2020) 
2098

2099

2100

2101

2102

2103

2104

2105

2106

2107

2108

2109

2110

2111

2112

2113

2114

2115

2116

2117

2118

2119

2120

2121

2122

2123

2124

2125

2126

2127

2128

2129

2130

2131

2132

2133

2134

2135

2136

2137

2138

Miller MA, Pfeiffer W, Schwartz T. 2010. Creating the CIPRES Science Gateway for inference of large phylogenetic trees. Gateway Computing Environments Workshop, GCE 2010.

Papenfuss TJ, Wake DB. 1987. Two new species of plethodontid salamanders (genus Nototriton) from Mexico. Acta Zoologica Mexicana, 21: 1-16.

Parra-Olea G, García-París M, Wake DB. 1999. Status of some populations of Mexican salamanders (Amphibia: Plethodontidae). Revista de Biología Tropical, 47: 217-223.

Parra-Olea G, Papenfuss TJ, Wake DB. 2001. New species of lungless salamanders of the genus Pseudoeurycea (Amphibia: Caudata: Plethodontidae) from Veracruz, Mexico. Scientific Papers, Natural History Museum, University of Kansas, 20:1-9.

Parra-Olea G, García-París M, Wake DB. 2002. Phylogenetic relationships among the salamanders of the Bolitoglossa macrinii species group (Amphibia: Plethodontidae), with descriptions of two new species from Oaxaca (Mexico). Journal of Herpetology, 36: 356-366.

Parra-Olea G. 2003. Phylogenetic relationships of the genus Chiropterotriton (Caudata: Plethodontidae) based on $16 \mathrm{~S}$ ribosomal mtDNA. Canadian Journal of Zoology, 81: 2048-2060.

Parra-Olea G, Canseco-Márquez L, García-París M. 2004. A morphologically distinct new species of Pseudoeurycea(Caudata: Plethodontidae) from the Sierra Madre Oriental of Puebla, Mexico. Herpetologica, 60: 478-484.

Parra-Olea G, García-París M, Hanken J, Wake DB. 2004b. A new species of arboreal salamander (Caudata: Plethodontidae: Pseudoeurycea) from the mountains of Oaxaca, Mexico. Journal of Natural History, 38: 2119-2131.

Parra-Olea G, García-París M, Hanken J, Wake DB. 2005. Two new species of Pseudoeurycea (Caudata: Plethodontidae) from the mountains of northern Oaxaca, Mexico. Copeia, 2005: 461-469.

Parra-Olea G, García-París M, Papenfuss TJ, Wake DB. 2005b. Systematics of the Pseudoeurycea bellii (Caudata: Plethodontidae) species complex.

Herpetologica, 61: 145-158.

Parra-Olea G, Wake D. 2008. Chiropterotriton orculus. The IUCN Red List of Threatened Species 2008: e.T59230A11903382. DOI 10.2305/IUCN.UK.2008.RLTS.T59230A11903382.en.

Parra-Olea G, Wake D, Hanken J. 2008. Chiropterotriton chiropterus. The IUCN Red List of Threatened Species 2008: e.T59222A11901075.

Parra-Olea G, Rovito SM, Marquez-Valdelamar L, Cruz G, Murrieta-Galindo R, Wake, DB. 2010. A new species of Pseudoeurycea from the cloud forest in Veracruz, México. Zootaxa, 27: 57-68.

Parra-Olea G, Rovito SM, García-París M, Maisano JA, Wake DB, Hanken J. 2016. Biology of tiny animals: three new species of minute salamanders (Plethodontidae: Thorius) from Oaxaca, Mexico. PeerJ 4: e2694. 
2139

2140

2141

2142

2143

2144

2145

2146

2147

2148

2149

2150

2151

2152

2153

2154

2155

2156

2157

2158

2159

2160

2161

2162

2163

2164

2165

2166

2167

2168

2169

2170

2171

2172

2173

2174

2175

2176

2177

2178

Rabb GB. 1958. On certain Mexican salamanders of the plethodontid genus Chiropterotriton. Occasional Papers of the Museum of Zoology, University of Michigan, 587: $1-37$.

Rabb GB. 1965. A new salamander of the genus Chiropterotriton (Caudata: Plethodontidae) from Mexico. Breviora, 235: 1-8.

Raffaëlli, J. 2007. Les Urodèles du Monde. France: Penclen editions, 377 pp.

Raffaëlli, J. 2013. Les Urodèles du Monde. Deuxieme Ed. France: Penclen editions, $473 \mathrm{pp}$.

Rambaut A, Drummond AJ, Xie D, Baele G, Suchard MA. 2018. Posterior

summarisation in Bayesian phylogenetics using Tracer 1.7. Systematic Biology. syy032. doi:10.1093/sysbio/syy032.

Rovito SM, Parra-Olea G, Vásquez-Almazán CR, Papenfuss TJ, Wake DB. 2009. Dramatic declines in neotropical salamander populations are an important part of the global amphibian crisis. Proceedings of the National Academy of Sciences, 106: 32313236.

Rovito SM, Parra-Olea G, Lee D, Wake DB. 2012. A new species of Bolitoglossa (Amphibia, Caudata) from the Sierra de Juárez, Oaxaca, Mexico. ZooKeys 185: 55. Rovito SM, Parra-Olea G. 2015. Two new species of Chiropterotriton (Caudata: Plethodontidae) from northern Mexico. Zootaxa 4048: 57-74.

Rovito SM, Parra-Olea G, Recuero E, Wake DB. 2015. Diversification and biogeographical history of Neotropical plethodontid salamanders. Zoological Journal of the Linnean Society 175: 167-188.

Rovito SM, Vásquez-Almazán CR, Papenfuss TJ, Parra-Olea G, Wake DB. 2015b. Biogeography and evolution of Central American cloud forest salamanders (Caudata: Plethodontidae: Cryptotriton), with the description of a new species. Zoological Journal of the Linnean Society 175: 150-166.

Sandoval-Comte A, Pineda E, Rovito SM, Luría-Manzano R. 2017. A new species of Isthmura (Caudata: Plethodontidae) from the montane cloud forest of central Veracruz, Mexico. Zootaxa 4277: 573-582.

Sessions SK, Kezer J. 1991. Evolutionary cytogenetics of bolitoglossine salamanders (Family Plethodontidae). In: Green DM, Sessions SK, eds. Amphibian Cytogenetics and Evolution. San Diego, Academic Press, 89-130.

Smith HM, Taylor EH. (1948). An annotated checklist and key to the Amphibia of Mexico. Bulletin of the United States National Museum. 18: 38-46.

Stamatakis A. 2014. RAxML version 8: A tool for phylogenetic analysis and postanalysis of large phylogenies. Bioinformatics, 30: 1312-1313.

Taylor EH. 1942. New Caudata and Salientia from México. University of Kansas Science Bulletin 28: 295-323.

Taylor EH. 1944. The genera of plethodont salamanders in Mexico. The University of Kansas Science Bulletin, 12: 189-232. 
2179

2180

2181

2182

2183

2184

2185

2186

2187

2188

2189

2190

2191

2192

Taylor EH, Smith HM. 1945. Summary of the collections of amphibians made in México under the Walter Rathbone Bacon traveling scholarship. Proceedings of the United States National Museum, 95: 521-613 pp.

Wake DB, Lynch J. 1976. The distribution, ecology, and evolutionary history of plethodontid salamanders in tropical America. Bulletin Natural History Museum Los Angeles County, 25: 1-65.

Wake DB. 1987. Adaptive radiation of salamanders in Middle American cloud forests. Annals of the Missouri Botanical Garden, 74: 242-264.

Wake DB, Papenfuss TJ, Lynch JF. 1992. Distribution of salamanders along elevational transects in Mexico and Guatemala. Tulane Studies in Zoology and Botany, Supplementary Publication, 1: 303-319.

Zhang P, Papenfuss TJ, Wake MH, Qu L, Wake DB. 2008. Phylogeny and biogeography of the family Salamandridae (Amphibia: Caudata) inferred from complete mitochondrial genomes. Molecular Phylogenetics and Evolution, 49: 586-597. 


\section{Figure 1}

Geographic distribution of the genus Chiropterotriton in Mexico

\section{Geographic distribution of the genus Chiropterotriton in Mexico. Numbers}

correspond to the following species: (1) C. priscus; (2) C. miquihuanus; (3) C. infernalis; (4) C.

cieloensis; (5) C. cracens; (6) C. multidentatus (Cd. Maíz); (7) C. multidentatus (Rancho

Borbotón); (8) C. multidentatus (Sierra de Álvarez); (9) C. magnipes; (10) C. mosaueri; (11) C. chondrostega; (12) C. terrestris; (13) C. arboreus (Zacualtipán); (14) C. arboreus (Zilacatipan); (15) C. dimidiatus; (16) C. chico; (17) C. melipona sp. nov. (Xicotepec); (18) C. melipona sp. nov. (Cuetzalan); (19) C. sp. G; (20) C. casasi sp. nov.; (21) C. aureus; (22) C. totonacus sp. nov.; (23) C. lavae; (24) C. nubilus (Tlalnehuayocan); (25) C. nubilus (Coxmatla);(26) C. perotensis sp. nov. (Las Lajas); (27) C. perotensis sp. nov. (Llanillo redondo); (28) C. perotensis sp. nov. (Conejo); (29) C. chiropterus (Huatusco); (30) C. ceronorum sp. nov. (Xometla); (31) C. ceronorum sp. nov. (Texmalaquilla); (32) C. orculus (Amecameca); (33) C. orculus (Amecameca); (34) C. orculus (Ciudad de México); (35) C. orculus (Bosque de Tlalpan); (36) C. orculus (Desierto de los Leones); (37) C. orculus (Ajusco); (38) C. orculus (Lagunas de Zempoala); (39) C. chiropterus (La Esperanza); (40) C. chiropterus (Yolox) and (41) C. sp. K. 


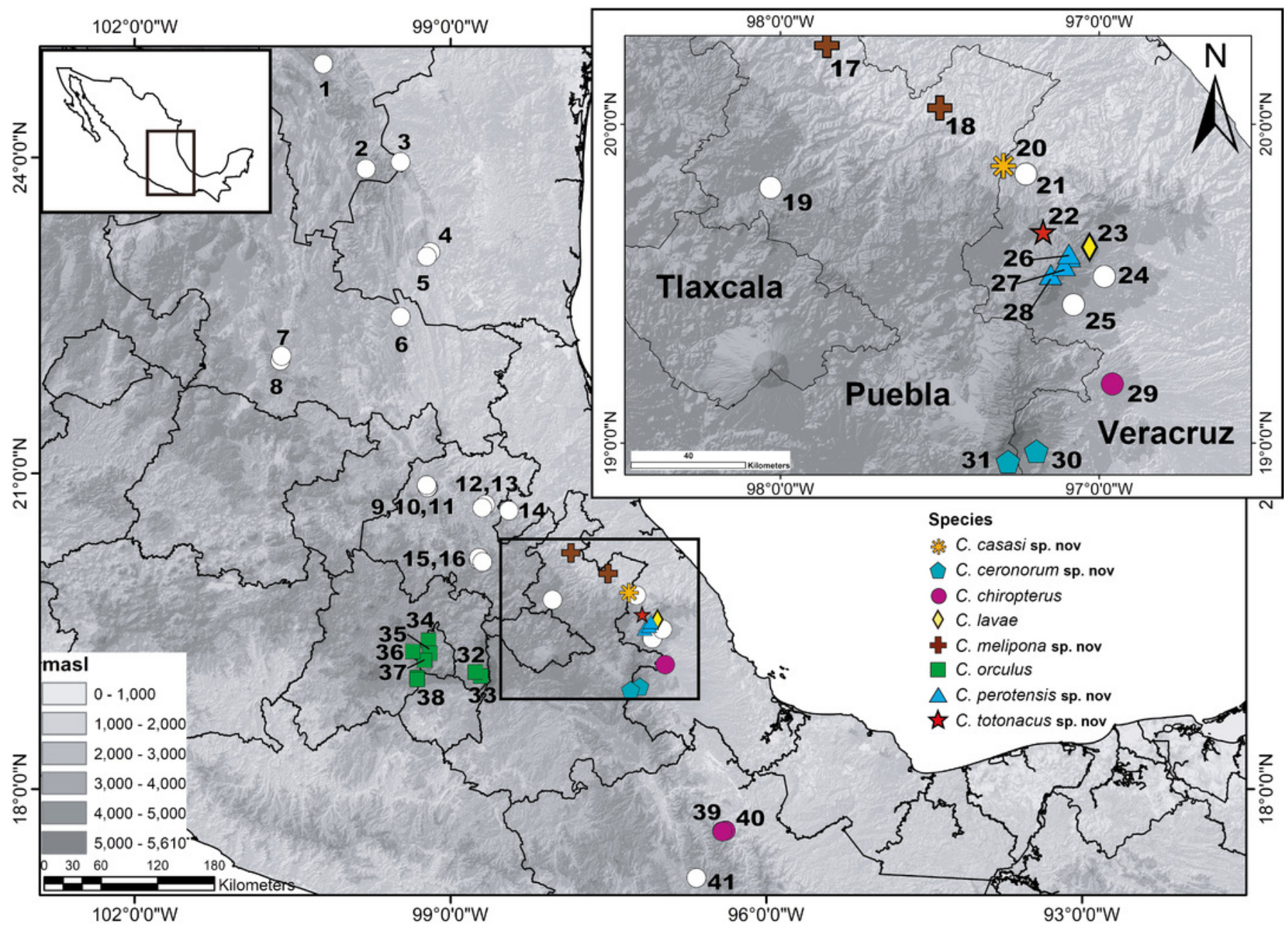




\section{Figure 2}

Skull of the holotype of Chiropterotriton casasi sp. nov. seen in dorsal, ventral and lateral views.

Figure 2: Skull of the holotype of Chiropterotriton casasi sp. nov. seen in (A) dorsal, (B) ventral and (C) lateral views. . Images are derived from a $\mu C T$ scan of MVZ 92874, an adult male. Arrows point to the septomaxillary bone. Abbreviations: AP, ascending process of the premaxilla; $\mathrm{CO}$, columella; $\mathrm{CP}$, coronoid process of the prearticular; $\mathrm{DE}$, dentary; FP, facial process of the maxilla; FR, frontal; MX, maxilla; NA, nasal; NL, foramen of the nasolacrimal duct; OC, otic capsule; OR, orbitosphenoid; PA, parietal; PF, prefrontal; PM, premaxilla; PO, preorbital process of the vomer; PR, prearticular; PS, parasphenoid; QU, quadrate; SQ, squamosal; VO, vomer. Scale bar, $1 \mathrm{~mm}$. 


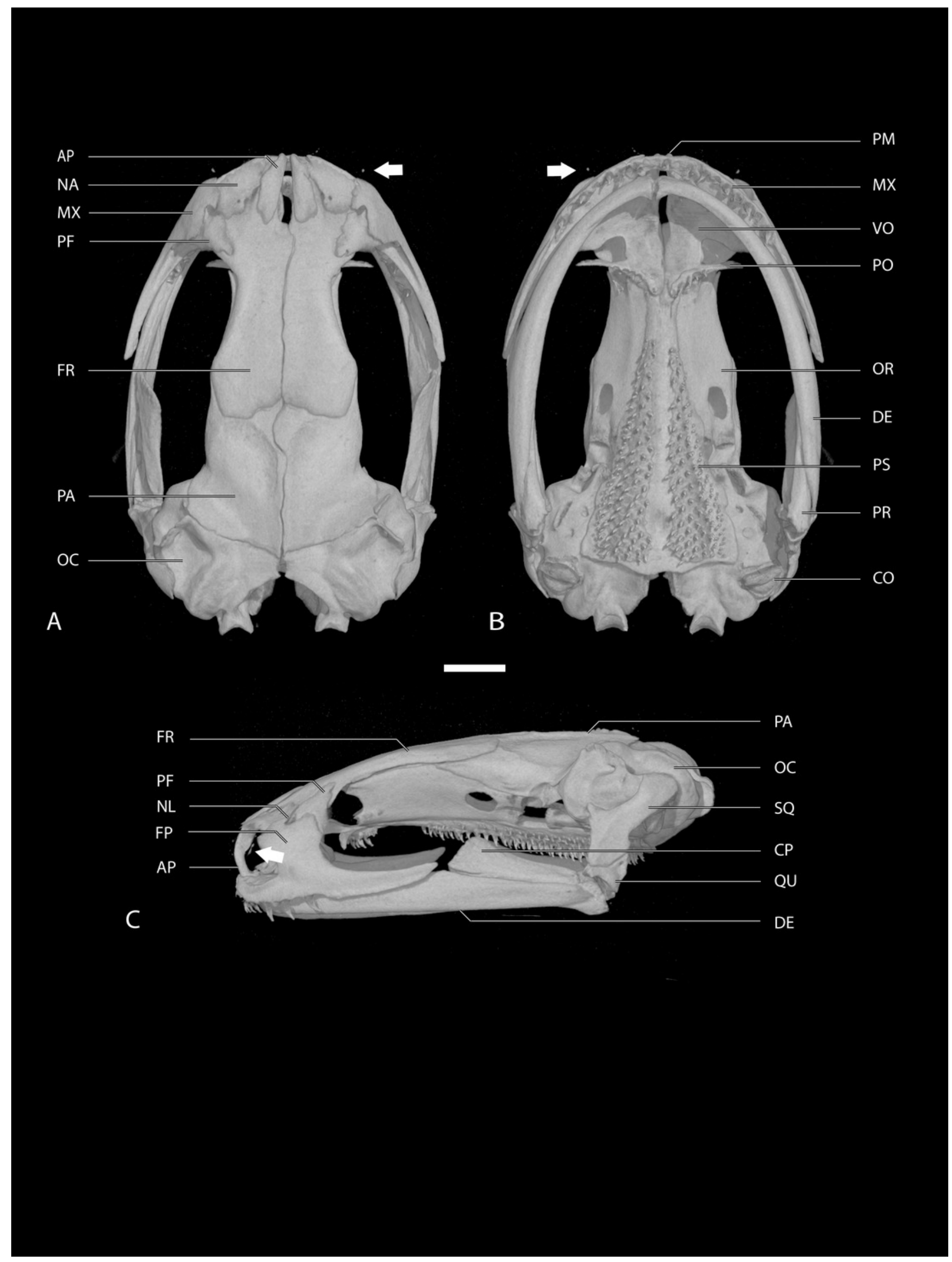




\section{Figure 3}

Maximum likelihood (ML) phylogeny of the genus Chiropterotriton based on two mitochondrial markers

Maximum likelihood (ML) phylogeny of the genus Chiropterotriton based on two mitochondrial markers. Both ML and Bayesian measures of nodal support are indicated by bootstrap proportions (BS; above) and posterior probabilities (PP; below), respectively. Asterisks indicate statistically significant support in both analyses (PP $>0.95$, BS $>70$ ). Numbers in parentheses refer to localities from Figure 1. 
Thorius sp. IBH 30942

Aquiloeurycea cephalica IBH30253

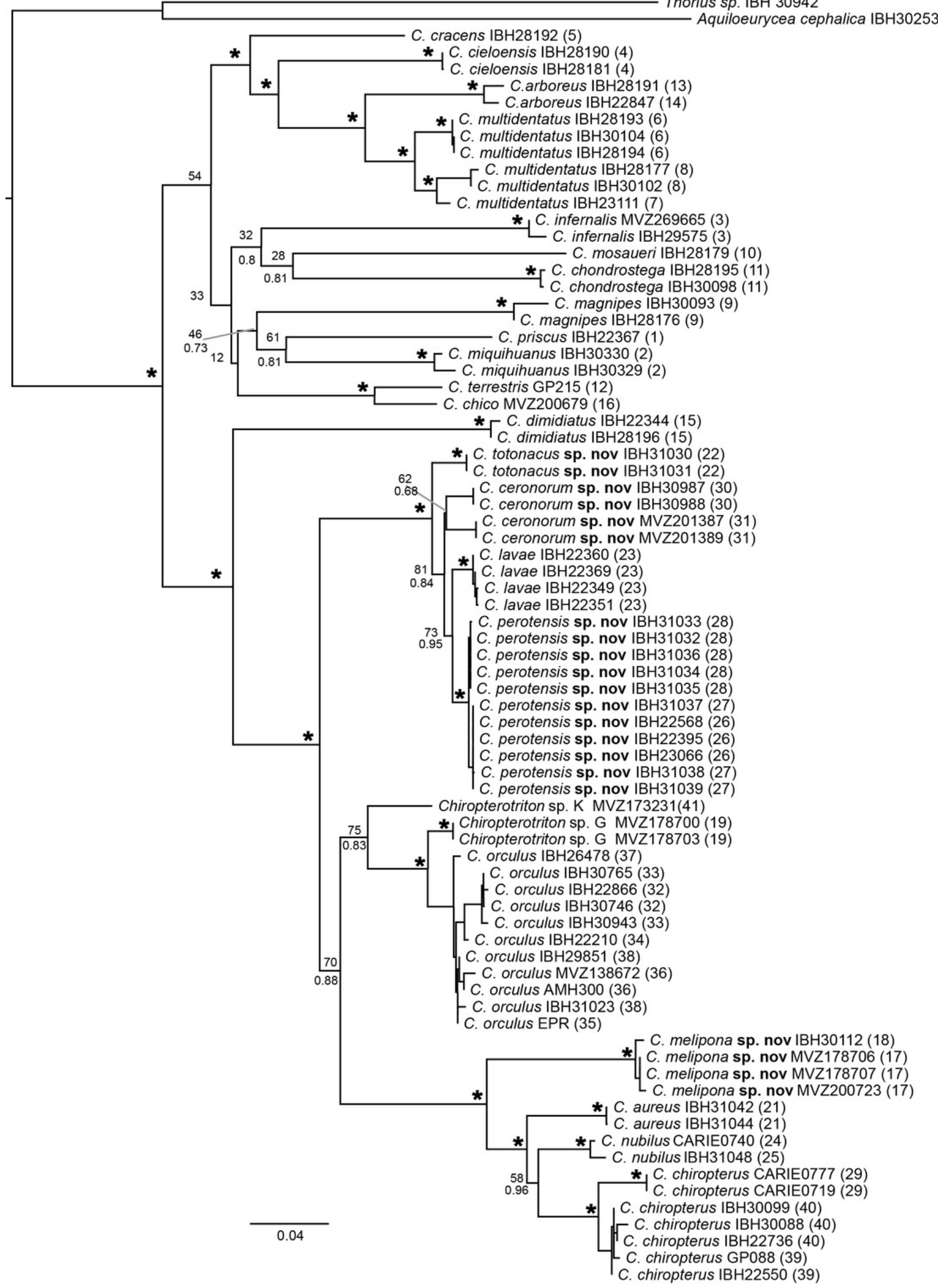


Figure 4

Photographs of heads, hands and feet of preserved specimens of eight species of Chiropterotriton

Figure 4: Photographs of heads, hands and feet of preserved specimens of eight species of Chiropterotriton. (A, B, C) C. ceronorum, holotype, USNM 224212; (D, E, F) C. perotensis, paratype, MVZ 186711; (G, H, I) C. totonacus, holotype, MVZ 163945; (J, K, L) C. melipona, paratype, MVZ 178706; (M, N, O) C. casasi, holotype, MVZ 92874; (P, Q, R) C. chiropterus, neotype, MVZ 85590; (S, T, U) C. orculus, MVZ 138776; (V, W, X) C. lavae, MVZ 106436. Right hands and feet are seen in dorsal view.

A

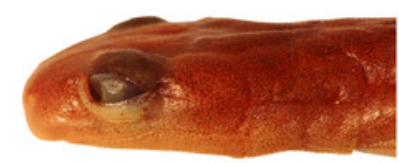

G

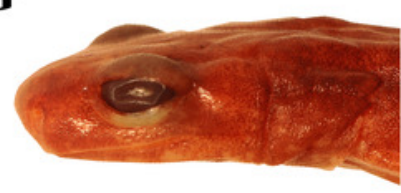

M

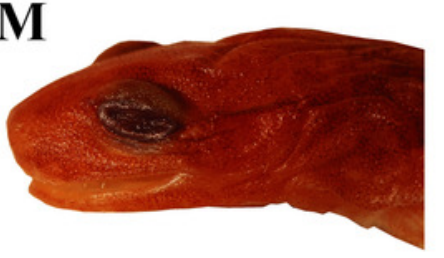

S

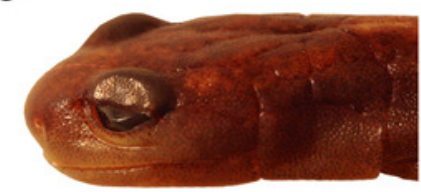

B

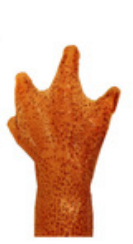

H
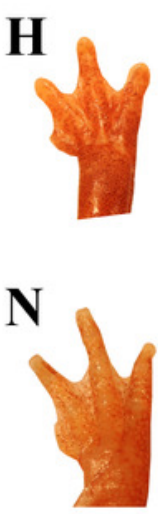

$\mathbf{T}$

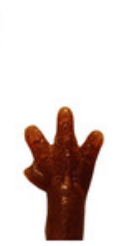

C
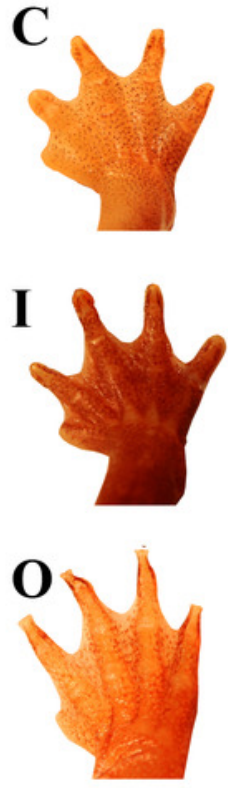

$\mathbf{U}$

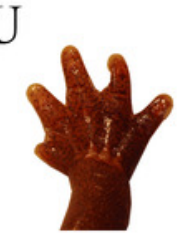

D

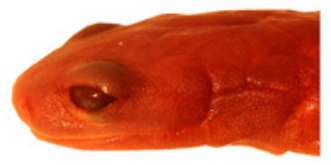

$\mathbf{J}$

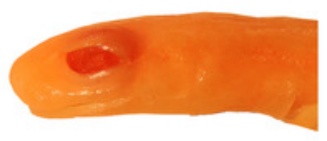

$\mathbf{P}$

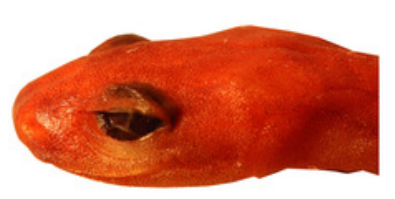

V

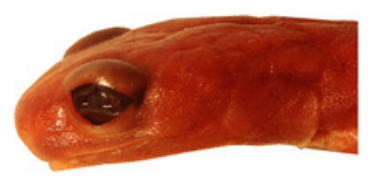

$\mathbf{E}$

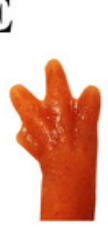

$\mathbf{K}$
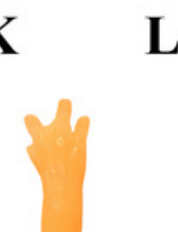

Q

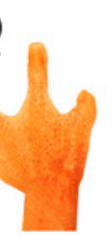

$\mathbf{R}$

W

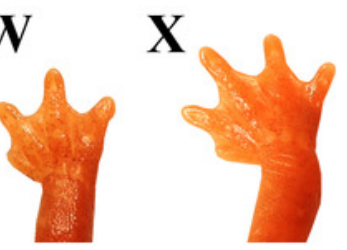

$1 \overline{\mathrm{m} m}$ 
Figure 5

Photographs of live and preserved specimens of eight species of Chiropterotriton.

Photographs of live and preserved specimens of eight species of Chiropterotriton.

(A) C. ceronorum sp. nov., IBH 30988; (B) C. perotensis sp. nov., IBH 30745; (C) C. totonacus

sp. nov., IBH 31031; (D) C. melipona sp. nov., IBH 30112; (E) C. casasi sp. nov., paratype, MVZ 92876; (F) C. chiropterus, CARIE 0719; (G) C. orculus, IBH 30997; (H) C. lavae, IBH 22365. 


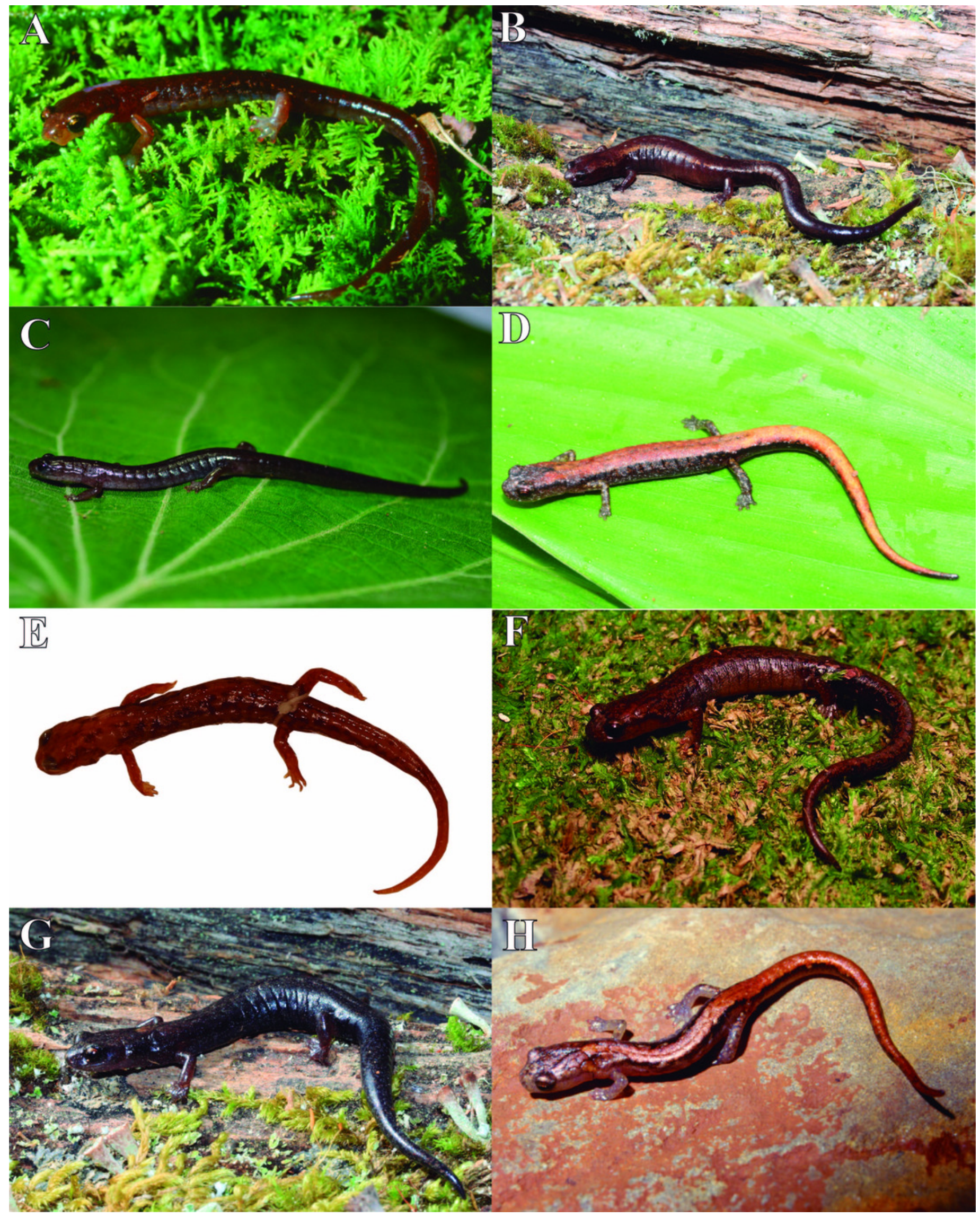




\section{Figure 6}

Skulls of eight Chiropterotriton species seen in dorsal view

Skulls of eight Chiropterotriton species seen in dorsal view. A: C. casasi sp.

nov.-holotype, MVZ 92874, an adult male; B: C. ceronorum sp. nov.-holotype, USNM 224212, an adult male; C: C. lavae-neotype, MVZ 163912, an adult male; D: C. melipona sp. nov.-paratype, MVZ 178706, an adult male; E: C. orculus-neotype, MVZ 138783, an adult male; F: C. perotensis sp. nov. -paratype, MVZ 200693, an adult male; G: C. totonacus sp. nov.-holotype, MVZ 163945, an adult female; H: C. chiropterus-MVZ 85602, an adult male. Arrows point to the prominent frontoparietal fontanelle in the cranial roof in $D$ and $F$, to the unusually narrow ascending processes of the premaxillary bone at the rostral end of the skull in $\mathrm{D}$ and $\mathrm{G}$, and to the tiny septomaxillary bones adjacent to the external nares in $\mathrm{E}$ and $\mathrm{H}$. All skulls are depicted at the same length; scale bar, $1 \mathrm{~mm}$. Anterior is at the top. Images are derived from $\mu \mathrm{CT}$ scans. 


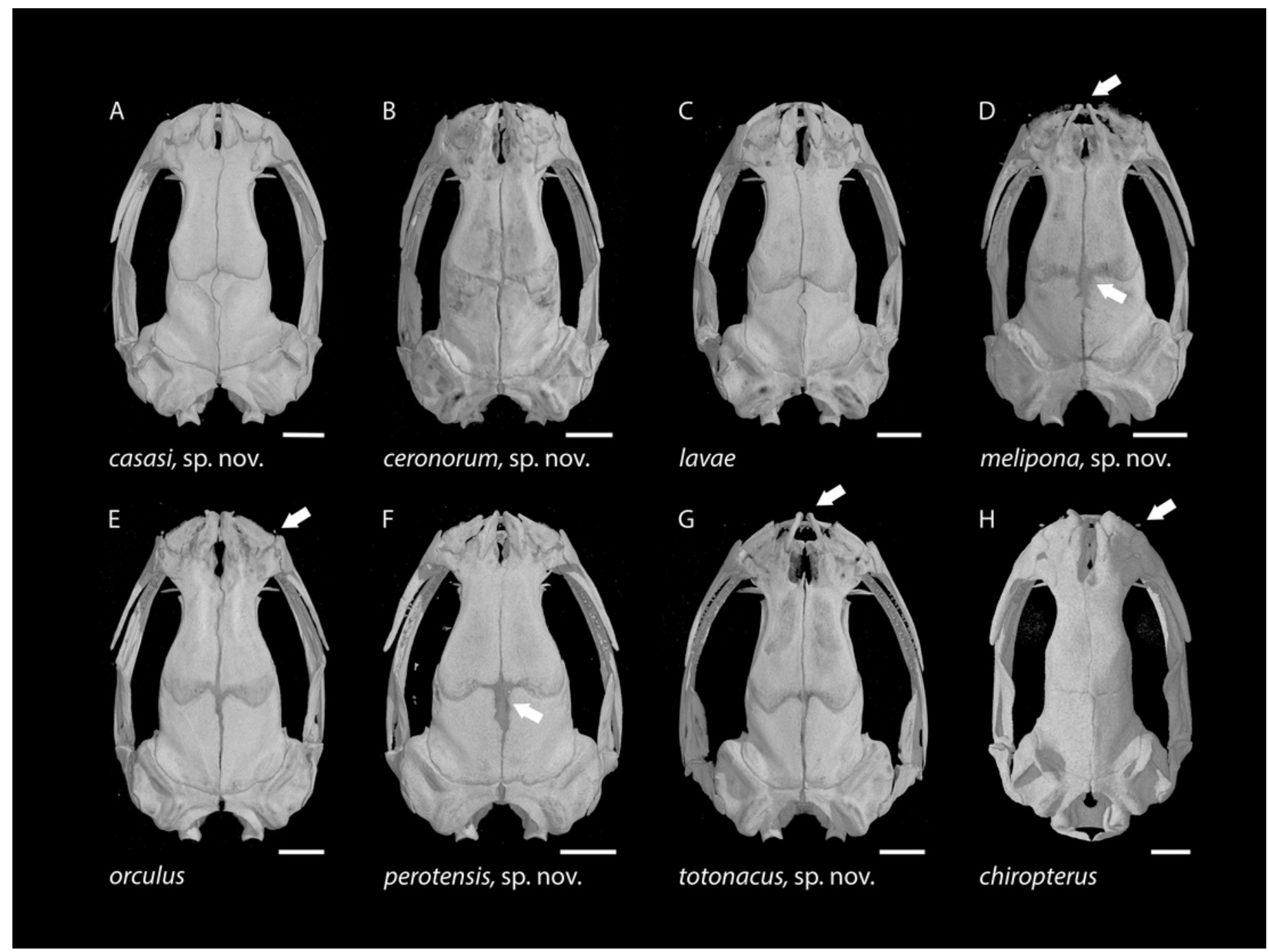




\section{Figure 7}

Skulls of eight Chiropterotriton species seen in ventral view.

Skulls of eight Chiropterotriton species seen in ventral view. A: C. casasi sp.

nov.-holotype, MVZ 92874, an adult male; B: C. ceronorum sp. nov.-holotype, USNM 224212, an adult male; C: C. lavae-neotype, MVZ 163912, an adult male; D: C. melipona sp. nov.-paratype, MVZ 178706, an adult male; E: C. orculus-neotype, MVZ 138783, an adult male; F: C. perotensis sp. nov.-paratype, MVZ 200693, an adult male; G: C. totonacus sp. nov.-holotype, MVZ 163945, an adult female; H: C. chiropterus-MVZ 85602, an adult male. Arrows point to the long versus short preorbital process of the vomer in A and F, respectively; and to the unusually small parasphenoid tooth patch in $\mathrm{C}$ versus the much larger patch in $\mathrm{F}$. All skulls are depicted at the same length; scale bar, $1 \mathrm{~mm}$. Anterior is at the top. Images are derived from $\mu \mathrm{CT}$ scans. 


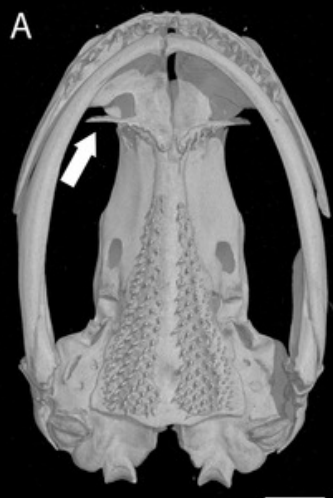

casasi, sp. nov.

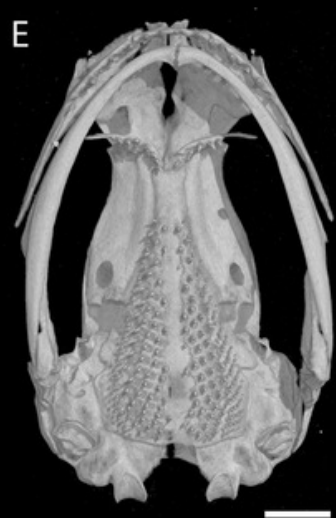

orculus

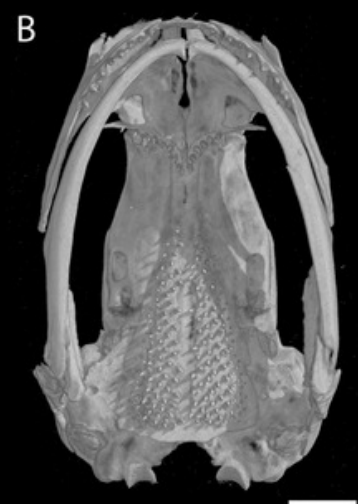

ceronorum, sp. nov.

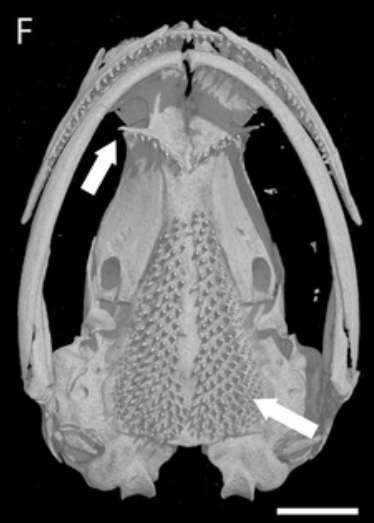

perotensis, sp. nov.

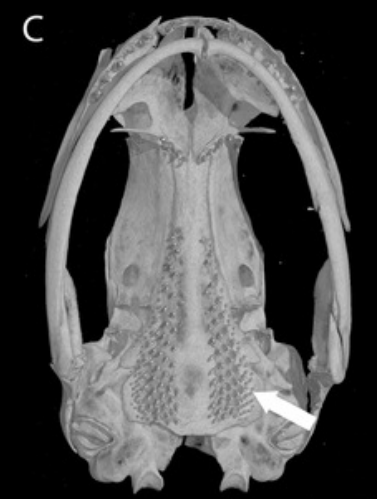

lavae

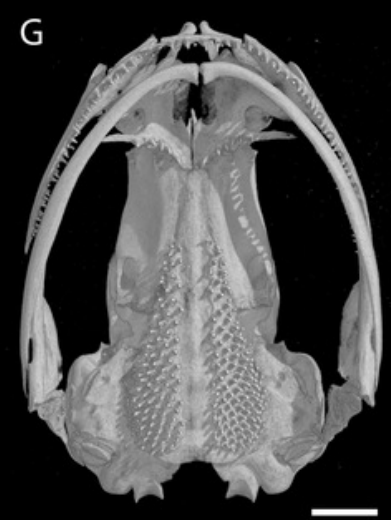

totonacus, sp. nov.

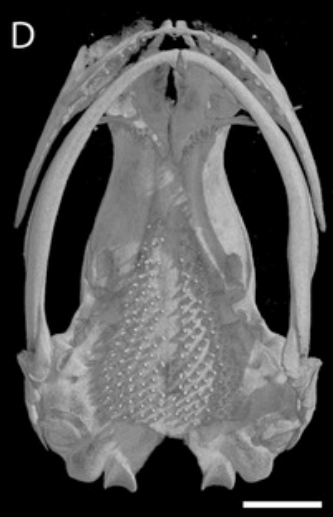

melipona, sp. nov.

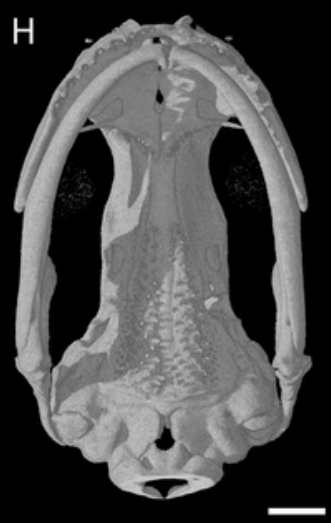

chiropterus 


\section{Figure 8}

Skulls of eight Chiropterotriton species seen in lateral view

Skulls of eight Chiropterotriton species seen in lateral view. A: C. casasi sp.

nov.-holotype, MVZ 92874, an adult male; B: C. ceronorum sp. nov.-holotype, USNM 224212, an adult male; C: C. lavae-neotype, MVZ 163912, an adult male; D: C. melipona sp. nov.-paratype, MVZ 178706, an adult male; E: C. orculus-neotype, MVZ 138783, an adult male; F: C. perotensis sp. nov.-paratype, MVZ 200693, an adult male; G: C. totonacus sp. nov.-holotype, MVZ 163945, an adult female; H: C. chiropterus-MVZ 85602, an adult male. Arrows point to prominent dorsal crests on the otic capsule in $\mathrm{A}, \mathrm{C}$ and $\mathrm{H}$; to the high versus low coronoid process on the prearticular bone of the lower jaw in $C$ and $D$, respectively; to the tiny septomaxillary bones in $\mathrm{B}, \mathrm{E}$ and $\mathrm{H}$; and to the posterior portion of the maxillary bone, which typically is dorsoventrally expanded and edentulous in males (A) versus narrow and toothed in females (G). All skulls are depicted at the same length; scale bar, $1 \mathrm{~mm}$. Anterior is to the left. Images are derived from $\mu \mathrm{CT}$ scans. 

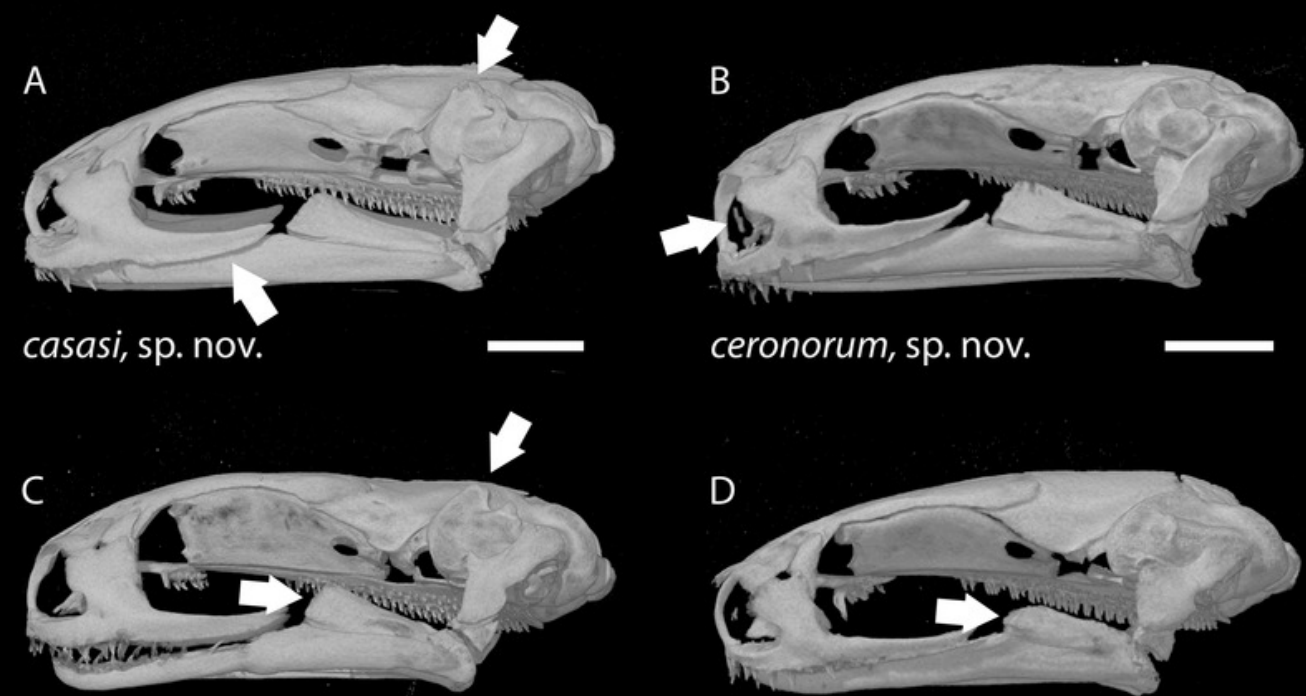

lavae
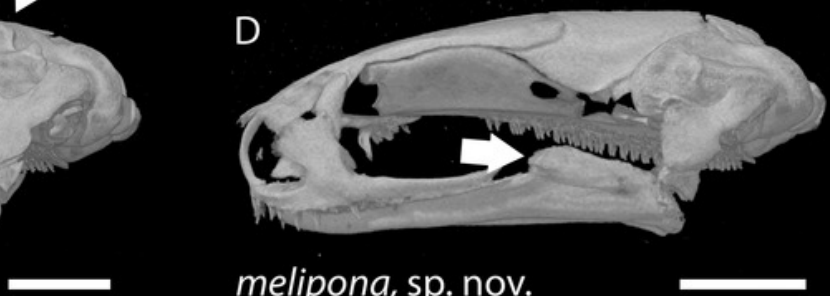

melipona, sp. nov.
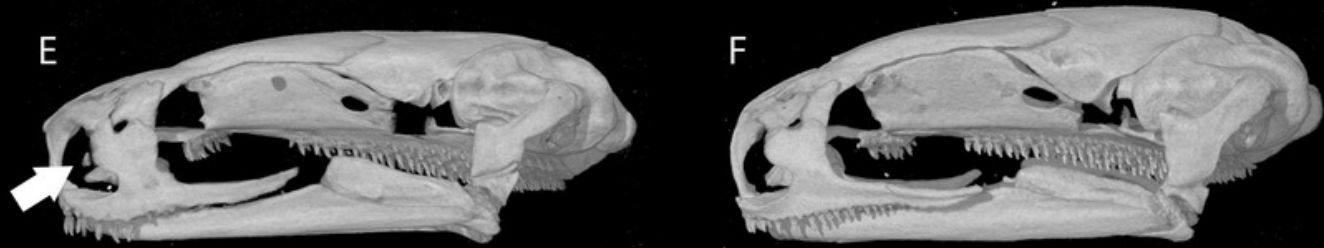

orculus

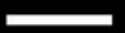

perotensis, sp. nov.

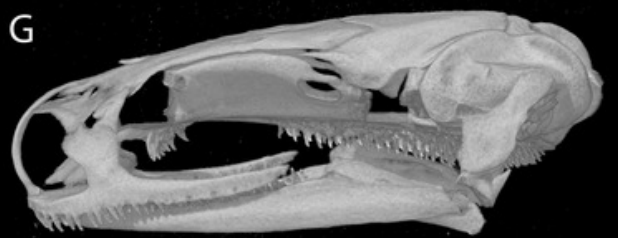

totonacus, sp. nov.

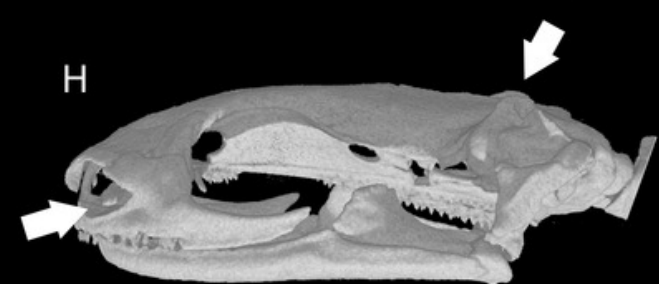

chiropterus 


\section{Table $\mathbf{1}$ (on next page)}

Voucher information and Genbank numbers

Voucher information and Genbank numbers for specimens used for phylogenetic analyses from Colección Nacional de Anfibios y Reptiles, Instituto de Biología, UNAM (IBH), Museum of Vertebrate Zoology (MVZ) and Colección de Referencia de Anfibios y Reptiles del Instituto de Ecología, A. C. Numbers in parentheses correspond to geographic location shown in Figure 1 
1 Table 1. Voucher information and Genbank numbers for specimens used for phylogenetic

2 analyses from Colección Nacional de Anfibios y Reptiles, Instituto de Biología, UNAM (IBH),

3 Museum of Vertebrate Zoology (MVZ) and Colección de Referencia de Anfibios y Reptiles del

4 Instituto de Ecología, A. C. Numbers in parentheses correspond to geographic location shown in

5 Figure 1.

\begin{tabular}{|c|c|c|c|c|}
\hline Species & $\begin{array}{l}\text { Voucher } \\
\text { Number }\end{array}$ & Locality & $\begin{array}{c}16 S \\
\text { Genbank }\end{array}$ & $\begin{array}{c}\text { COI } \\
\text { Genbank }\end{array}$ \\
\hline C. arboreus & IBH 28191 & $\begin{array}{l}\text { Hidalgo: } 6.8 \text { km SW (by rd) of Zacualtipán on road to } \\
\text { Tianguistengo (13) }\end{array}$ & MK335386 & MK335232 \\
\hline C. arboreus & IBH 22847 & Veracruz: 3.2 km S Zilacatipan (14) & MN914712 & - \\
\hline C. aureus & IBH 31042 & $\begin{array}{l}\text { Veracruz: } 6.5 \mathrm{~km} \text { (by air) } \mathrm{N} \text { from Atzalan, ejido de } \\
\text { desarrollo urbano Quetzalcoatl }(21)\end{array}$ & MK335396 & MK335242 \\
\hline C. aureus & IBH 31044 & $\begin{array}{l}\text { Veracruz: } 6.5 \mathrm{~km} \text { (by air) } \mathrm{N} \text { from Atzalan, ejido de } \\
\text { desarrollo urbano Quetzalcoatl ( } 21)\end{array}$ & MK335397 & MK335243 \\
\hline $\begin{array}{l}\text { C. ceronorum } \mathrm{sp} \text {. } \\
\text { nov. }\end{array}$ & IBH 30987 & Veracruz: 1.1 km N Xometla (30) & MN914713 & MN920423 \\
\hline $\begin{array}{l}\text { C. ceronorum sp. } \\
\text { nov. }\end{array}$ & IBH 30988 & Veracruz: 1.1 km N Xometla (30) & MN914714 & MN920424 \\
\hline $\begin{array}{l}\text { C. ceronorum } \mathrm{sp} \text {. } \\
\text { nov. }\end{array}$ & MVZ 201387 & Puebla: Santa Cruz de Texmalaquilla (31) & AY522488 & - \\
\hline $\begin{array}{l}\text { C. ceronorum sp. } \\
\text { nov. }\end{array}$ & MVZ 201389 & Puebla: Santa Cruz de Texmalaquilla (31) & AY 522487 & - \\
\hline C. chico & MVZ 200679 & Hidalgo: 3.8 km S Mineral del Chico (16) & AY522471 & - \\
\hline C. chiropterus & CARIE 0777 & Veracruz: Huatusco (29) & MK335407 & MK335253 \\
\hline C. chiropterus & CARIE 0719 & Veracruz: Huatusco (29) & MK335408 & - \\
\hline C. chiropterus & IBH 30099 & $\begin{array}{l}\text { Oaxaca: San Bernardo, } 4.8 \mathrm{~km} \mathrm{SW} \text { (by rd) of La } \\
\text { Esperanza on MX } 177(40)\end{array}$ & MK335409 & MK335254 \\
\hline C. chiropterus & IBH 22736 & $\begin{array}{l}\text { Oaxaca: San Bernardo, ca. } 5 \mathrm{~km} \mathrm{SW} \text { (by rd) of La } \\
\text { Esperanza on MX } 175(40)\end{array}$ & MN914715 & - \\
\hline C. chiropterus & IBH 30088 & $\begin{array}{l}\text { Oaxaca: ca. } 400 \text { m from MX } 175 \text { on road to San Isidro } \\
\text { Yolox (40) }\end{array}$ & MN914716 & - \\
\hline C. chiropterus & IBH 22550 & $\begin{array}{l}\text { Oaxaca: La Galera, } 11.0 \mathrm{~km} \mathrm{SW} \text { (by rd) of La } \\
\text { Esperanza on MX175 (39) }\end{array}$ & MN914717 & - \\
\hline C. chiropterus & GP 088 & $\begin{array}{l}\text { Oaxaca: } 67 \mathrm{Km} \text { N Guelatao, trail to San Isidro, La } \\
\text { Esperanza (39) }\end{array}$ & AY522490 & - \\
\hline C. chondrostega & IBH 28195 & $\begin{array}{l}\text { Hidalgo: } 1.0 \mathrm{~km} \mathrm{~S} \text { (by rd) of La Encarnación on road } \\
\text { to MX } 85 \text {, Parque Nacional los Marmoles (11) }\end{array}$ & MN914718 & - \\
\hline C. chondrostega & IBH 30098 & $\begin{array}{l}\text { Hidalgo: } 1.0 \mathrm{~km} \mathrm{~S} \text { (by rd) of La Encarnación on road } \\
\text { to MX } 85 \text {, Parque Nacional los Marmoles (11) }\end{array}$ & MK335383 & MK335229 \\
\hline C. cieloensis & IBH 28181 & $\begin{array}{l}\text { Tamaulipas: } 0.2 \text { km E (by air) of Rancho El Cielo, } 6.9 \\
\text { km NNW (by air) of center of Gómez Farías, Reserva } \\
\text { de la Biosfera El Cielo (4) }\end{array}$ & MK335385 & MK335231 \\
\hline C. cieloensis & IBH 28190 & $\begin{array}{l}\text { Tamaulipas: } 0.2 \mathrm{~km} \mathrm{E} \mathrm{(by} \mathrm{air)} \mathrm{of} \mathrm{Rancho} \mathrm{El} \mathrm{Cielo,} 6.9 \\
\text { km NNW (by air) of center of Gómez Farías, Reserva } \\
\text { de la Biosfera El Cielo (4) }\end{array}$ & MN914719 & - \\
\hline
\end{tabular}




\begin{tabular}{|c|c|c|c|c|}
\hline C. cracens & IBH 28192 & $\begin{array}{l}\text { Tamaulipas: Road from Alta Cima to San Jose, } 1.3 \mathrm{~km} \\
\text { NE (by air) of San Jose, Reserva de la Biosfera El } \\
\text { Cielo (5) }\end{array}$ & MK335384 & MK335230 \\
\hline C. dimidiatus & IBH 22344 & $\begin{array}{l}\text { Hidalgo: } 4.3 \mathrm{~km} \text { N Hwy } 105 \text { at Mineral del Monte } \\
\text { (15) }\end{array}$ & MN914720 & - \\
\hline C. dimidiatus & IBH 28196 & $\begin{array}{l}\text { Hidalgo: } 4.1 \mathrm{~km} \mathrm{~S} \text { (by rd) of Mineral del Chico on road } \\
\text { to Pachuca, Parque Nacional El Chico (15) }\end{array}$ & MK335390 & MK335236 \\
\hline C. infernalis & MVZ 269665 & $\begin{array}{l}\text { Tamps: Cueva del Brinco, Conrado Castillo, ca. } 43.5 \\
\text { km SW (by rd) of Ejido Guayabas (3) }\end{array}$ & MK335382 & MK335228 \\
\hline C. infernalis & IBH 29575 & $\begin{array}{l}\text { Tamaulipas: Conrado Castillo, ca. } 43.5 \mathrm{~km} \mathrm{SW} \text { (by rd) } \\
\text { of Ejido Guayabas ( } 3 \text { ) }\end{array}$ & MN914721 & MN920425 \\
\hline C. lavae & IBH 22349 & Veracruz: 200 m N Hwy 140 at La Joya (23) & MN914724 & - \\
\hline C. lavae & IBH 22351 & Veracruz: 200 m N Hwy 140 at La Joya (23) & MN914723 & - \\
\hline C. lavae & IBH 22360 & Veracruz: 200 m N Hwy 140 at La Joya (23) & MN914722 & - \\
\hline C. lavae & IBH 22369 & Veracruz: 200 m N Hwy 140 at La Joya (23) & MK335393 & MK335239 \\
\hline C. magnipes & IBH 28176 & $\begin{array}{l}\text { Hidalgo: "El Coní", } 900 \mathrm{~m} \text { SSE of center of Durango, } \\
\text { Municipio Zimapan, Parque Nacional los Marmoles } \\
\text { (9) }\end{array}$ & MK335387 & MK335233 \\
\hline C. magnipes & IBH 30093 & $\begin{array}{l}\text { Hidalgo: "El Coní", } 900 \mathrm{~m} \text { SSE of center of Durango, } \\
\text { Municipio Zimapan, Parque Nacional los Marmoles } \\
\text { (9) }\end{array}$ & MN914725 & - \\
\hline $\begin{array}{l}\text { C. melipona sp. } \\
\text { nov. }\end{array}$ & IBH 30112 & $\begin{array}{l}\text { Puebla: } 7.1 \mathrm{~km} \mathrm{~N} \text { (by rd) of center of Cuetzalan on } \\
\text { road to Yohualichán (18) }\end{array}$ & MK335410 & MK335255 \\
\hline $\begin{array}{l}\text { C. melipona sp. } \\
\text { nov. }\end{array}$ & MVZ 178706 & Puebla: 3.9 km S Xicotepec de Juárez (17) & AY522477 & - \\
\hline $\begin{array}{l}\text { C. melipona } \mathrm{sp} \text {. } \\
\text { nov. }\end{array}$ & MVZ 200723 & Puebla: Xicotepec de Juárez (17) & AY522478 & - \\
\hline $\begin{array}{l}\text { C. melipona } \mathrm{sp} \text {. } \\
\text { nov. }\end{array}$ & MVZ 178707 & Puebla: Xicotepec de Juárez (17) & AY522479 & - \\
\hline C. miquihuanus & IBH 30329 & $\begin{array}{l}\text { Nuevo León: } 1.8 \mathrm{~km} \mathrm{~S} \text { (by rd) of La Encantada on } \\
\text { road from La Bolsa to Zaragoza ( } 2 \text { ) }\end{array}$ & M 335381 & MK335227 \\
\hline C. miquihuanus & IBH 30330 & $\begin{array}{l}\text { Nuevo León: } 22.6 \mathrm{~km} \mathrm{~N} \text { (by rd) of La Bolsa on road to } \\
\text { Zaragoza (2) }\end{array}$ & MN914726 & - \\
\hline C. mosaueri & IBH 28179 & $\begin{array}{l}\text { Hidalgo: "El Coní", } 900 \text { m SSE of center of Durango, } \\
\text { Municipio Zimapan, Parque Nacional los Marmoles } \\
\text { (10) }\end{array}$ & MK335388 & MK335234 \\
\hline C. multidentatus & IBH 28177 & $\begin{array}{l}\text { San Luis Potosí: Cueva el Madroño, } 900 \text { m NW (by } \\
\text { air) of entrance to Valle de los Fantasmas on MX 70, } \\
\text { Sierra de Alvarez (8) }\end{array}$ & MK335416 & - \\
\hline C. multidentatus & IBH 30102 & $\begin{array}{l}\text { San Luis Potosí: Cueva el Madroño, } 900 \text { m NW (by } \\
\text { air) of entrance to Valle de los Fantasmas on MX 70, } \\
\text { Sierra de Alvarez (8) }\end{array}$ & MK335417 & - \\
\hline C. multidentatus & IBH 28193 & $\begin{array}{l}\text { San Luis Potosí: } 26.2 \mathrm{~km} \mathrm{E} \mathrm{(by} \mathrm{rd)} \mathrm{of} \mathrm{center} \mathrm{of} \mathrm{Ciudad} \\
\text { del Maíz on MX 80, at turnoff to RMO Las Antenas } \\
\text { San Luis Potosí (6) }\end{array}$ & MK335412 & - \\
\hline C. multidentatus & IBH 30104 & $\begin{array}{l}\text { San Luis Potosí: } 26.2 \mathrm{~km} \mathrm{E} \mathrm{(by} \mathrm{rd)} \mathrm{of} \mathrm{center} \mathrm{of} \mathrm{Ciudad} \\
\text { del Maíz on MX 80, at turnoff to RMO Las Antenas } \\
\text { San Luis Potosí (6) }\end{array}$ & MK335414 & - \\
\hline
\end{tabular}




\begin{tabular}{|c|c|c|c|c|}
\hline C. multidentatus & IBH 28194 & $\begin{array}{l}\text { San Luis Potosí: } 26.2 \text { km E (by rd) of center of Ciudad } \\
\text { del Maíz on MX 80, at turnoff to RMO Las Antenas } \\
\text { San Luis Potosí (6) }\end{array}$ & MK335413 & - \\
\hline C. multidentatus & IBH 23111 & San Luis Potosí: Rancho Borbortón (7) & MK335415 & - \\
\hline C. nubilus & IBH 31048 & Veracruz: $8.2 \mathrm{~km} \mathrm{~W}$ from Xico, Coxmatla (25) & MK335402 & MK335248 \\
\hline C. nubilus & CARIE 0740 & Veracruz: Bosque Rancho Viejo, Tlalnehuayocan (24) & MK335406 & MK335252 \\
\hline C. orculus & IBH 30765 & $\begin{array}{l}\text { Estado de México: Amecameca, road to Popocatepetl } \\
\text { volcano (33) }\end{array}$ & MK335391 & MK335237 \\
\hline C. orculus & IBH 30746 & $\begin{array}{l}\text { Estado de México: Amecameca, road to Popocatepetl } \\
\text { volcano ( } 32 \text { ) }\end{array}$ & MK335392 & MK335238 \\
\hline C. orculus & IBH 30943 & $\begin{array}{l}\text { Estado de México: Amecameca, road to Popocatepetl } \\
\text { volcano (33) }\end{array}$ & MN914727 & - \\
\hline C. orculus & IBH 22866 & $\begin{array}{l}\text { Estado de México: Amecameca, road to Popocatepetl } \\
\text { volcano (32) }\end{array}$ & MN914728 & - \\
\hline C. orculus & IBH 22210 & $\begin{array}{l}\text { Ciudad de Mexico: Colonia Prolongación Miguel } \\
\text { Hidalgo (34) }\end{array}$ & MN914729 & - \\
\hline C. orculus & AMH 300 & Ciudad de Mexico: Desierto de los Leones (36) & MN914730 & - \\
\hline C. orculus & EPR & Ciudad de Mexico: Bosque de Tlalpan (35) & MN914731 & - \\
\hline C. orculus & IBH 29851 & Morelos: Parque Nacional Lagunas de Zempoala (38) & MN914732 & - \\
\hline C. orculus & IBH 31023 & Morelos: Parque Nacional Lagunas de Zempoala (38) & MN914733 & - \\
\hline C. orculus & IBH 26478 & $\begin{array}{l}\text { Ciudad de Mexico: El Ajusco, km } 29.4 \text { from Picacho- } \\
\text { Ajusco road (37) }\end{array}$ & MN914734 & - \\
\hline C. orculus & MVZ 138672 & $\begin{array}{l}\text { Ciudad de Mexico: Desierto de Los Leones National } \\
\text { Park, } 8.8 \mathrm{~km} \text { [rd.] SW La Venta by Mexico Hwy. } 15 \\
\text { (36) }\end{array}$ & AY522442 & - \\
\hline $\begin{array}{l}\text { C. perotensis sp. } \\
\text { nov. }\end{array}$ & IBH 22395 & $\begin{array}{l}\text { Veracruz: } 15.9 \mathrm{~km} \text { on microondas road, Las Vigas } \\
\text { (26) }\end{array}$ & MN914735 & - \\
\hline $\begin{array}{l}\text { C. perotensis sp. } \\
\text { nov. }\end{array}$ & IBH 22568 & Veracruz: Microondas las Lajas (26) & KP886893 & - \\
\hline $\begin{array}{l}\text { C. perotensis sp. } \\
\text { nov. }\end{array}$ & IBH 23066 & $\begin{array}{l}\text { Veracruz: } 15.9 \mathrm{~km} \text { on microondas road, Las Vigas } \\
\text { (26) }\end{array}$ & MN914736 & - \\
\hline $\begin{array}{l}\text { C. perotensis sp. } \\
\text { nov. }\end{array}$ & IBH 31032 & $\begin{array}{l}\text { Veracruz: Conejo, road to the peak of Cofre de Perote } \\
\text { (28) }\end{array}$ & MN914743 & - \\
\hline $\begin{array}{l}\text { C. perotensis sp. } \\
\text { nov. }\end{array}$ & IBH 31033 & $\begin{array}{l}\text { Veracruz: Conejo, road to the peak of Cofre de Perote } \\
\text { (28) }\end{array}$ & MN914744 & - \\
\hline $\begin{array}{l}\text { C. perotensis sp. } \\
\text { nov. }\end{array}$ & IBH 31034 & $\begin{array}{l}\text { Veracruz: Conejo, road to the peak of Cofre de Perote } \\
\text { (28) }\end{array}$ & MN914737 & - \\
\hline $\begin{array}{l}\text { C. perotensis sp. } \\
\text { nov. }\end{array}$ & IBH 31035 & $\begin{array}{l}\text { Veracruz: Conejo, road to the peak of Cofre de Perote } \\
\text { (28) }\end{array}$ & MN914738 & MN920426 \\
\hline $\begin{array}{l}\text { C. perotensis sp. } \\
\text { nov. }\end{array}$ & IBH 31036 & $\begin{array}{l}\text { Veracruz: Conejo, road to the peak of Cofre de Perote } \\
\text { (28) }\end{array}$ & MN914739 & - \\
\hline $\begin{array}{l}\text { C. perotensis sp. } \\
\text { nov. }\end{array}$ & IBH 31037 & $\begin{array}{l}\text { Veracruz: } 2 \mathrm{~km} \text { (by air) al NE de Llanillo redondo } \\
\text { camino a Valle Alegre (27) }\end{array}$ & MN914740 & - \\
\hline
\end{tabular}




\begin{tabular}{|c|c|c|c|c|}
\hline $\begin{array}{l}\text { C. perotensis sp. } \\
\text { nov. }\end{array}$ & IBH 31038 & $\begin{array}{l}\text { Veracruz: } 2 \mathrm{~km} \text { (by air) al NE de Llanillo redondo } \\
\text { camino a Valle Alegre (27) }\end{array}$ & MN914741 & - \\
\hline $\begin{array}{l}\text { C. perotensis } \mathrm{sp} \text {. } \\
\text { nov. }\end{array}$ & IBH 31039 & $\begin{array}{l}\text { Veracruz: } 2 \mathrm{~km} \text { (by air) al NE de Llanillo redondo } \\
\text { camino a Valle Alegre (27) }\end{array}$ & MN914742 & MN920427 \\
\hline C. priscus & IBH 22367 & $\begin{array}{l}\text { Nuevo León: } 19.4 \text { km W } 18 \text { de Marzo, Cerro Potosí } \\
\text { (1) }\end{array}$ & MK335380 & MK335226 \\
\hline C. terrestris & GP 215 & Hidalgo: $5.3 \mathrm{~km} \mathrm{~N} \mathrm{Hwy} 105$ at Zacualtipan (12) & MK335389 & MK335235 \\
\hline $\begin{array}{l}\text { C. totonacus sp. } \\
\text { nov. }\end{array}$ & IBH 31030 & Veracruz: El Polvorín, 5 km SW of Villa Aldama (22) & MN914745 & MN920428 \\
\hline $\begin{array}{l}\text { C. totonacus sp. } \\
\text { nov. }\end{array}$ & IBH 31031 & Veracruz: El Polvorín, 5 km SW of Villa Aldama (22) & MN914746 & MN920429 \\
\hline $\begin{array}{l}\text { Chiropterotriton } \\
\text { sp. G }\end{array}$ & MVZ 178700 & Puebla: 4 km S Chignahuapan (19) & AY522480 & - \\
\hline $\begin{array}{l}\text { Chiropterotriton } \\
\text { sp. G }\end{array}$ & MVZ 178703 & Puebla: 4 km S Chignahuapan (19) & AY522481 & - \\
\hline $\begin{array}{l}\text { Chiropterotriton } \\
\text { sp. K }\end{array}$ & MVZ 173231 & Oaxaca: Cerro San Felipe (41) & AY522493 & - \\
\hline $\begin{array}{l}\text { Aquiloeurycea } \\
\text { cephalica }\end{array}$ & IBH 30253 & $\begin{array}{l}\text { Hidalgo: } 1.0 \mathrm{~km} \mathrm{~S} \text { (by rd) of La Encarnación on road } \\
\text { to MX 85, Parque Nacional los Mármoles }\end{array}$ & MK335378 & - \\
\hline Thorius sp. & IBH 30942 & Oaxaca: Santa María Chilchotla, Sierra Mazateca. & MN914747 & - \\
\hline
\end{tabular}

6 


\section{Table 2 (on next page)}

Mean \pm standard deviation (above) and range (below) of morphometric variables

Mean \pm standard deviation (above) and range (below) of morphometric variables from males and females of $C$. aureus, $C$. nubilus, $C$. ceronorum, $C$. perotensis, $C$. totonacus, $C$. melipona, C. casasi, C. chiropterus, C. orculus and C. lavae. Measurements are given in millimeters (mm), except TL/SLV (proportional value), LI (limb interval), and tooth counts. 
Table 2. Mean \pm standard deviation (above) and range (below) of morphometric variables from males and females of $C$. aureus, $C$. nubilus, C. ceronorum sp. nov., C. perotensis sp. nov., C. totonacus sp. nov., C. melipona sp. nov., C. casasi sp. nov., C. chiropterus, C. orculus and C. lavae. Measurements are given in millimeters ( $\mathrm{mm}$ ), except TL/SLV (proportional value), LI (limb interval), and tooth counts.

\begin{tabular}{|c|c|c|c|c|c|c|c|c|c|c|}
\hline males & $\begin{array}{c}\text { C. aureus } \\
\mathrm{N}=1\end{array}$ & $\begin{array}{c}\text { C. nubilus } \\
\mathrm{N}=1\end{array}$ & $\begin{array}{l}\text { C. ceronorum } \\
\text { sp. nov. } \\
\mathrm{N}=10\end{array}$ & $\begin{array}{l}\text { C. perotensis } \\
\text { sp. nov. } \\
\mathrm{N}=12\end{array}$ & $\begin{array}{l}\text { C. totonacus } \\
\text { sp. nov. } \\
\mathrm{N}=10\end{array}$ & $\begin{array}{l}\text { C. melipona } \\
\text { sp. nov. } \\
\mathrm{N}=4\end{array}$ & $\begin{array}{c}\text { C. casasi } \\
\text { sp. nov. } \\
\mathrm{N}=4\end{array}$ & $\begin{array}{c}\text { C. chiropterus } \\
\mathrm{N}=8\end{array}$ & $\begin{array}{l}\text { C. orculus } \\
\mathrm{N}=10\end{array}$ & $\begin{array}{l}\text { C. lavae } \\
\mathrm{N}=10\end{array}$ \\
\hline SVL & 28.5 & 29.4 & $\begin{array}{c}33.9 \pm 1.54 \\
(30.6-36.2)\end{array}$ & $\begin{array}{c}29.7 \pm 1.92 \\
(26.5-32.8)\end{array}$ & $\begin{array}{c}35.7 \pm 1.96 \\
(32.0-38.6)\end{array}$ & $\begin{array}{c}29.2 \pm 2.25 \\
(26.4-31.4)\end{array}$ & $\begin{array}{l}37.8 \pm 3.10 \\
(34.5-42.0)\end{array}$ & $\begin{array}{c}37.5 \pm 0.98 \\
(36.1-38.8)\end{array}$ & $\begin{array}{c}35.9 \pm 1.36 \\
(33.6-38.9)\end{array}$ & $\begin{array}{l}32.4 \pm 0.92(31 \\
33.8)\end{array}$ \\
\hline TL & 36.5 & 40.2 & $\begin{array}{c}33.9 \pm 1.99 \\
(30.4-37.7)\end{array}$ & $\begin{array}{c}30.9 \pm 3.06 \\
(26.0-35.2) \\
N=8\end{array}$ & $\begin{array}{c}41.1 \pm 3.20 \\
(34.3-44.9) \\
N=9\end{array}$ & $\begin{array}{c}33.9 \pm 3.37 \\
(31.0-38.2)\end{array}$ & $\begin{array}{c}39.1 \pm 3.29 \\
(36.8-42.9) \\
N=3\end{array}$ & $\begin{array}{c}47.3 \pm 3.24 \\
(42.6-52.3) \\
N=7\end{array}$ & $\begin{array}{c}36.6 \pm 2.87 \\
(33.3-41.0) \\
N=9\end{array}$ & $\begin{array}{c}38.5 \pm 2.11 \\
(36.2-42.3)\end{array}$ \\
\hline TL/SVL & 1.28 & 1.37 & $\begin{array}{c}1.00 \pm 0.06 \\
(0.89-1.12)\end{array}$ & $\begin{array}{c}1.03 \pm 0.08 \\
(0.92-1.16) \\
\mathrm{N}=8\end{array}$ & $\begin{array}{c}1.16 \pm 0.10(0.92- \\
1.24) \\
N=9\end{array}$ & $\begin{array}{c}1.16 \pm 0.05 \\
(1.10-1.22)\end{array}$ & $\begin{array}{c}1.04 \pm 0.13 \\
(0.90-1.15) \\
N=3\end{array}$ & $\begin{array}{c}1.25 \pm 0.08(1.13- \\
1.38) \\
N=7\end{array}$ & $\begin{array}{c}1.02 \pm 0.08 \\
(0.86-1.15) \\
N=9\end{array}$ & $\begin{array}{c}1.19 \pm 0.06 \\
(1.11-1.27)\end{array}$ \\
\hline $\mathrm{AX}$ & 15.5 & 15.9 & $\begin{array}{c}16.9 \pm 0.70 \\
(15.5-17.9)\end{array}$ & $\begin{array}{c}15.5 \pm 0.93 \\
(14.2-17.0)\end{array}$ & $\begin{array}{c}18.3 \pm 1.30 \\
(16.7-20.4)\end{array}$ & $\begin{array}{c}15.7 \pm 1.30 \\
(14.0-17.0)\end{array}$ & $\begin{array}{c}19.8 \pm 0.46 \\
(19.4-20.4)\end{array}$ & $\begin{array}{c}19.6 \pm 0.59 \\
(18.7-20.8)\end{array}$ & $\begin{array}{c}18.6 \pm 1.04 \\
(17.1-20.5)\end{array}$ & $\begin{array}{c}16.2 \pm 0.87 \\
(14.7-17.4)\end{array}$ \\
\hline FLL & 5.9 & 6.4 & $\begin{array}{c}8.9 \pm 0.69 \\
(7.2-10.0)\end{array}$ & $\begin{array}{l}6.8 \pm 0.59 \\
(5.5-7.8)\end{array}$ & $\begin{array}{l}10.0 \pm 0.72 \\
(8.9-10.9)\end{array}$ & $\begin{array}{l}6.3 \pm 0.86 \\
(5.1-7.0)\end{array}$ & $\begin{array}{l}9.9 \pm 0.59 \\
(9.4-10.7)\end{array}$ & $\begin{array}{l}9.1 \pm 0.44 \\
(8.2-9.5)\end{array}$ & $\begin{array}{l}8.9 \pm 0.65 \\
(7.4-9.6)\end{array}$ & $\begin{array}{c}9.3 \pm 0.59(8.4- \\
10.2)\end{array}$ \\
\hline HLL & 7.5 & 7.1 & $\begin{array}{c}9.4 \pm 0.83 \\
(7.5-10.3)\end{array}$ & $\begin{array}{l}7.2 \pm 0.61 \\
(6.1-8.2)\end{array}$ & $\begin{array}{l}11.0 \pm 1.00 \\
(9.4-12.2)\end{array}$ & $\begin{array}{l}7.2 \pm 0.83 \\
(6.1-7.9)\end{array}$ & $\begin{array}{r}11.5 \pm 0.74 \\
(11.1-12.6)\end{array}$ & $\begin{array}{l}10.3 \pm 0.47 \\
(9.5-10.8)\end{array}$ & $\begin{array}{c}9.3 \pm 0.64 \\
(8.2-10.4) \\
N=9\end{array}$ & $\begin{array}{c}9.9 \pm 0.72(8.5- \\
11.0)\end{array}$ \\
\hline $\mathrm{HL}$ & 6.4 & 6.6 & $\begin{array}{l}7.5 \pm 0.55 \\
(6.3-8.2)\end{array}$ & $\begin{array}{l}6.6 \pm 0.33 \\
(6.1-7.1)\end{array}$ & $\begin{array}{l}8.5 \pm 0.64 \\
(7.7-9.5)\end{array}$ & $\begin{array}{l}6.3 \pm 0.52 \\
(5.5-6.6)\end{array}$ & $\begin{array}{l}8.3 \pm 0.60 \\
(7.5-8.8)\end{array}$ & $\begin{array}{l}8.1 \pm 0.41 \\
(7.7-8.9)\end{array}$ & $\begin{array}{l}7.4 \pm 0.47 \\
(6.7-8.1)\end{array}$ & $\begin{array}{c}7.5 \pm 0.33(7.2- \\
8.1)\end{array}$ \\
\hline HW & 4.0 & 4.0 & $\begin{array}{l}5.1 \pm 0.35 \\
(4.3-5.5)\end{array}$ & $\begin{array}{l}4.2 \pm 0.18 \\
(3.9-4.5)\end{array}$ & $\begin{array}{l}5.2 \pm 0.29 \\
(4.8-5.7)\end{array}$ & $\begin{array}{l}4.3 \pm 0.33 \\
(3.9-4.6)\end{array}$ & $\begin{array}{l}5.8 \pm 0.45 \\
(5.3-6.3)\end{array}$ & $\begin{array}{l}5.6 \pm 0.22 \\
(5.4-6.0)\end{array}$ & $\begin{array}{l}5.0 \pm 0.35 \\
(4.5-5.5)\end{array}$ & $\begin{array}{c}4.9 \pm 0.31(4.5- \\
5.6)\end{array}$ \\
\hline
\end{tabular}




\begin{tabular}{|c|c|c|c|c|c|c|c|c|c|c|}
\hline HD & 1.8 & 2.0 & $\begin{array}{l}2.5 \pm 0.17 \\
(2.1-2.7)\end{array}$ & $\begin{array}{l}2.0 \pm 0.18 \\
(1.7-2.3)\end{array}$ & $\begin{array}{l}2.4 \pm 0.34 \\
(2.1-3.3)\end{array}$ & $\begin{array}{l}2.3 \pm 0.22 \\
(2.1-2.6)\end{array}$ & $\begin{array}{l}2.5 \pm 0.28 \\
(2.2-2.8)\end{array}$ & $\begin{array}{l}2.7 \pm 0.07 \\
(2.6-2.8)\end{array}$ & $\begin{array}{l}2.4 \pm 0.13 \\
(2.2-2.7)\end{array}$ & $\begin{array}{c}2.5 \pm 0.19(2.3- \\
2.9)\end{array}$ \\
\hline SW & 3.4 & 3.4 & $\begin{array}{l}3.6 \pm 0.29 \\
(3.0-3.9)\end{array}$ & $\begin{array}{l}2.7 \pm 0.28 \\
(2.3-3.4)\end{array}$ & $\begin{array}{l}3.6 \pm 0.28 \\
(3.2-4.0)\end{array}$ & $\begin{array}{l}3.3 \pm 0.26 \\
(3.1-3.7)\end{array}$ & $\begin{array}{l}3.5 \pm 0.37 \\
(3.1-3.8)\end{array}$ & $\begin{array}{l}4.0 \pm 0.35 \\
(3.2-4.4)\end{array}$ & $\begin{array}{l}3.4 \pm 0.30 \\
(3.1-4.0)\end{array}$ & $\begin{array}{c}3.1 \pm 0.30(2.6- \\
3.5)\end{array}$ \\
\hline IN & 1.0 & 1.2 & $\begin{array}{l}2.3 \pm 0.18 \\
(2.0-2.6)\end{array}$ & $\begin{array}{l}1.7 \pm 0.26 \\
(1.1-2.0)\end{array}$ & $\begin{array}{l}2.4 \pm 0.23 \\
(1.9-2.7)\end{array}$ & $\begin{array}{l}1.4 \pm 0.13 \\
(1.3-1.6)\end{array}$ & $\begin{array}{l}2.1 \pm 0.30 \\
(1.7-2.4)\end{array}$ & $\begin{array}{l}1.9 \pm 0.13 \\
(1.7-2.1)\end{array}$ & $\begin{array}{l}2.2 \pm 0.19 \\
(1.9-2.5)\end{array}$ & $\begin{array}{c}2.3 \pm 0.20(1.9 \\
2.5)\end{array}$ \\
\hline FW & 2.4 & 2.6 & $\begin{array}{l}3.8 \pm 0.44 \\
(2.9-4.6)\end{array}$ & $\begin{array}{l}2.6 \pm 0.33 \\
(2.1-3.1)\end{array}$ & $\begin{array}{l}4.2 \pm 0.45 \\
(3.5-4.9)\end{array}$ & $\begin{array}{l}2.4 \pm 0.27 \\
(2.2-2.8)\end{array}$ & $\begin{array}{l}3.7 \pm 0.19 \\
(3.6-4.0)\end{array}$ & $\begin{array}{l}3.7 \pm 0.33 \\
(3.3-4.4)\end{array}$ & $\begin{array}{l}3.2 \pm 0.22 \\
(2.8-3.5)\end{array}$ & $\begin{array}{c}3.7 \pm 0.39(3.1- \\
4.2)\end{array}$ \\
\hline LI & 2.0 & 2.0 & $\begin{array}{c}0.0 \pm 0.41 \\
(-0.5-1.0)\end{array}$ & $\begin{array}{l}2.5 \pm 0.67 \\
(1.0-3.0)\end{array}$ & $\begin{array}{l}-0.6 \pm 0.70 \\
(-1.0-1.0)\end{array}$ & $\begin{array}{l}2.3 \pm 0.29 \\
(2.0-2.5)\end{array}$ & $\begin{array}{l}0.8 \pm 0.50 \\
(0.0-1.0)\end{array}$ & $\begin{array}{l}0.3 \pm 0.53 \\
(-0.5-1.0)\end{array}$ & $\begin{array}{l}1.9 \pm 0.88 \\
(0.0-3.0)\end{array}$ & $\begin{array}{c}-0.6 \pm 0.52(- \\
1.0-0.0)\end{array}$ \\
\hline PMT & 4.0 & 7.0 & $\begin{array}{l}3.4 \pm 0.97 \\
(3.0-6.0)\end{array}$ & $\begin{array}{l}2.8 \pm 0.97 \\
(0.0-4.0)\end{array}$ & $\begin{array}{l}4.8 \pm 0.63 \\
(4.0-6.0)\end{array}$ & $\begin{array}{l}2.3 \pm 1.50 \\
(1.0-4.0)\end{array}$ & $\begin{array}{l}3.5 \pm 1.29 \\
(2.0-5.0)\end{array}$ & $\begin{array}{l}3.6 \pm 1.30 \\
(2.0-5.0)\end{array}$ & $\begin{array}{l}2.7 \pm 0.82 \\
(2.0-4.0)\end{array}$ & $\begin{array}{c}3.3 \pm 2.00(0.0- \\
6.0)\end{array}$ \\
\hline MT & 10.0 & 13.0 & $\begin{array}{l}11.0 \pm 3.30 \\
(7.0-18.0)\end{array}$ & $\begin{array}{c}7.2 \pm 4.73 \\
(2.0-17.0)\end{array}$ & $\begin{array}{c}32.9 \pm 7.80 \\
(18.0-48.0)\end{array}$ & $\begin{array}{l}9.5 \pm 2.38 \\
(7.0-12.0)\end{array}$ & $\begin{array}{l}9.0 \pm 2.94 \\
(6.0-13.0)\end{array}$ & $\begin{array}{l}12.6 \pm 3.46 \\
(9.0-17.0)\end{array}$ & $\begin{array}{c}8.2 \pm 2.25 \\
(5.0-11.0)\end{array}$ & $\begin{array}{c}7.0 \pm 2.71(1.0- \\
10.0)\end{array}$ \\
\hline VT & 15.0 & 10.0 & $\begin{array}{c}13.0 \pm 2.05 \\
(11.0-17.0)\end{array}$ & $\begin{array}{c}9.0 \pm 1.65 \\
(7.0-12.0)\end{array}$ & $\begin{array}{c}11.6 \pm 1.90 \\
(10.0-15.0)\end{array}$ & $\begin{array}{l}11.0 \pm 2.94 \\
(8.0-15.0)\end{array}$ & $\begin{array}{c}9.0 \pm 1.41 \\
(8.0-11.0)\end{array}$ & $\begin{array}{l}10.6 \pm 1.06 \\
(9.0-12.0)\end{array}$ & $\begin{array}{c}8.6 \pm 1.90 \\
(5.0-11.0)\end{array}$ & $\begin{array}{c}8.9 \pm 1.10(7.0- \\
10.0)\end{array}$ \\
\hline
\end{tabular}

6

\begin{tabular}{|c|c|c|c|c|c|c|c|c|c|c|}
\hline females & $\begin{array}{l}\text { C. aureus } \\
\quad N=3\end{array}$ & $\begin{array}{l}\text { C. nubilus } \\
\quad N=2\end{array}$ & $\begin{array}{c}\text { C. ceronorum } \\
\text { sp. nov. } \\
N=10\end{array}$ & $\begin{array}{c}\text { C. perotensis } \\
\text { sp. nov. } \\
N=8\end{array}$ & $\begin{array}{l}\text { C. totonacus } \\
\text { sp. nov. } \\
\quad N=10\end{array}$ & $\begin{array}{c}\text { C. melipona } \\
\text { sp. nov. } \\
N=3\end{array}$ & $\begin{array}{c}\text { C. casasi } \\
\text { sp. nov. } \\
N=1\end{array}$ & $\begin{array}{l}\text { C. chiropterus } \\
\qquad N=4\end{array}$ & $\begin{array}{l}\text { C. orculus } \\
N=10\end{array}$ & $\begin{array}{c}\text { C. lavae } \\
N=9\end{array}$ \\
\hline SVL & $\begin{array}{c}26.8 \pm 0.86 \\
(26.0-27.7)\end{array}$ & $\begin{array}{l}30.5 \pm 3.89 \\
(27.7-33.2)\end{array}$ & $\begin{array}{c}34.9 \pm 1.53 \\
(33.3-38.4)\end{array}$ & $\begin{array}{c}31.7 \pm 2.19 \\
(27.4-34.3)\end{array}$ & $\begin{array}{c}35.5 \pm 1.90 \\
(31.8-38.3)\end{array}$ & $\begin{array}{c}28.5 \pm 1.36 \\
(27.1-29.8)\end{array}$ & 40.9 & $\begin{array}{c}33.5 \pm 2.55 \\
(30.7-36.7)\end{array}$ & $\begin{array}{c}39.0 \pm 2.70 \\
(34.9-43.0)\end{array}$ & $\begin{array}{c}31.6 \pm 2.46 \\
(27.9-34.9)\end{array}$ \\
\hline TL & $\begin{array}{c}31.1 \pm 1.41 \\
(30.1-32.1)\end{array}$ & $\begin{array}{c}34.3 \pm 5.16 \\
(30.6-37.9)\end{array}$ & $\begin{array}{c}33.9 \pm 2.82 \\
(28.5-38.2)\end{array}$ & $\begin{array}{c}31.5 \pm 3.31 \\
(27.0-37.3) \\
N=7\end{array}$ & $\begin{array}{c}42.6 \pm 5.08 \\
(36.3-49.2) \\
N=6\end{array}$ & $\begin{array}{c}32.3 \pm 2.26 \\
(30.7-33.9) \\
N=2\end{array}$ & $34.0 \mathrm{br}$ & $\begin{array}{c}39.5 \pm 2.35 \\
(37.0-42.6)\end{array}$ & $\begin{array}{c}39.2 \pm 3.64 \\
(34.7-44.7) \\
N=9\end{array}$ & $\begin{array}{c}32.5 \pm 4.89 \\
(25.7-40.1)\end{array}$ \\
\hline TL/SVL & $1.16 \pm 0.00$ & $1.12 \pm 0.03$ & $0.97 \pm 0.07$ & $1.00 \pm 0.11$ & $1.20 \pm 0.13$ & $1.11 \pm 0.11$ & - & $1.19 \pm 0.12(1.01-$ & $1.02 \pm 0.08$ & $1.02 \pm 0.10$ \\
\hline
\end{tabular}




\begin{tabular}{|c|c|c|c|c|c|c|c|c|c|c|}
\hline & $(1.16-1.16)$ & $(1.10-1.14)$ & $(0.85-1.07)$ & $\begin{array}{c}(0.79-1.11) \\
N=7\end{array}$ & $\begin{array}{c}(1.06-1.38) \\
N=6\end{array}$ & $\begin{array}{c}(1.03-1.18) \\
N=2\end{array}$ & & 1.26) & $\begin{array}{c}(0.87-1.12) \\
N=9\end{array}$ & $(0.85-1.15)$ \\
\hline $\mathrm{AX}$ & $\begin{array}{c}15.0 \pm 0.49 \\
(14.7-15.6)\end{array}$ & $\begin{array}{c}16.4 \pm 2.69 \\
(14.5-18.3)\end{array}$ & $\begin{array}{c}18.5 \pm 0.95 \\
(17.1-20.0)\end{array}$ & $\begin{array}{c}16.6 \pm 1.58 \\
(13.6-19.2)\end{array}$ & $\begin{array}{c}18.7 \pm 0.95 \\
(17.3-20.1)\end{array}$ & $\begin{array}{c}15.8 \pm 0.59 \\
(15.4-16.5)\end{array}$ & 20.3 & $\begin{array}{c}18.5 \pm 2.27 \\
(15.4-20.7)\end{array}$ & $\begin{array}{c}21.2 \pm 1.58 \\
(18.6-23.2)\end{array}$ & $\begin{array}{c}16.3 \pm 1.68 \\
(13.9-18.5)\end{array}$ \\
\hline FLL & $\begin{array}{l}5.3 \pm 0.42 \\
(4.8-5.6)\end{array}$ & $\begin{array}{l}6.5 \pm 0.28 \\
(6.3-6.7)\end{array}$ & $\begin{array}{c}8.6 \pm 0.38(8.1- \\
9.3)\end{array}$ & $\begin{array}{c}6.7 \pm 0.61(5.9- \\
7.5)\end{array}$ & $\begin{array}{c}9.7 \pm 0.85 \\
(8.7-11.3)\end{array}$ & $\begin{array}{l}6.5 \pm 0.72 \\
(6.0-7.3)\end{array}$ & 10.6 & $\begin{array}{l}7.8 \pm 0.48 \\
(7.1-8.2)\end{array}$ & $\begin{array}{c}8.9 \pm 0.63 \\
(7.6-10.0)\end{array}$ & $\begin{array}{l}8.2 \pm 0.72 \\
(7.1-9.5)\end{array}$ \\
\hline HLL & $\begin{array}{l}6.7 \pm 0.35 \\
(6.4-7.1)\end{array}$ & $\begin{array}{l}7.2 \pm 0.14 \\
(7.1-7.3)\end{array}$ & $\begin{array}{c}8.9 \pm 0.70(7.3- \\
9.9)\end{array}$ & $\begin{array}{c}7.1 \pm 0.66(6.1- \\
8.2)\end{array}$ & $\begin{array}{l}10.8 \pm 0.93 \\
(9.3-12.5)\end{array}$ & $\begin{array}{l}7.4 \pm 0.58 \\
(7.1-8.1)\end{array}$ & 12.0 & $\begin{array}{l}8.9 \pm 0.31 \\
(8.4-9.1)\end{array}$ & $\begin{array}{c}9.5 \pm 0.57 \\
(8.6-10.4)\end{array}$ & $\begin{array}{l}8.8 \pm 0.73 \\
(7.5-9.8)\end{array}$ \\
\hline $\mathrm{HL}$ & $\begin{array}{l}6.0 \pm 0.31 \\
(5.7-6.3)\end{array}$ & $\begin{array}{l}7.4 \pm 0.99 \\
(6.7-8.1)\end{array}$ & $\begin{array}{c}7.1 \pm 0.29(6.6- \\
7.6)\end{array}$ & $\begin{array}{c}6.7 \pm 0.31(6.2- \\
7.2)\end{array}$ & $\begin{array}{l}7.6 \pm 0.38 \\
(7.0-8.1)\end{array}$ & $\begin{array}{l}6.4 \pm 0.60 \\
(5.8-7.0)\end{array}$ & 8.6 & $\begin{array}{l}7.3 \pm 0.56 \\
(6.5-7.8)\end{array}$ & $\begin{array}{l}8.0 \pm 0.52 \\
(7.4-8.9)\end{array}$ & $\begin{array}{l}7.0 \pm 0.42 \\
(6.3-7.6)\end{array}$ \\
\hline HW & $\begin{array}{l}3.6 \pm 0.10 \\
(3.5-3.7)\end{array}$ & $\begin{array}{l}4.4 \pm 0.14 \\
(4.3-4.5)\end{array}$ & $\begin{array}{c}5.1 \pm 0.21(4.7- \\
5.3)\end{array}$ & $\begin{array}{c}4.4 \pm 0.21(4.1- \\
4.6)\end{array}$ & $\begin{array}{l}5.2 \pm 0.22 \\
(5.0-5.6)\end{array}$ & $\begin{array}{l}4.2 \pm 0.25 \\
(4.0-4.5)\end{array}$ & 5.9 & $\begin{array}{l}4.8 \pm 0.21 \\
(4.5-5.0)\end{array}$ & $\begin{array}{l}5.2 \pm 0.29 \\
(4.7-5.6)\end{array}$ & $\begin{array}{l}4.7 \pm 0.30 \\
(4.1-5.0)\end{array}$ \\
\hline HD & $\begin{array}{l}1.8 \pm 0.02 \\
(1.8-1.8)\end{array}$ & $\begin{array}{l}2.0 \pm 0.07 \\
(1.9-2.0)\end{array}$ & $\begin{array}{c}2.4 \pm 0.12(2.3- \\
2.6)\end{array}$ & $\begin{array}{c}2.2 \pm 0.17(2.0- \\
2.5)\end{array}$ & $\begin{array}{l}2.3 \pm 0.17 \\
(2.0-2.6)\end{array}$ & $\begin{array}{l}2.4 \pm 0.12 \\
(2.3-2.5)\end{array}$ & 2.6 & $\begin{array}{l}2.5 \pm 0.14 \\
(2.3-2.6)\end{array}$ & $\begin{array}{l}2.6 \pm 0.32 \\
(2.3-3.4)\end{array}$ & $\begin{array}{l}2.3 \pm 0.18 \\
(2.1-2.7)\end{array}$ \\
\hline SW & $\begin{array}{l}3.1 \pm 0.17 \\
(3.0-3.3)\end{array}$ & $\begin{array}{l}3.3 \pm 0.28 \\
(3.1-3.5)\end{array}$ & $\begin{array}{c}3.7 \pm 0.24(3.3- \\
4.1)\end{array}$ & $\begin{array}{c}3.1 \pm 0.22(2.6- \\
3.3)\end{array}$ & $\begin{array}{l}3.6 \pm 0.17 \\
(3.4-3.9)\end{array}$ & $\begin{array}{l}3.2 \pm 0.15 \\
(3.1-3.4)\end{array}$ & 3.3 & $\begin{array}{l}3.6 \pm 0.38 \\
(3.3-4.1)\end{array}$ & $\begin{array}{l}3.9 \pm 0.46 \\
(3.4-4.8)\end{array}$ & $\begin{array}{l}3.3 \pm 0.33 \\
(2.8-3.8)\end{array}$ \\
\hline IN & $\begin{array}{l}1.1 \pm 0.06 \\
(1.0-1.1)\end{array}$ & $\begin{array}{l}1.2 \pm 0.02 \\
(1.2-1.2)\end{array}$ & $\begin{array}{c}1.9 \pm 0.15(1.5- \\
2.1)\end{array}$ & $\begin{array}{c}1.8 \pm 0.14(1.6- \\
2.0)\end{array}$ & $\begin{array}{l}2.2 \pm 0.19 \\
(2.0-2.5)\end{array}$ & $\begin{array}{l}1.4 \pm 0.06 \\
(1.4-1.5)\end{array}$ & 2.3 & $\begin{array}{l}1.7 \pm 0.38 \\
(1.4-2.1)\end{array}$ & $\begin{array}{l}2.1 \pm 0.25 \\
(1.7-2.5)\end{array}$ & $\begin{array}{l}1.8 \pm 0.13 \\
(1.6-2.0)\end{array}$ \\
\hline FW & $\begin{array}{l}1.8 \pm 0.21 \\
(1.6-2.0)\end{array}$ & $\begin{array}{l}2.3 \pm 0.57 \\
(1.9-2.7)\end{array}$ & $\begin{array}{c}3.5 \pm 0.40(2.8- \\
3.9)\end{array}$ & $\begin{array}{c}2.6 \pm 0.24(2.2- \\
3.0)\end{array}$ & $\begin{array}{l}4.0 \pm 0.52 \\
(3.3-4.8)\end{array}$ & $\begin{array}{l}2.6 \pm 0.38 \\
(2.3-3.0)\end{array}$ & 3.7 & $\begin{array}{l}3.1 \pm 0.37 \\
(2.6-3.5)\end{array}$ & $\begin{array}{l}3.4 \pm 0.37 \\
(2.6-3.9)\end{array}$ & $\begin{array}{l}3.3 \pm 0.27 \\
(3.0-3.7)\end{array}$ \\
\hline LI & $\begin{array}{l}2.3 \pm 0.58 \\
(2.0-3.0)\end{array}$ & $\begin{array}{l}1.5 \pm 0.71 \\
(1.0-2.0)\end{array}$ & $\begin{array}{c}1.5 \pm 0.41(1.0- \\
2.0)\end{array}$ & $\begin{array}{c}3.3 \pm 0.71(2.0- \\
4.0)\end{array}$ & $\begin{array}{c}0.0 \pm 0.67(- \\
1.0-1.0)\end{array}$ & $\begin{array}{l}1.8 \pm 0.76 \\
(1.0-2.5)\end{array}$ & 1.0 & $\begin{array}{l}2.0 \pm 0.41 \\
(1.5-2.5)\end{array}$ & $\begin{array}{l}2.9 \pm 0.32 \\
(2.0-3.0)\end{array}$ & $\begin{array}{l}0.6 \pm 0.73 \\
(0.0-2.0)\end{array}$ \\
\hline PMT & $\begin{array}{l}6.3 \pm 0.58 \\
(6.0-7.0)\end{array}$ & $\begin{array}{l}6.5 \pm 0.71 \\
(6.0-7.0)\end{array}$ & $\begin{array}{c}7.4 \pm 0.97(6.0- \\
9.0)\end{array}$ & $\begin{array}{c}6.1 \pm 2.17(4.0- \\
11.0)\end{array}$ & $\begin{array}{l}7.0 \pm 1.05 \\
(6.0-9.0)\end{array}$ & $\begin{array}{l}7.0 \pm 1.73 \\
(6.0-9.0)\end{array}$ & 6.0 & $\begin{array}{l}6.3 \pm 1.26 \\
(5.0-8.0)\end{array}$ & $\begin{array}{l}7.1 \pm 0.88 \\
(6.0-8.0)\end{array}$ & $\begin{array}{c}7.2 \pm 1.99 \\
(4.0-10.0)\end{array}$ \\
\hline MT & $\begin{array}{c}38.3 \pm 1.53 \\
(37.0-40.0)\end{array}$ & $\begin{array}{c}41.5 \pm 2.12 \\
(40.0-43.0)\end{array}$ & $\begin{array}{c}47.7 \pm 7.26 \\
(36.0-56.0)\end{array}$ & $\begin{array}{c}27.9 \pm 5.03 \\
(19.0-36.0)\end{array}$ & $\begin{array}{c}52.6 \pm 4.50 \\
(45.0-60.0)\end{array}$ & $\begin{array}{c}31.0 \pm 5.20 \\
(25.0-34.0)\end{array}$ & 30.0 & $\begin{array}{c}48.0 \pm 7.94 \\
(42.0-57.0) \\
N=3\end{array}$ & $\begin{array}{c}28.8 \pm 4.05 \\
(23.0-35.0)\end{array}$ & $\begin{array}{c}20.8 \pm 6.69 \\
(13.0-36.0)\end{array}$ \\
\hline
\end{tabular}




\begin{tabular}{|c|c|c|c|c|c|c|c|c|c|c|}
\hline VT & $\begin{array}{c}12.3 \pm 1.53 \\
(11.0-14.0)\end{array}$ & $\begin{array}{c}13.5 \pm 0.71 \\
(13.0-14.0)\end{array}$ & $\begin{array}{c}15.9 \pm 2.69 \\
(13.0-22.0)\end{array}$ & $\begin{array}{c}11.1 \pm 1.13 \\
(10.0-13.0)\end{array}$ & $\begin{array}{c}13.7 \pm 2.11 \\
(9.0-17.0)\end{array}$ & $\begin{array}{c}13.0 \pm 5.29 \\
(9.0-19.0)\end{array}$ & 13.0 & $\begin{array}{c}12.5 \pm 2.38 \\
(10.0-15.0)\end{array}$ & $\begin{array}{c}12.0 \pm 1.94 \\
(9.0-15.0)\end{array}$ & $\begin{array}{l}11.4 \pm 2.30 \\
(8.0-15.0)\end{array}$ \\
\hline
\end{tabular}




\section{Table 3 (on next page)}

Cranial osteological variation among Chiropterotriton species based on characters and character states defined by Darda \& Wake (2015).

Cranial osteological variation among Chiropterotriton species based on characters and character states defined by Darda $\&$ Wake (2015). Each species is represented by a single $\mu C T$-scanned specimen except C. chiropterus, for which there are an additional four clearedand-stained $(c \& s)$ specimens. States that are not observed in these specimens are omitted, e.g., character 6 , state c. All specimens show the same state for characters 11 (squamosal process absent) and 12 (vomer preorbital process present). Each species name is followed by the specimen's museum catalog number, sex ( $F$, female; $M$, male) and snout-vent length. Instances in which two states are listed for a given character $\left(^{*}\right)$ represent right-left asymmetry in that specimen. 
Table 3. Cranial osteological variation among Chiropterotriton species based on characters and character states defined by Darda \& Wake (2015). and-stained $(c \& s)$ specimens. States that are not observed in these specimens are omitted, e.g., character 6 , state c. All specimens show the same specimen's museum catalog number, sex (F, female; M, male) and snout-vent length. Instances in which two states are listed for a given character

\begin{tabular}{|c|c|c|c|c|c|c|c|c|c|c|c|c|c|}
\hline \multirow[b]{2}{*}{ Species } & \multicolumn{2}{|c|}{$\begin{array}{c}\text { 1. Septomaxilla } \\
\text { development }\end{array}$} & \multicolumn{3}{|c|}{$\begin{array}{c}\text { 2. Nasal-premaxilla } \\
\text { articulation }\end{array}$} & \multicolumn{3}{|c|}{$\begin{array}{l}\text { 3. Nasal-maxilla } \\
\text { articulation }\end{array}$} & \multicolumn{3}{|c|}{$\begin{array}{l}\text { 4. Nasal-prefrontal } \\
\text { articulation }\end{array}$} & \multicolumn{2}{|c|}{$\begin{array}{l}\text { 5. Nasal-frontal } \\
\text { articulation }\end{array}$} \\
\hline & $\begin{array}{c}\text { a) } \\
\text { absen } \\
t\end{array}$ & $\begin{array}{c}\text { b) } \\
\text { presen } \\
\mathbf{t}\end{array}$ & $\begin{array}{c}\text { a) } \\
\text { separat } \\
\text { e }\end{array}$ & $\begin{array}{c}\text { b) } \\
\text { abu } \\
t\end{array}$ & $\begin{array}{c}\text { c) } \\
\text { overla } \\
p\end{array}$ & $\begin{array}{c}\text { a) } \\
\text { separat } \\
\text { e }\end{array}$ & $\begin{array}{c}\text { b) } \\
\text { abu } \\
t\end{array}$ & $\begin{array}{c}\text { c) } \\
\text { overla } \\
p\end{array}$ & $\begin{array}{c}\text { a) } \\
\text { separat } \\
\text { e }\end{array}$ & $\begin{array}{c}\text { b) } \\
\text { abu } \\
t\end{array}$ & $\begin{array}{c}\text { c) } \\
\text { overla } \\
p\end{array}$ & $\begin{array}{c}\text { a) } \\
\text { separat } \\
\text { e }\end{array}$ & $\begin{array}{c}\text { b) } \\
\text { overla } \\
\mathbf{p}\end{array}$ \\
\hline $\begin{array}{l}\text { C. ceronorum,sp. nov. } \\
\text { USNM 224212, M, } \\
36.2 \mathrm{~mm}\end{array}$ & & $x$ & - & $x$ & & - & & $x$ & - & $x$ & & - & $x$ \\
\hline $\begin{array}{l}\text { C. perotensis,sp. nov. } \\
\text { MVZ 200693, F, } 31.1 \\
\mathrm{~mm}\end{array}$ & $x$ & & $x$ & & & & $x$ & & $X^{*}$ & $X^{*}$ & & & $x$ \\
\hline $\begin{array}{l}\text { C. totonacus,sp. nov. } \\
\text { MVZ 163945, F, } 35.8 \\
\mathrm{~mm}\end{array}$ & $x$ & & $x$ & & & $x$ & & & $x$ & & & $x$ & \\
\hline $\begin{array}{l}\text { C. melipona,sp. nov. } \\
\text { MVZ 178706, M, } 28.5 \\
\mathrm{~mm}\end{array}$ & & $x$ & $x$ & & & & $x$ & & & $x$ & & $x$ & \\
\hline $\begin{array}{l}\text { C. casasi,sp. nov. } \\
\text { MVZ 92874, M, } 42.0\end{array}$ & & $x$ & & & $x$ & & & $x$ & & $x$ & & & $x$ \\
\hline
\end{tabular}




\section{$\mathrm{mm}$ \\ C. chiropterus}

MVZ 85602, M, 38.9

$\mathrm{mm}$

C. chiropterus, c\&s

MVZ 85596, M, 40.0

$\mathrm{mm}$

\section{C. chiropterus, c\&s}

MVZ 85632, F, 34 mm

\section{C. chiropterus, c\&s}

MVZ 85594, M, 36 mm

\section{C. chiropterus, c\&s}

MVZ 85613, M, 37.7

$\mathrm{mm}$

\section{C. orculus}

MVZ 138783, M, 38.9

$\mathrm{mm}$

\section{C. lavae}

MVZ 163912, M, 33.8

$\mathrm{mm}$

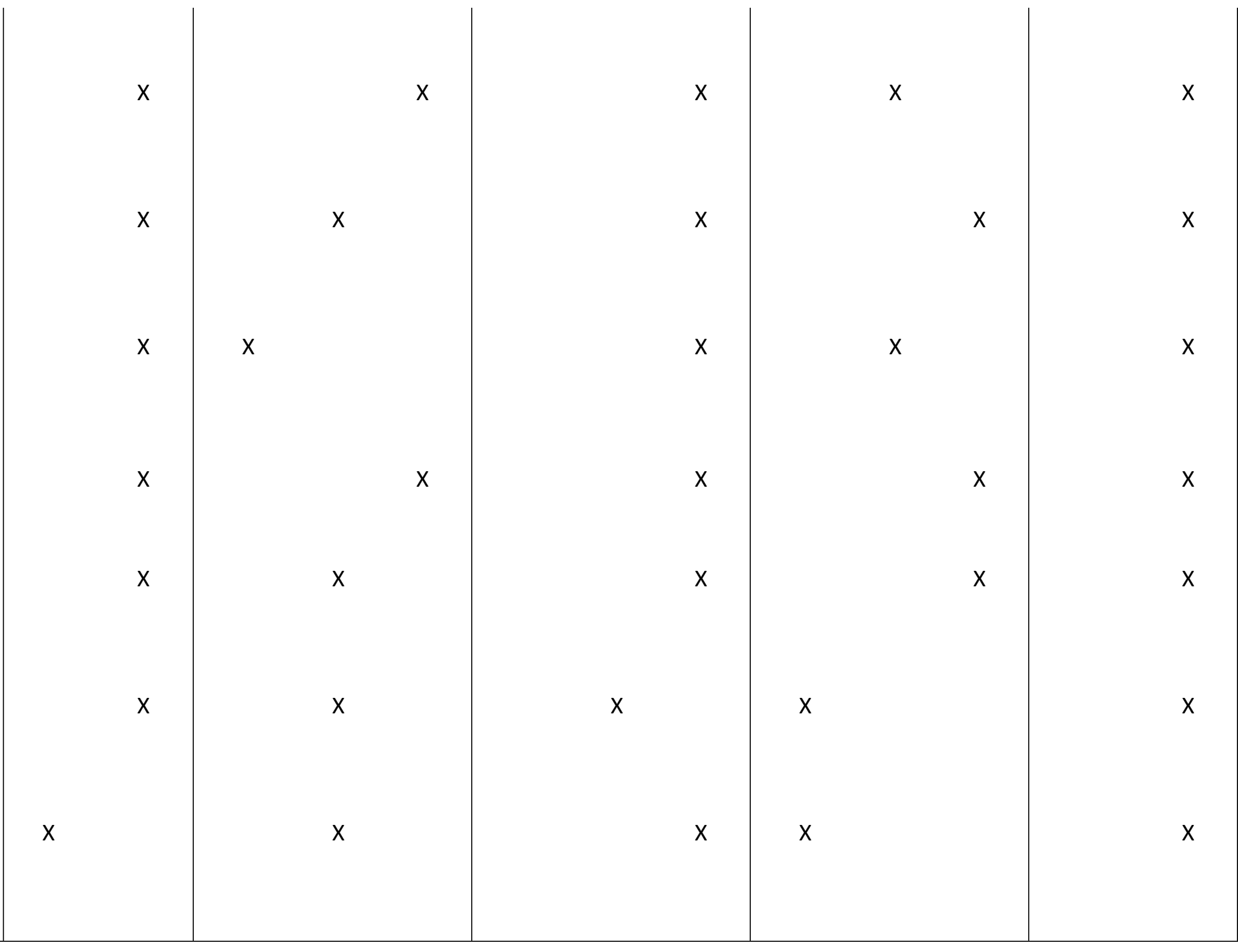


Table 4 (on next page)

Appendix

Specimens examined for morphological comparison 
1 APPENDIX 1. Specimens examined for morphological comparisons.

2 11 Chicuellar.

12

13

Chiropterotriton casasi sp.nov.: Mexico, Veracruz: MVZ 92874-78, $13 \mathrm{mi}$ SW Tlapacoyan.

Chiropterotriton ceronorum sp.nov.: Mexico, Puebla: USNM 224202, 224207-08, 224211-12, 224218-20, 224230, 224236, 224240-41, 224247, 224250, 224252-53, 224257, 224259, 224275-76, Santa Cruz Texmalaquilla (4.7 mi by road NE of Atzitzintla), ca. $1 \mathrm{~km} \mathrm{NE}$ of, on south slope of Pico de Orizaba. Chiropterotriton chiropterus: Mexico, Veracruz: MVZ 85588-92, 85594, 85597-99, 85605, 85613, 85632, 1.4 mi SW (by road) SW edge of Huatusco de

Chiropterotriton lavae: Mexico, Veracruz: MVZ 106537, 106548, W edge of La Joya, along Hwy. 140; MVZ 163912-13, 163915, 171873-74, 171876, 171881, 171885, 171901, 173394-95, 173398, 192788-89, 197788, La Joya; 178685, La Joya, Mexico Hwy. 140; MVZ 200638 forest W of La Joya.

km S Xicotepec de Juárez on Hwy. 130; MVZ 185972, 2.2 km on road to Patla from junction with Hwy. 120 SW out of Xicotepec de Juárez; MVZ 200724-26, $3.3 \mathrm{~km} \mathrm{~S}$ of Hotel M Ranchito on Mexico Hwy. 130, $2.1 \mathrm{~km}$ E on road to La Unión, Xicotepec de Juárez.

1 Chiropterotriton orculus: Mexico, Estado de México: MVZ 76161, 138686, 2 138688, 138694, 138696-97, 138700, 138776-79, 138781, 138783-84, 138793, 3 138796-97, 138804, 200629-30, ridge between Volcanoes Popocatepetl and 4 Iztaccihuatl, along Mexico Hwy. 196, 16.2 km E (by road) Hwy. 115. 5 Chiropterotriton perotensis sp.nov.: Mexico, Veracruz: MVZ 114356, 6 114359, road from Las Vigas de Ramírez to Microwave Station on N Flank Cofre 7 de Perote, 11.6 km S (by road) Las Vigas; MVZ 173428-29, 173438-39, Las 
28 Vigas de Ramírez, Microondas road; MVZ 178661, 178663-65, 8-15.5km S (via 29 Microondas Rd.) Las Vigas de Ramírez; MVZ 186711, road to Microwave Station, 3015 km S (by road) Las Vigas de Ramírez; MVZ 200681-83, 200691, 200693-95, 31 200698, 20070214.4 km S (by Rock Rd.) Las Vigas de Ramírez at Microwave 32 Station.

33 Chiropterotriton totonacus sp.nov.: MVZ 136981-82, 136986, pine forest 34 along Mexico Hwy. 140, 4 km W Las Vigas de Ramírez; MVZ 138703-04, 35 138716, 138765, Mexico Hwy. 140, 4.5 km W (by road) Las Vigas de Ramírez; 36 MVZ 163943, 163945, 163947-49, 163989-90, 163993, 171903, 171905, 171907, 37 171909-10, 6 km W Las Vigas de Ramírez. 